Volume 2: Task 2.2

\title{
Radiological Instrumentation Assessment for King County Wastewater Treatment Division
}

August 2005

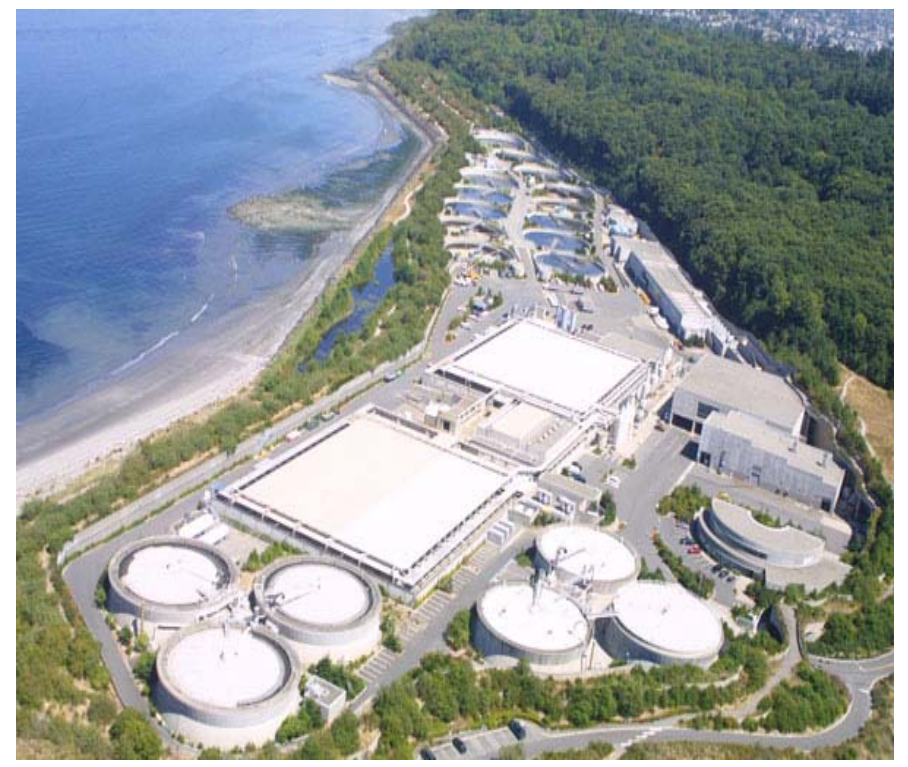

Prepared for King County, Washington, under a grant from the Department of Homeland Security as a work for others project under U.S. Department of Energy contract DE-AC05-76RL01830

Pacific Northwest National Laboratory Richland, Washington 99352 


\title{
DISCLAIMER
}

This report was prepared as an account of work sponsored by an agency of the United States Government. Neither the United States Government nor any agency thereof, nor Battelle Memorial Institute, nor any of their employees, makes any warranty, express or implied, or assumes any legal liability or responsibility for the accuracy, completeness, or usefulness of any information, apparatus, product, or process disclosed, or represents that its use would not infringe privately owned rights. Reference herein to any specific commercial product, process, or service by trade name, trademark, manufacturer, or otherwise does not necessarily constitute or imply its endorsement, recommendation, or favoring by the United States Government or any agency thereof, or Battelle Memorial Institute. The views and opinions of authors expressed herein do not necessarily state or reflect those of the United States Government or any agency thereof.

\author{
PACIFIC NORTHWEST NATIONAL LABORATORY \\ operated by \\ BATTELLE \\ for the \\ UNITED STATES DEPARTMENT OF ENERGY \\ under Contract DE-AC05-76RL01830
}

This document was printed on recycled paper.

$(9 / 2003)$ 
Volume 2: Task 2.2

Radiological Instrumentation Assessment

for King County

Wastewater Treatment Division

D. J. Strom

R.J. McConn

R.L. Brodzinski

August 2005

Prepared for King County, Washington, under a grant from the

Department of Homeland Security as a work for others project under U.S.

Department of Energy contract DE-AC05-76RL01830

Pacific Northwest National Laboratory

Richland, Washington 99352 



\section{Executive Summary}

Staff of the King County Wastewater Treatment Division (WTD) have concern about the aftermath of a radiological dispersion event (RDE) leading to the introduction of significant quantities of radioactive material into the combined sanitary and storm sewer system in King County, Washington. Radioactive material could come from the use of a radiological dispersion device (RDD). RDDs include "dirty bombs" that are not nuclear detonations but are conventional explosives designed to spread radioactive material (National Council on Radiation Protection and Measurements (NCRP) 2001). Radioactive material also could come from deliberate introduction or dispersion of radioactive material into the environment, including waterways and water supply systems.

This document, Volume 2 of PNNL-15163, is an assessment of the radiological instrumentation needs for detection of radiological or nuclear terrorism in support of decisions to treat contaminated wastewater or to bypass the West Point Treatment Plant (WPTP) and in support of radiation protection of the workforce, the public, and the infrastructure of this publicly-owned treatment works (POTW).

Two broad categories of scenarios were considered in Volume 1. The first category includes events that may be suspected from the outset, such as an explosion of a dirty bomb in downtown Seattle. The explosion would most likely be heard, but the type of explosion (e.g., natural gas, industrial explosion, or terrorist RDD) may not be immediately known. Emergency first responders must be able to quickly detect the radioisotopes previously listed, assess the situation, and deploy a response to contain and mitigate (if possible) detrimental effects resulting from the incident. In such scenarios, advance notice of 3 to 4 hours might be available before any contaminated wastewater reaches a treatment plant.

The second category includes events that could go initially undetected by emergency personnel. Examples of such a scenario include the inadvertent or surreptitious introduction of radioactive material into the sewer system. Intact rogue radioactive sources from industrial radiography devices, well-logging apparatus, or moisture density gages may get into wastewater and be carried to a treatment plant. Other scenarios include a terrorist deliberately putting a dispersible radioactive material into wastewater. Alternatively, a botched terrorism preparation of an RDD may result in radioactive material entering wastewater without anyone's knowledge. Drinking water supplies, bottled or packaged beverages, and foodstuffs may also be contaminated, with the result that some or most of the radioactivity ends up in wastewater. In some of these scenarios, the first evidence that an incident has occurred may be detection of radioactive material in wastewater.

Fixed radiation detection instrumentation should be deployed in a defense-in-depth system that provides 1) early warning of significant radioactive material on the way to the WPTP, including identification of the radionuclide(s) and estimates of the soluble concentrations, with a floating detector located in the wet well at the Interbay Pump Station and telemetered via secure wideband communications to all authorized locations, 2) monitoring at strategic locations within the plant, including

a) the pipe beyond the hydraulic ram in the bar screen room

b) above the collection funnels in the fine grit facility

c) in the sampling tank in the raw sewage pump room

d) downstream of the concentration facilities that produce $6 \%$ blended and concentrated biosolids. 
Engineering challenges exist for these applications. Explosion-proof, corrosion resistant housings and temperature compensation must be designed for detectors. Cable-length challenges may exist for delivering power to detectors and retrieving required signals out of potentially explosive and corrosive environments. It will be necessary to engineer floating detectors that cannot become dams or become excessively fouled with grease between reasonable service intervals, and that can rise and fall with varying wastewater levels and flow rates. It is also necessary to deploy both ultra-sensitive detectors to provide early warning and identification and detectors capable of functioning in high-dose rate environments that are likely under some scenarios, capable of functioning from 10 microrems per hour (background) up to 1000 rems per hour, a full eight orders of magnitude (a factor of 100,000,000). While such instrumentation exists for other applications, all of this engineering will require deploying prototypes and perhaps dealing with unforeseen complications.

Software supporting fixed spectroscopic detectors would be developed to provide prompt, reliable, and simple interpretations of spectroscopic outputs that are of use to operators and decision-makers. Software to provide scientists and homeland security personnel with sufficient technical detail for identification, quantification, waste management decisions, and for the inevitable forensic and attribution needs must be developed. Such software is not an off-the-shelf product as of March 2005 but it is expected that, with sufficient resources and collaboration between government agencies, scientists, and vendors, it can be specified and developed within two years or less.

Computational modeling using the Monte Carlo N-Particle (MCNP) software has demonstrated that useful detection capabilities can be deployed. In particular, any of the isotopes examined can be detected at levels between 0.01 and 0.1 microcurie $(\mu \mathrm{Ci})$ per gallon. Thus, a $1 \mathrm{Ci}$ source dissolved in 10 million gallons of water could be detected within minutes.

In addition to fixed instruments, general purpose instruments that can be used to determine the nature and extent of radioactive contamination and measure radiation levels for purposes of protecting personnel and members of the public should be available to WTD personnel. One or more portable radioisotope identifiers (RIIDs) should be available to WTD personnel. Small, portable battery-powered personal radiation monitors should be widely available to WTD personnel. The personal monitors can be used for personal and group radiation protection decisions, and to alert management to the need to get expert backup.

All uses of radiological instrumentation will require training and periodic retraining of personnel, as well as periodic calibration and maintenance of instruments. Routine "innocent" alarms will occur due to medical radionuclides that are legally discharged into sanitary sewers on a daily basis. Innocent alarms may also be triggered by WTD workers who have recently been treated with medical radioisotopes. Instrumentation must provide signals that distinguish between routine medical discharges and off-normal occurrences that are due to malicious acts or undetected accidents. Operators and others who deal with instrument signals must be prepared to deal with innocent but real alarms, while being vigilant for alarms indicating malicious or other serious discharges.

It is recommended that the King County Wastewater Treatment Division seek Homeland Security resources to become the model POTW in the U.S. to design, deploy, and test such radiological instrumentation. 


\section{Contents}

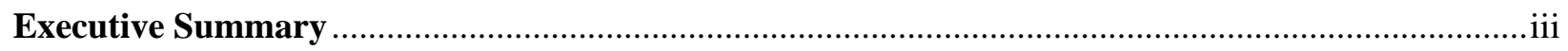

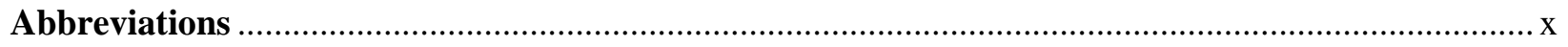

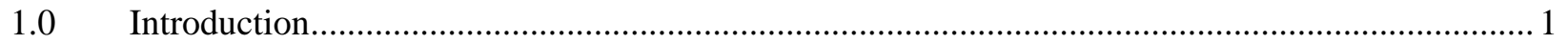

2.0 Types and Features of Radiation Measuring Instruments.......................................................... 3

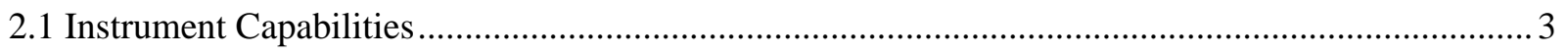

2.1.1 High Sensitivity for Rapid Detection ..............................................................................

2.1.2 Accurate Measurement of Radiation Levels (Radiation Dose Rates)................................. 3

2.1.3 Measurement of Intense Radiation Levels ........................................................................... 4

2.1.4 Identification of Radioactive Material ......................................................................... 4

2.1.5 Measurement of Amount (Activity) or Concentration (Activity per Unit Volume) of

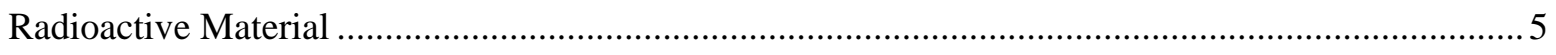

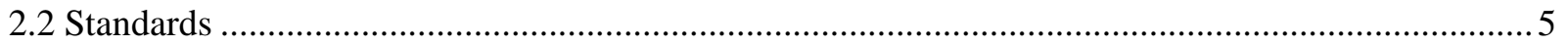

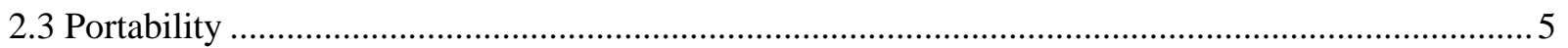

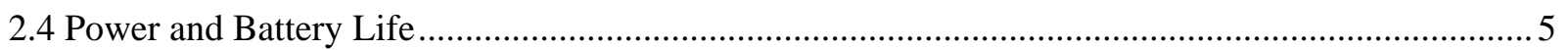

2.5 Protection from Radioactive Contamination and Capability to Be Decontaminated ........................ 6

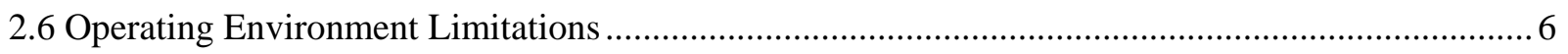

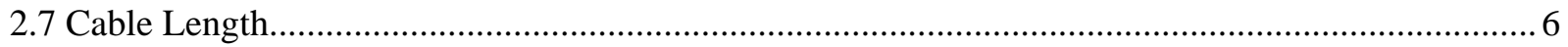

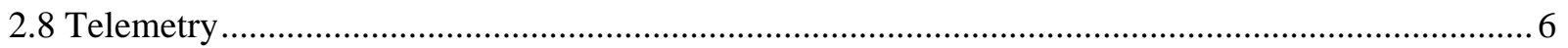

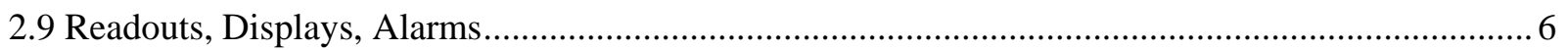

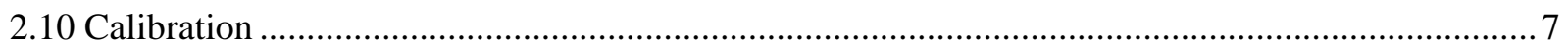

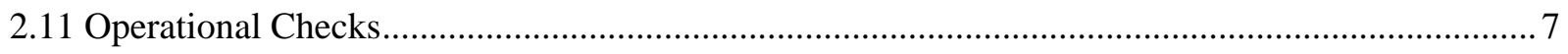

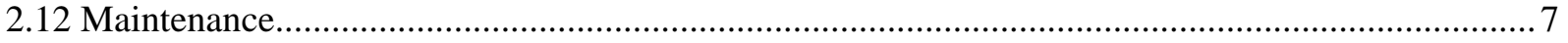

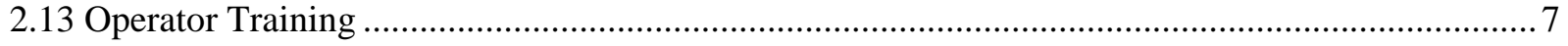

3.0 How Radiological Instruments Can Support King County WTD’s Mission................................. 9

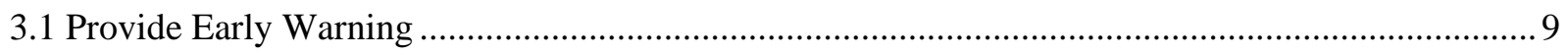

3.2 Provide Nearly Real-time Warnings within the WPTP ............................................................ 9

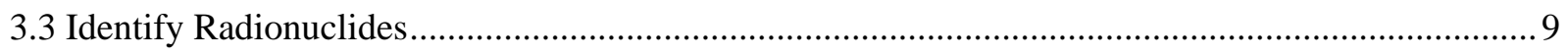

3.4 Determine Volume Concentrations and Activities ......................................................................... 9

3.5 Measure Radiation Levels (Dose Rates) ....................................................................................... 10 
3.6 Warn Workers of High Radiation Levels (Dose Rates) .............................................................. 10

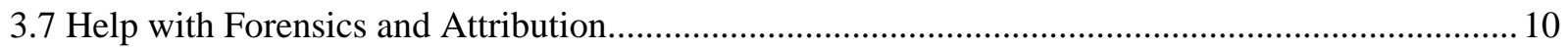

3.8 Recording of Doses to Workers, Public, and the Environment ..................................................... 10

4.0 Detection Capabilities of Fixed Radiological Instruments ..................................................... 11

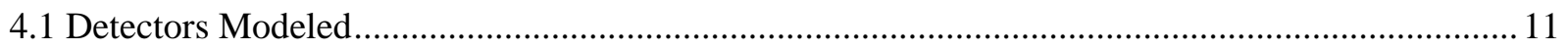

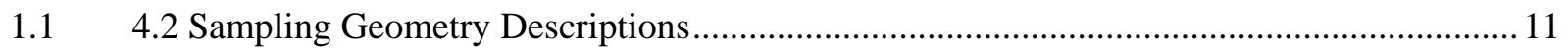

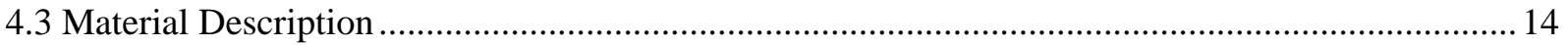

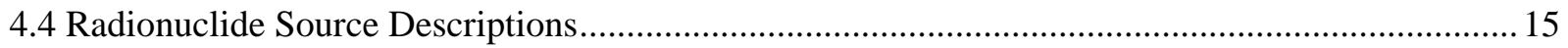

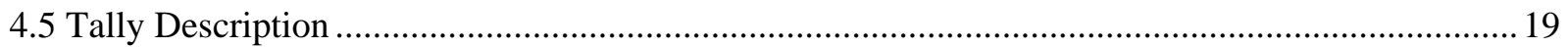

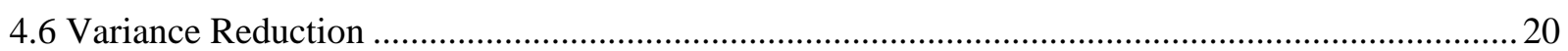

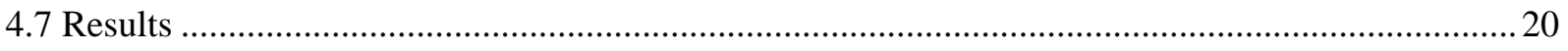

4.8 Relationship Between MCNP Results and Detection Capabilities.................................................. 21

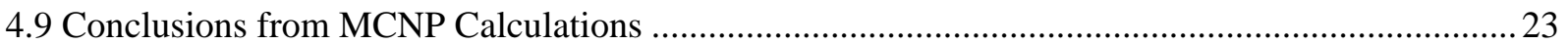

5.0 Recommendations to King County WTD for Radiological Instruments .................................... 25

5.1 Fixed Gamma Spectroscopy Instruments for Early Warning and Quantitative Threat

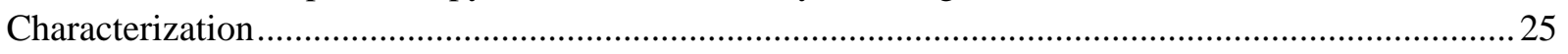

5.1.1 Early Warning from the Interbay Pump Station........................................................................ 25

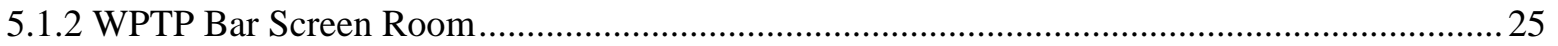

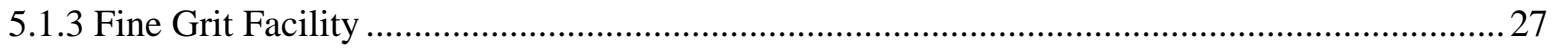

5.1.4 Sampling Tank in the Raw Sewage Pump Room................................................................ 28

5.1 .5 6\% Thickened, Blended Sludge Pipes ........................................................................... 29

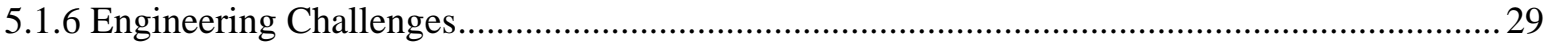

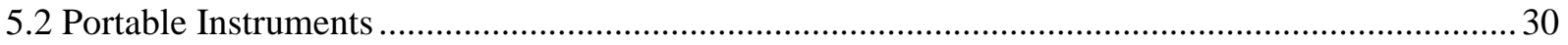

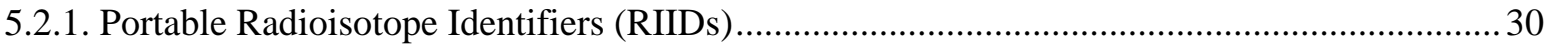

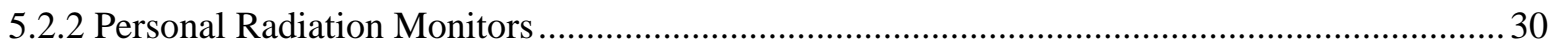

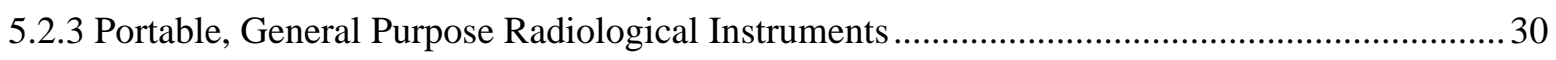

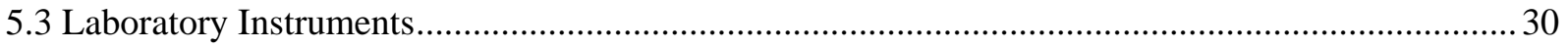

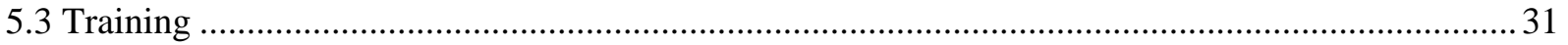

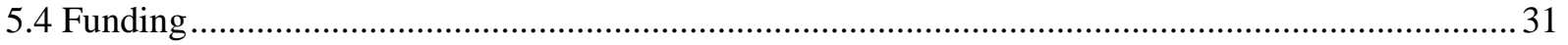

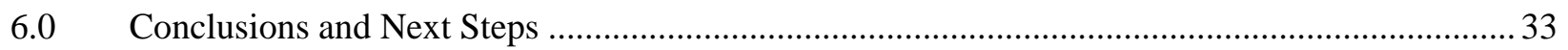

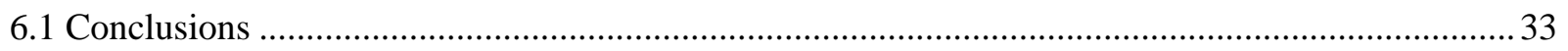

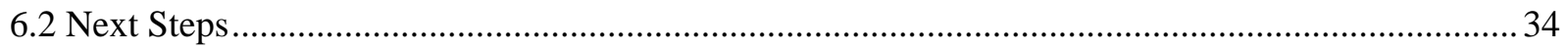

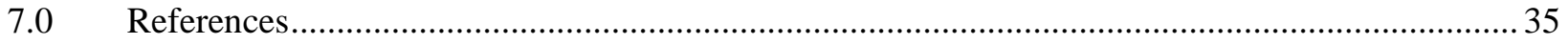




\section{Figures}

Figure 1. Sampling box in WPTP raw sewage pump room. Left: Side view, right: Looking downward into the wastewater with the overflow near the bottom of the picture.

Figure 2. Sampling box detector setup for MCNP modeling. Red is $\mathrm{NaI}(\mathrm{Tl})$, green is PVC, light blue is water, and dark blue is foamy water at 50\% density spilling over the overflow, white is dry air, yellow is aluminum.

Figure 3. The wet well at the Interbay Pump Station. The floating detector would have to rise and fall with changing wastewater levels.

Figure 4. Cross section of model of floating detector. Dark blue is NaI(Tl), yellow is water, light blue is rubber, green is PVC, magenta is aluminum.

Figure 5. Volume counting yield for full energy events (photopeaks) for the radionuclides in each of the four detector configurations.

Figure 6. Proposed detector location (arrow) to monitor the rags waste stream in the discharge pipe from the hydraulic ram in the bar screen room at WPTP.

Figure 7. Dose rate monitoring equipment should be located near the grit collection funnels (bottom of photo) in the grit facility......

Figure 8. Workers inspect the sampling tank in the raw sewage pump room.

Figure 9. Arrows indicate potential location inside a $90^{\circ}$ elbow for monitoring thickened, blended sludge.

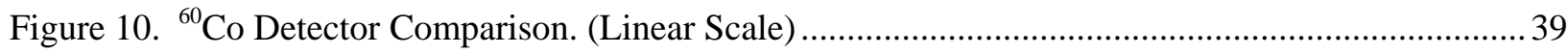

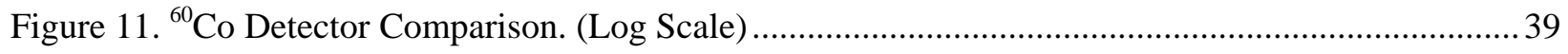

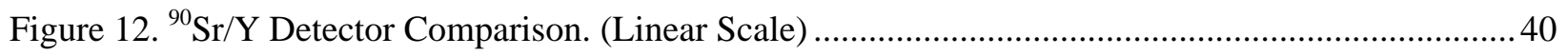

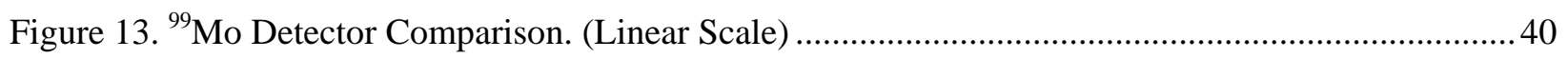

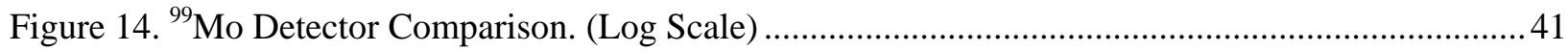

Figure 15. ${ }^{99 \mathrm{~m}}$ Tc Detector Comparison. (Linear Scale) ......................................................................... 41

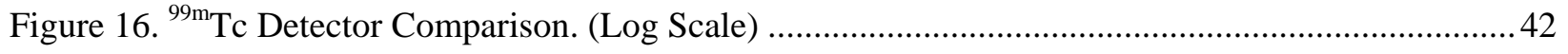

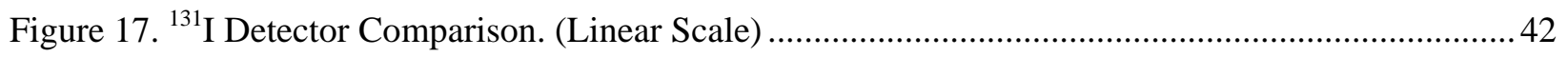

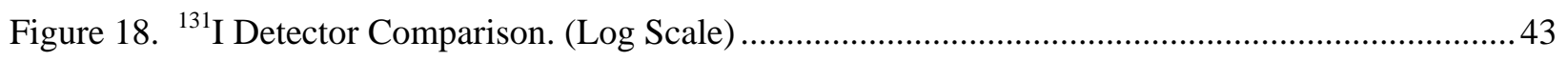

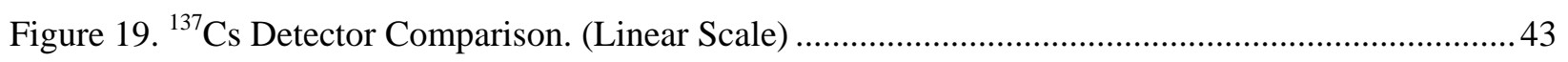

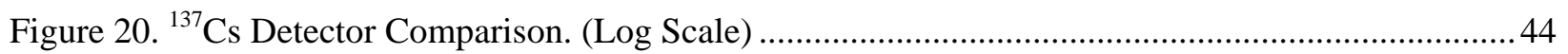

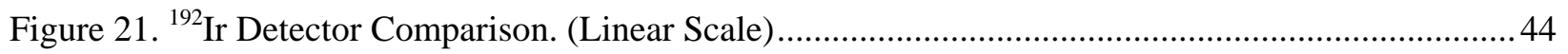

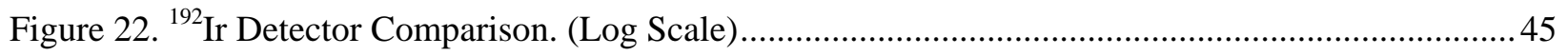

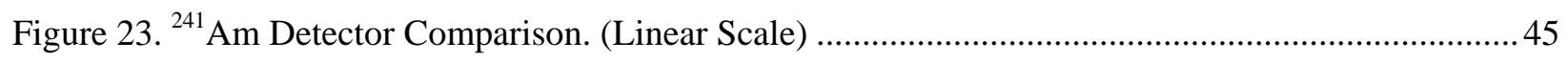




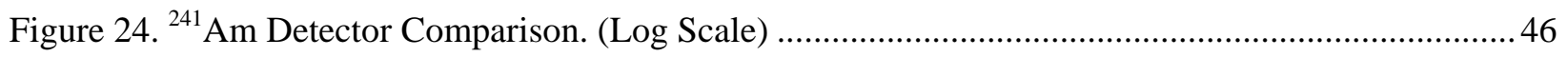

Figure 25. ${ }^{226}$ Ra Detector Comparison. (Linear Scale) ............................................................................. 46

Figure 26. ${ }^{226}$ Ra Detector Comparison. (Log Scale) ........................................................................... 47

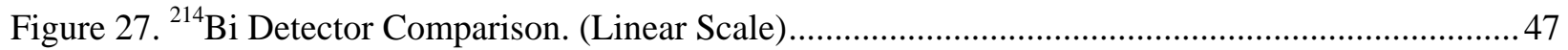

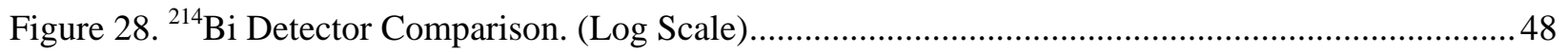

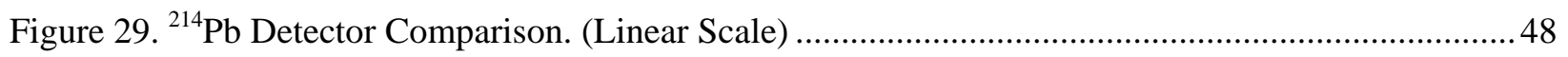

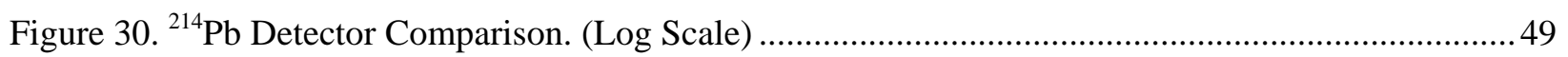

Figure 31. ${ }^{226}$ Ra plus Progeny Detector Comparison, Radon Escape Fraction=0. (Log Scale).................. 49

Figure 32. ${ }^{226}$ Ra plus Progeny Detector Comparison, Radon Escape Fraction=0.5. (Log Scale)...............50

Figure 33. ${ }^{226}$ Ra plus Progeny Detector Comparison, Radon Escape Fraction=0.9. (Log Scale)...............50

Figure 34. ${ }^{226}$ Ra plus Progeny Detector Comparison, Radon Escape Fraction=1. (Log Scale)..................51

Figure 35. Multi Nuclide Detector Comparison. 3×3 Sample Box Detector .............................................51

Figure 36. Multi Nuclide Detector Comparison. 3×3 Floating Detector ….............................................. 52

Figure 37. Multi Nuclide Detector Comparison. 2×2 Sample Box Detector............................................52

Figure 38. Multi Nuclide Detector Comparison. 2×2 Floating Detector .................................................... 53

Figure 39. Floating detector cross section. Dark blue is $\mathrm{NaI}(\mathrm{Tl})$, yellow is water, light blue is rubber, green is PVC, magenta is aluminum. Dots in water represent locations of individual nuclear transitions.

Figure 40. Floating detector horizontal cross section through sodium iodide crystal. Dark blue is NaI(Tl), light blue is rubber, green is PVC.

Figure 41. Sample box detector cross section seen from end. Red is $\mathrm{NaI}(\mathrm{Tl})$, green is $\mathrm{PVC}$, light blue is water, white is dry air, yellow is aluminum. Dots in water represent locations of individual nuclear transitions in all planes, i.e., in front of and behind the detector suspended in the water.

Figure 42. Sample box detector cross section seen from side. Red is $\mathrm{NaI}(\mathrm{Tl})$, green is PVC, light blue is water, dark blue is water at $50 \%$ density (that is, frothy, foamy water spilling over the top of the overflow), white is dry air, yellow is aluminum. Dots in water represent locations of individual nuclear transitions in all planes, i.e., in front of and behind the detector suspended in the water. ....57

Figure 43. Sample box detector cross section (through detector) seen from top. Red is $\mathrm{NaI}(\mathrm{Tl})$, green is PVC, light blue is water, dark blue is water at $50 \%$ density (that is, frothy, foamy water spilling over the top of the overflow), white is dry air, yellow is aluminum. Dots in water represent locations of individual nuclear transitions in all planes, i.e., in front of and behind the detector suspended in the water. 


\section{Tables}

Table 1. List of radionuclides of concern. Some emit more than one kind of radiation. D-values are threshold values for dangerous amounts in curies, terabecquerels, and milligrams (mg) if the radionuclide is not diluted with non-radioactive material. Use or origin indicates where the radionuclides may be in use.

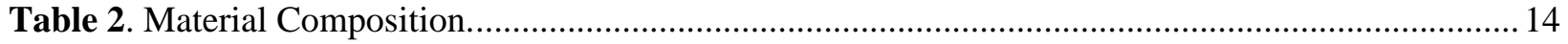

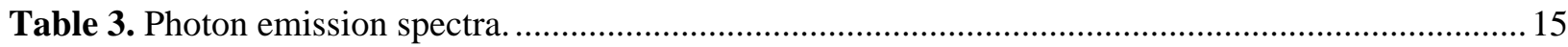

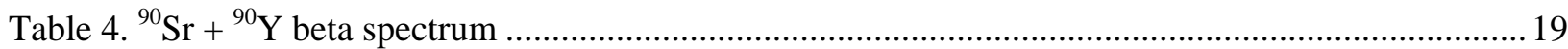

Table 5. Activity concentration in $\mathrm{Bq} / \mathrm{m}^{3}$ to produce 1 additional count per second above background in either gross counts or in photopeaks for various isotopes and four detector configurations

Table 6. Numerical results in $\mathrm{cps} /\left(\mathrm{Bq} / \mathrm{m}^{3}\right)$ from the MCNP calculations for each photopeak, for all photopeaks, and for gross counts for various radionuclides... 


\section{Abbreviations}

\begin{tabular}{ll} 
ANSI & American National Standards Institute \\
Bq & becquerel (1 nuclear transition per second) \\
CdZnTe & cadmium zinc telluride [detector] \\
Ci & curie (3.7× $\times 10^{10}$ nuclear transitions per second) \\
cps & counts per second \\
FWHM & full width at half maximum \\
gal & gallon \\
GEB & Gaussian energy broadening \\
GM & Geiger-Müller [detector] \\
GPS & global positioning system \\
HPGe & high-purity germanium \\
IND & improvised nuclear device \\
MCNP & Monte Carlo N-Particle [computer code] \\
mg & milligram \\
mrem & millirem \\
NaI(Tl) & thallium-doped sodium iodide [detector] \\
NCRP & National Council on Radiation Protection and Measurements \\
PNNL & Pacific Northwest National Laboratory \\
POTW & publicly-owned treatment works \\
PVC & polyvinyl chloride \\
RDD & radiological dispersion device \\
RDE & radiological dispersion event \\
RIID & radioisotope identifier \\
RPM & radiation portal monitor \\
SCADA & Supervisory Control and Data Acquisition \\
TBq & terabecquerel (10 12 Bq; 1 Ci $=0.037$ TBq) \\
UPS & uninterruptible power supply \\
VAC & volts (alternating current) \\
WPTP & West Point Treatment Plant \\
WTD & Wastewater Treatment Division \\
\hline
\end{tabular}




\subsection{Introduction}

In the United States there are no identified cases in which radioactive materials in sewage systems are a threat to the health and safety of publicly-owned treatment works (POTW) workers or the general public. However, there have been a small number of facilities where elevated levels of man-made radioactive materials were detected. Based upon this past experience, there is a concern that radioactive material could concentrate in sewage sludge and ash and could pose a threat to the health and safety of workers or the public.

(Interagency Steering Committee on Radiation Standards 2003).

Staff of the King County Wastewater Treatment Division (WTD) have concern about the aftermath of a radiological dispersion event (RDE) leading to the introduction of significant quantities of radioactive material into the combined sanitary and storm sewer system in King County, Washington. Radioactive material could come from the use of a radiological dispersion device (RDD). RDDs include "dirty bombs" that are not nuclear detonations but are conventional explosives designed to spread radioactive material (National Council on Radiation Protection and Measurements (NCRP) 2001). Radioactive material also could come from deliberate introduction or dispersion of radioactive material into the environment, including waterways and water supply systems.

This document, Volume 2 of PNNL-15163, is an assessment of the radiological instrumentation needs for detection of radiological or nuclear terrorism in support of decisions to treat contaminated wastewater or to bypass the West Point Treatment Plant (WPTP), and in support of radiation protection of the workforce, the public, and the infrastructure of this publicly-owned treatment works (POTW).

Volume 1 of PNNL-15163 (Strom 2005) reviewed the basics of radiation, radioactive material, and radiation protection. Two broad categories of scenarios were considered in Volume 1. The first category includes events that may be suspected from the outset, such as an explosion of a dirty bomb in downtown Seattle. The explosion would most likely be heard, but the type of explosion (e.g., natural gas, industrial explosion, or terrorist RDD) may not be immediately known. Emergency first responders must be able to quickly detect the radioisotopes listed in Volume $1\left({ }^{60} \mathrm{Co},{ }^{90} \mathrm{Sr},{ }^{137} \mathrm{Cs},{ }^{192} \mathrm{Ir},{ }^{226} \mathrm{Ra}\right.$, plutonium, and $\left.{ }^{241} \mathrm{Am}\right)$, assess the situation, and deploy a response to contain and mitigate (if possible) detrimental effects resulting from the incident. In such scenarios, advance notice of 3 to 4 hours might be available before any contaminated wastewater reaches a treatment plant.

The second category includes events that could go initially undetected by emergency personnel. Examples of such a scenario would be the inadvertent or surreptitious introduction of radioactive material into the sewer system. Intact rogue radioactive sources from industrial radiography devices, well-logging apparatus, or moisture density gages may get into wastewater and be carried to a treatment plant. Other scenarios might include a terrorist deliberately putting a dispersible radioactive material into wastewater. Alternatively, a botched terrorism preparation of an RDD may result in radioactive material entering wastewater without anyone's knowledge. Drinking water supplies, bottled or packaged beverages, and foodstuffs may also be contaminated, with the result that some or most of the radioactivity ends up in wastewater. In some of these scenarios, the first evidence that an incident has occurred may be detection of radioactive material in wastewater.

Pacific Northwest National Laboratory (PNNL) staff made two visits to WTD facilities serving downtown Seattle and points north to determine strategic locations for fixed detector placement, and to refine the radiological risk assessment (Volume 1 of PNNL-15163, Strom 2005, referred to as "Vol. 1 in 
this report). Engineering constraints on detector design and locations were determined. Vendors were contacted to discuss the availability of the types of equipment required. Monte Carlo calculations were performed to predict detector capabilities. Needs and uses of portable radiation detection equipment available on the state of Washington approved equipment list were assessed.

While Volume 1 covered only briefly the event of the detonation of an improvised nuclear device (IND), accidents at nuclear reactors or sabotage of spent nuclear fuel shipment, the instrumentation described in Volume 2 has significant capabilities for responding to such events. 


\subsection{Types and Features of Radiation Measuring Instruments}

This section provides background information on instruments that are of interest in the context of detecting and responding to radiological terrorism. It is important to recognize that RDEs can be silent, that is, radioactive material is silently and secretly dispersed via deliberate contamination of food, beverage, water, air, crops, or elsewhere in the environment. This possibility requires special detection and identification capabilities.

Instruments are grouped into four categories: instruments that detect radiation, instruments that measure radiation levels and amounts (dose-rate and dose), instruments that identify radioisotopes, and instruments that can measure how much of a radioisotope is present (activity or activity concentration).

\subsection{Instrument Capabilities}

Various kinds of detector and associated electronics have particular strengths and weaknesses. In the sections that follow, instruments are categorized as having

- high sensitivity for rapid detection

- good accuracy for measurement of radiation levels

- capability to function in and measure intense radiation levels

- capability to identify radioactive materials, or

- capability to measure the activity of known radioactive materials.

\subsubsection{High Sensitivity for Rapid Detection}

Some instruments, such as those employing Geiger-Müller (GM) detectors, are very sensitive to alpha, beta, and gamma radiation. With modest training, users of such instruments can distinguish among the three types of radiation. However, GM detectors are much less suitable for accurate measurement of radiation levels.

Other instruments, like the radiation "pagers" used by law enforcement agencies, are quite sensitive to gamma radiation, are small, portable, rugged, and have long battery life. Some have built-in alarming capability to warn the user when a certain radiation level is exceeded. They, too, are not accurate for measurement of radiation levels, and should not be relied on for that purpose.

Detectors employing large volume plastic scintillators, such as the radiation portal monitors (RPMs) that are deployed at U.S. land border crossings, are extremely sensitive to gamma radiation, but have very limited capabilities for identifying which radioactive material is emitting the radiation. Such detectors also have significant neutron detection capabilities for the detection of special nuclear materials that have the potential to be used to make an improvised nuclear device (homemade atomic bomb).

As of March, 2005, development of highly sensitive RPMs with spectroscopic capability is underway in the U.S. and elsewhere.

\subsubsection{Accurate Measurement of Radiation Levels (Radiation Dose Rates)}

Portable instruments are available for the accurate measurement of radiation levels (radiation dose rates) from a variety of gamma and x radiation sources, in units such as millirems per hour (mrem/hour) or 
rems/hour. Such instruments are generally of the air ionization type, or use a plastic scintillator coupled to a photomultiplier tube.

\subsubsection{Measurement of Intense Radiation Levels}

Under one of the scenarios in Vol. 1, it is possible that radioactive material in the form of pellets of ${ }^{60} \mathrm{Co}$ may reconcentrate at one or more locations in the system. Also, an intact radioactive source of high strength (high activity), such as an industrial radiography source or brachytherapy source, may find its way into the system. In particular, reconcentration may occur in the grit facility or the rock box in the bar screen room. Such an event could lead to dangerously high radiation levels requiring prompt local evacuation to at least 100 feet away.

\subsubsection{Identification of Radioactive Material}

Characteristics of radionuclides of concern are listed in Table 1 (reproduced from Vol. 1). These are of particular interest because they are plentiful in relatively large amounts. Half-lives and principal radiation types are shown. The "D-values" are internationally-recognized "dangerous" amounts of these radionuclides (International Atomic Energy Agency (IAEA) 2003) in units of curies or terabecquerels $(\mathrm{TBq})$, where $1 \mathrm{Ci}=0.037 \mathrm{TBq}$. For the most common chemical forms of these radionuclides, note the incredibly small mass associated with a dangerous amount of radioactivity. As shown in the last three columns, these radioactive materials may have industrial, medical, or defense uses.

Table 1. List of radionuclides of concern. Some emit more than one kind of radiation. D-values are threshold values for dangerous amounts in curies, terabecquerels, and milligrams (mg) if the radionuclide is not diluted with non-radioactive material. Use or origin indicates where the radionuclides may be in use.

\begin{tabular}{|c|c|c|c|c|c|c|c|c|c|c|c|}
\hline \multirow[b]{2}{*}{ Radionuclide } & \multirow[b]{2}{*}{ Symbol } & \multirow[b]{2}{*}{ Half-life } & \multicolumn{3}{|c|}{ Radiation } & \multicolumn{3}{|c|}{ D-value } & \multicolumn{3}{|c|}{ Use or Origin } \\
\hline & & & $\frac{\pi}{\frac{\pi}{\pi}}$ & 萢 & 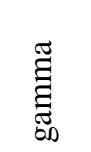 & $\mathrm{Ci}$ & $\mathrm{TBq}$ & $\mathrm{mg}$ & 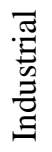 & 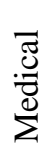 & 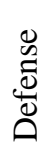 \\
\hline cobalt-60 & ${ }^{60} \mathrm{Co}$ & 5 years & & $\beta$ & $\gamma$ & 0.8 & 0.03 & 0.7 & $\mathrm{x}$ & $\mathrm{x}$ & \\
\hline strontium-90 & ${ }^{90} \mathrm{Sr}$ & 28 years & & $\beta$ & & 30 & 1 & 450 & $\mathrm{x}$ & $\mathrm{x}$ & \\
\hline molybdenum-99 & ${ }^{99} \mathrm{Mo}$ & 66 hours & & $\beta$ & $\gamma$ & 8 & 0.3 & 0.017 & & $\mathrm{x}$ & \\
\hline iodine-131 & ${ }^{131} \mathrm{I}$ & 8 days & & $\beta$ & $\gamma$ & 5 & 0.2 & 0.04 & & $\mathrm{x}$ & \\
\hline cesium-137 & ${ }^{137} \mathrm{Cs}$ & 30 years & & $\beta$ & $\gamma$ & 3 & 0.1 & 44 & $\mathrm{x}$ & $\mathrm{x}$ & \\
\hline iridium-192 & ${ }^{192} \mathrm{Ir}$ & 75 days & & $\beta$ & $\gamma$ & 2 & 0.08 & 0.2 & $\mathrm{x}$ & $\mathrm{x}$ & \\
\hline radium-226 & ${ }^{226} \mathrm{Ra}$ & 1600 years & $\alpha$ & $\beta$ & $\gamma$ & 1 & 0.04 & 1,000 & $\mathrm{x}$ & & \\
\hline uranium & $\mathrm{U}$ & 4.5 billion years & $\alpha$ & $\beta$ & weak & & & - & $\mathrm{X}$ & & $\mathrm{X}$ \\
\hline americium-241 & ${ }^{241} \mathrm{Am}$ & 432 years & $\alpha$ & & $\gamma$ & 2 & 0.06 & 580 & $\mathrm{x}$ & & $\mathrm{X}$ \\
\hline plutonium & $\mathrm{Pu}$ & 24,000 years & $\alpha$ & $\beta$ & weak & 2 & 0.06 & - & $\mathrm{x}$ & & $\mathrm{x}$ \\
\hline
\end{tabular}


Identification of various radionuclides, such as ${ }^{60} \mathrm{Co},{ }^{90} \mathrm{Sr}+{ }^{90} \mathrm{Y},{ }^{137} \mathrm{Cs},{ }^{192} \mathrm{Ir},{ }^{226} \mathrm{Ra},{ }^{239} \mathrm{Pu}$, and ${ }^{241} \mathrm{Am}$ requires gamma spectroscopy equipment, usually based on sodium iodide (NaI) detectors, high purity germanium (HPGe) detectors, cadmium zinc telluride (CdZnTe) detectors, or other solid-state or scintillation detectors. The outputs of such detectors are fed into multichannel analyzers that provide "color vision" for gamma and x radiation. Each radionuclide listed above has a particular gamma signature that is identifiable by gamma spectroscopy. The gamma signatures are distinct from those of common medical radionuclides like ${ }^{67} \mathrm{Ga},{ }^{99 \mathrm{~m}} \mathrm{Tc},{ }^{99} \mathrm{Mo},{ }^{131} \mathrm{I}$, and ${ }^{201} \mathrm{Tl}$. The ${ }^{90} \mathrm{Sr}+{ }^{90} \mathrm{Y}$ pair, while not emitting gamma radiation, does produce some $\mathrm{x}$ radiation that can be detected using gamma spectroscopy equipment.

Some radionuclides, such as ${ }^{238} \mathrm{Pu}$, emit virtually no gamma radiation and very little $\mathrm{x}$ radiation, and can only be detected by their emissions of $\alpha$-particles. Such radionuclides are only hazardous if inhaled or ingested, and are not likely to affect health of WTD workers.

\subsubsection{Measurement of Amount (Activity) or Concentration (Activity per Unit Volume) of Radioactive Material}

One must know what radioactive material is present in order to measure the activity (in curies, Ci; or becquerels, Bq; see Volume 1) or volume concentration (in curies per gallon, Ci/gal; or becquerels per cubic meter, $\mathrm{Bq} / \mathrm{m}^{3}$ ) of a radioactive material. Additionally, one must know where the material is with respect to the detector. If the sample to be measured is in a small vial, one can put it on or near a detector and have a good idea what the geometric efficiency is. On the other hand, if the sample is dissolved or suspended in a large volume of water, sensitivity is significantly diminished for a detector near the surface. For a dispersed sample, surrounding a detector with it provides the best compromise for maximizing sensitivity for measuring the activity or volume concentration of a radioisotope

\subsection{Standards}

Radiation detection instruments should meet applicable standards, such as the recent ANSI N42 series (American National Standards Institute (ANSI) 2004a; 2004b; 2004c; 2004d).

\subsection{Portability}

Radiation detection instruments can be made to be portable, "luggable,” or require fixed installation. Radiation pagers can be clipped to a belt or hand-held. Other survey instruments are hand-held, such as a "pancake" GM detector connected to a hand-held ratemeter or scaler. Still others, such as hand-held radioisotope identifiers (RIIDs), are more appropriately termed luggable, since their weight and size make them a burden for use over an 8-hour day.

Portability is not of interest for fixed-installation instruments that function as remote detectors.

\subsection{Power and Battery Life}

Some instruments require standard 117 VAC electric power, while others may operate on rechargeable or disposable batteries.

Instruments requiring computers, such as gamma spectroscopic systems, should have uninterruptible power supplies (UPSs) that can power the system during brief power outages. 


\subsection{Protection from Radioactive Contamination and Capability to Be Decontaminated}

Radioactive contamination is just like any other kind of dirt, with the additional property of being radioactive. If radiological instruments become contaminated with radioactive material, that is, dirty, they will continuously sense the presence of the radioactive material on the instrument, raising the background indication of the instrument.

In a wastewater environment, there may also be biohazardous materials present that can contaminate an instrument.

Thus it is vitally important to keep instruments, and any detectors attached to them, free of radioactive contamination. This may be done by using plastic sheaths or other removable or strippable coatings.

\subsection{Operating Environment Limitations}

Instruments for permanent placement in WTD facilities, such as a wet well, bar screen room, raw sewage pump room, fine grit facility, or biosolids facility, may need to be housed in waterproof, explosion-proof, corrosion resistant housings. Temperature stability of detectors can be addressed by insulation and installation of low-power thermostatically-controlled heaters to keep temperature constant and above operating facility temperature.

Instrument housings in contact with wastewater must be durable and easily cleaned of layers of grease or other material that may build up.

\subsection{Cable Length}

The length of cabling for power, control, and data is a critical problem for instrumentation located in explosive, corrosive, or wet areas. Currently, options are being explored to manage this problem.

\subsection{Telemetry}

Some of the output information for fixed instrumentation may be amenable to transmission via a Supervisory Control and Data Acquisition (SCADA) system, but secure wideband communications capability to interface through a hardware firewall with the Internet would be highly desirable, permitting authorized personnel at remote locations to access, read out, diagnose, and control the systems.

GPS capability for portable systems would be highly desirable for coordinating and managing data in the aftermath of an RDE.

\subsection{Readouts, Displays, Alarms}

The various categories of instruments described in Section 2.1 have a variety of readout, display and alarm capabilities. Ideally, readouts would be very simple and would lead to pre-determined actions. There are opportunities for development of software and systems that minimize the need for advanced training in radiological matters. 


\subsection{Calibration}

All radiation detection instruments must be periodically calibrated. Most portable instruments should be calibrated every 6 months, and tested on various ranges. Spectroscopic instruments should have energy calibrations and tests with a calibration source at least every 6 months. Calibration is needed whether instruments are in use or not.

\subsection{Operational Checks}

All portable instruments should be put through daily operational checks with a small radioactive check source each day they are used. Permanently-installed radiation detectors should be checked on a periodic basis. The period for such checks depends on the ease of getting to the instrument to perform the checks and the expected reliability of the instrument in its environment.

\subsection{Maintenance}

Routine maintenance includes recharging of rechargeable batteries, and replacement of disposable batteries.

For fixed instruments, inspection of cables and detector condition will be required at intervals to be determined from experience.

\subsection{Operator Training}

Operator training must cover routine checks and routine maintenance (e.g., changing batteries and cleaning), operation, and interpretation of readouts and information, as well as decisions that must be made based on instrument results. Operators need to be trained in contamination control and in decontaminating instruments and detectors that become contaminated. 



\subsection{How Radiological Instruments Can Support King County WTD's Mission}

Radiological instruments can serve the following functions:

- provide early warning of significant radioactive material in wastewater on its way to the WPTP

- provide nearly real-time warnings within the plant of material that was not detected prior to reaching the plant

- identify the radionuclides at various locations in interceptors and in the WPTP

- determine the volume concentration $\left(\mathrm{Ci} / \mathrm{gal}\right.$ or $\left.\mathrm{Bq} / \mathrm{m}^{3}\right)$ in wastewater

- determine the activity in rocks, grit, rags, and biosolids

- measure the radiation levels that workers or members of the public may be exposed to

- warn workers of significantly elevated radiation levels

- measure doses to workers, equipment, and microbes.

\subsection{Provide Early Warning}

Given notification an hour before contaminated wastewater arrives at the WPTP, operators can decide whether to bypass the plant or treat the contaminated water. Treating may be the best option in some cases, and these will be outlined in the Radiological Emergency Response Plan. If the decision is made to treat, then there are options that may arise depending on what radionuclides are involved.

\subsection{Provide Nearly Real-time Warnings within the WPTP}

Instrumentation within the plant may be very much more sensitive than instrumentation deployed in a wet well upstream of the plant. Nearly real-time warnings may arise from various locations within the plant, including the rock box, rags waste stream, grit facility, raw sewage pump area, and the thickened, blended sludge piping. Each path or wastestream can lead to different radiological conditions that may expose workers, and different risk management decisions concerning how to manage a particular waste stream.

\subsection{Identify Radionuclides}

Identification of radionuclides can lead to decisions to bypass or treat, and to invoke other options for waste management and worker protection. It also alerts other public agencies to the specific nature of a potential radiological problem.

\subsection{Determine Volume Concentrations and Activities}

Waste management decisions will depend on the activity and concentration of radioactive materials in various waste streams, and enable managers to predict dose rates and radiation hazards to workers and the public. 


\subsection{Measure Radiation Levels (Dose Rates)}

Direct radiation measurements will facilitate worker protection and enable managers to cordon off areas to all but essential personnel, and limit stay times in areas with high radiation levels. Additionally, dose rate measurements are needed to plan recovery operations.

\subsection{Warn Workers of High Radiation Levels (Dose Rates)}

In conjunction with fixed location instruments, alarming personal dosimeters can help keep workers' doses as low as reasonably achievable while permitting them to work confidently in areas of low radiation hazard.

\subsection{Help with Forensics and Attribution}

If an RDE is the result of criminal or malicious actions, law enforcement and radiation regulatory agencies will immediately get involved. All of the radiation measurement results from fixed and portable instruments will be needed to assess the problem and guide investigations.

\subsection{Recording of Doses to Workers, Public, and the Environment}

Having radiation measurement results available, recording them, and communicating them can help manage fear and enhance peace of mind. Doses received on the job may later become a subject of litigation, and having measurement records will inevitably help with this problem 


\subsection{Detection Capabilities of Fixed Radiological Instruments}

Computational research was performed to simulate the photon response of two configurations of fixed thallium-doped sodium iodide $\mathrm{NaI}(\mathrm{Tl})$ scintillation detectors to radionuclides suspended in wastewater for the purpose of determining concentrations that could be detected above background for a variety of medical and industrial radionuclides.

\subsection{Detectors Modeled}

Two thick crystal types, the 2 inch by 2 inch $(2 \times 2)$ and 3 inch by 3 inch $(3 \times 3)$ with a right circular cylinder geometry, are chosen due to availability, ruggedness, and overall energy response. Two different detector locations are also considered. The first has the detector sealed in a polyvinyl chloride (PVC) pipe and submerged in the contaminated water. The second has the detector sealed in PVC then surrounded by a rubber buoy and floated atop the contaminated stream.

The response of the detectors to various radionuclides was simulated using the Monte Carlo N-Particle (MCNP) computer code versions MCNP-5 (X-5 Monte Carlo Team 2004) and MCNP-X (Hendricks et al. 2005). These computer codes allow the accurate simulation of the radiation interactions with the $\mathrm{NaI}(\mathrm{Tl})$ and the surrounding environment. Not included in the simulation is the response of the associated detector electronics (e.g., photomultiplier tube and multichannel analyzer).

\subsection{2 Sampling Geometry Descriptions}

Each of the $\mathrm{NaI}(\mathrm{Tl})$ detectors, $2 \times 2$ and $3 \times 3$ are represented in MCNP as simple right circular cylinders. The $\mathrm{NaI}(\mathrm{Tl})$ material is then surrounded by thin $(0.5 \mathrm{~mm})$ aluminum on the front and sides with 1-inch at the back to represent the effect of the photomultiplier tube on the incident radiation. This description is based on the specification of Canberra model 802 (www.canberra.com) detectors.

Surrounding the aluminum clad detectors is a 0.25-inch thick 4-inch diameter PVC to seal the detectors from intrusion of water. This configuration with be referred to as the detector unit.

The detector unit is then placed in two separate scenarios. The first has the detector unit submerged in water contained in a small PVC box, modeled after the sampling station in the raw sewage pump room at WPTP, shown in Figure 1. The box that was modeled was made of 1/2 in. thick PVC, 30 in. high, 22 in. wide, 11 in. thick, with a water depth of $24.5 \mathrm{in}$. The sampling box and detector is graphically represented in Figure 2 and in several views in Appendix A.

The second scenario places the detector unit within a 60-cm (2-foot) diameter 1-inch thick spherical rubber buoy that could be floated in the wet well at the Interbay Pump Station, shown in Figure . This buoy allows the detector unit to float on top of the contaminated stream. This is graphically represented in Figure 4

Figure 4. Cross section of model of floating detector. Dark blue is $\mathrm{NaI}(\mathrm{Tl})$, yellow is water, light blue is rubber, green is PVC, magenta is aluminum. . It is recognized that in a fielded device, part of the buoy would reside under the water. For this initial study assuming that the entire buoy is above water is a conservative assumption. The water below the floating buoy detector was taken as a cylinder with a 60 $\mathrm{cm}$ radius and $60 \mathrm{~cm}$ deep. 

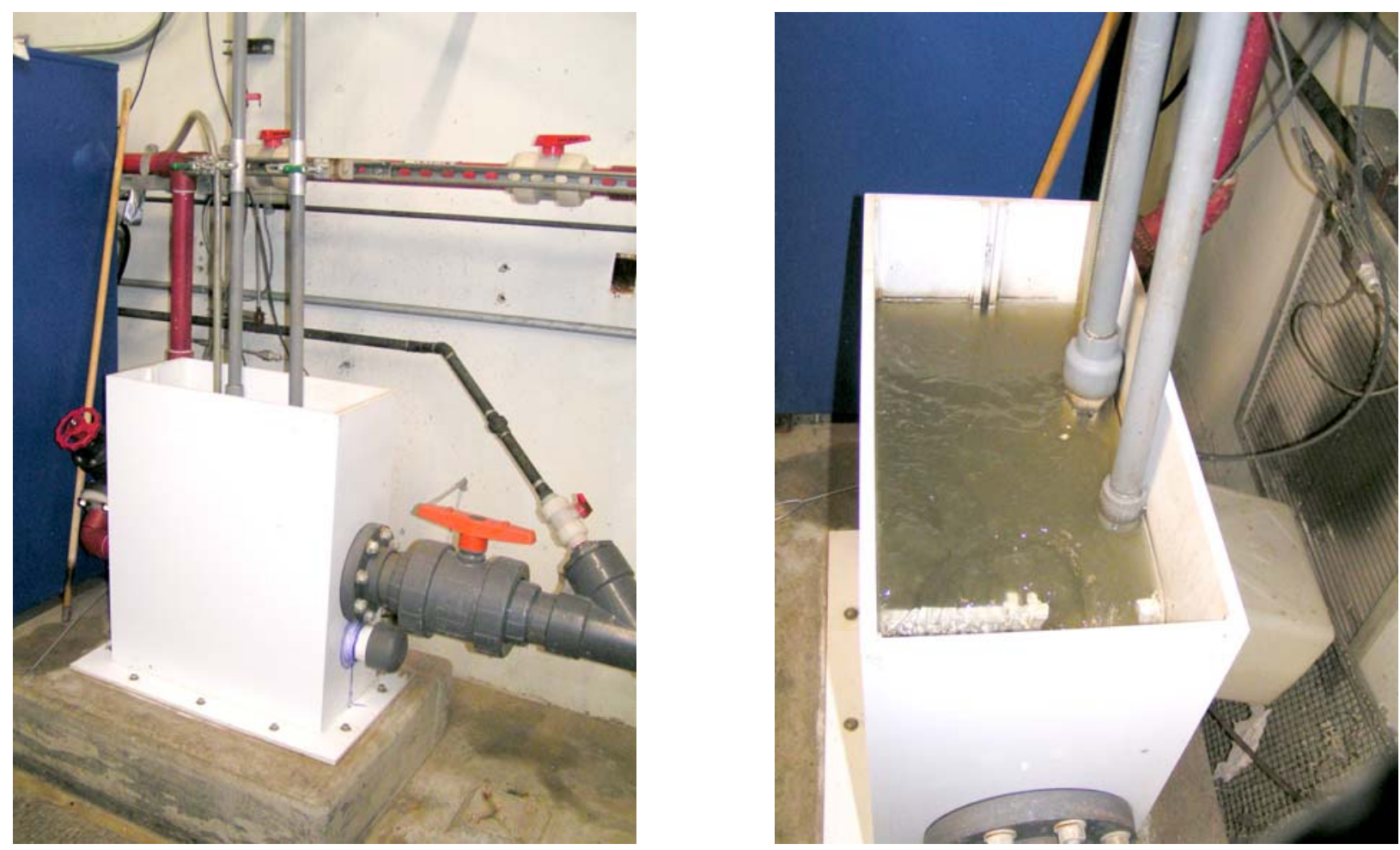

Figure 1. Sampling box in WPTP raw sewage pump room. Left: Side view, right: Looking downward into the wastewater with the overflow near the bottom of the picture.

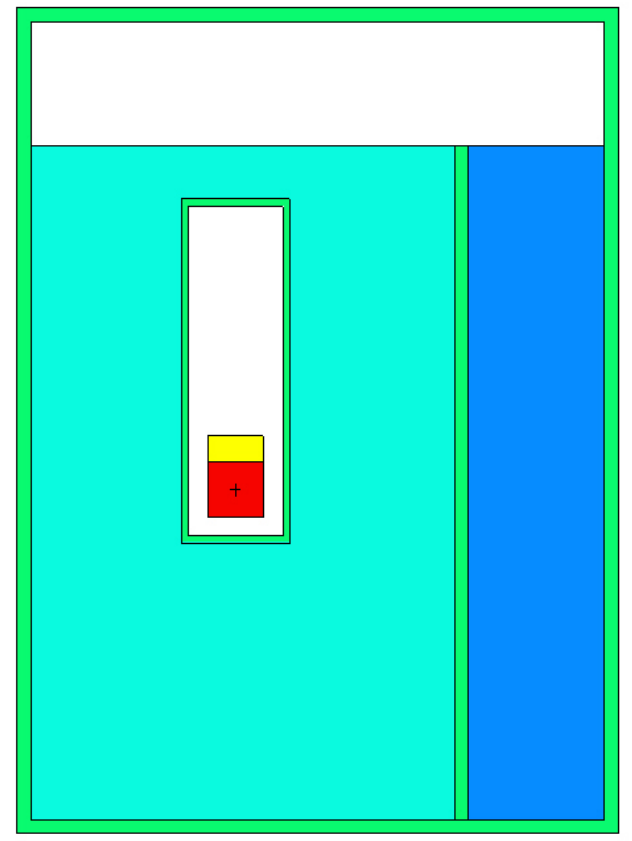

Figure 2. Sampling box detector setup for MCNP modeling. Red is NaI(Tl), green is PVC, light blue is water, and dark blue is foamy water at $50 \%$ density spilling over the overflow, white is dry air, yellow is aluminum. 


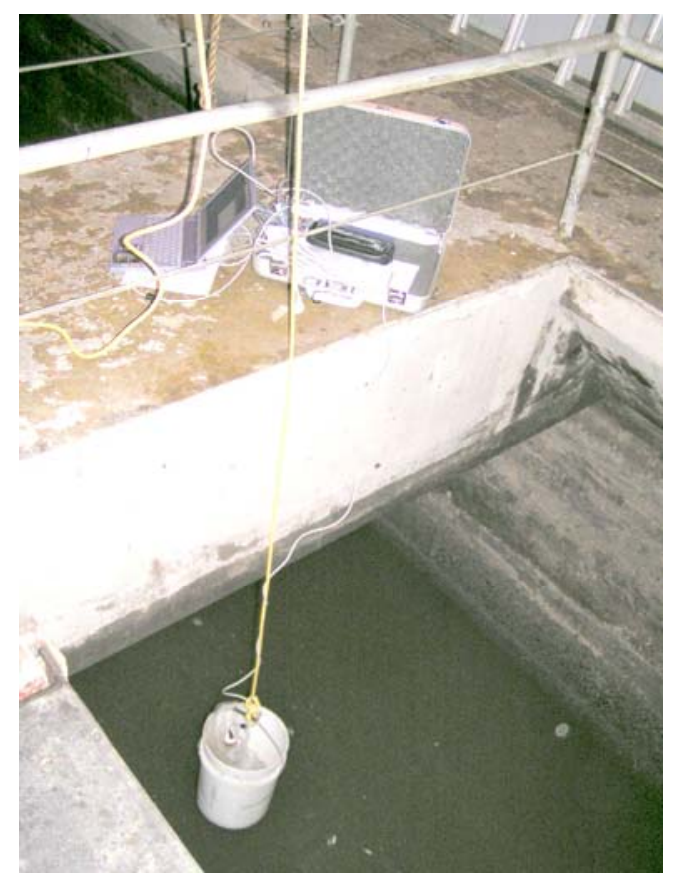

Figure 3. The wet well at the Interbay Pump Station. The floating detector would have to rise and fall with changing wastewater levels.

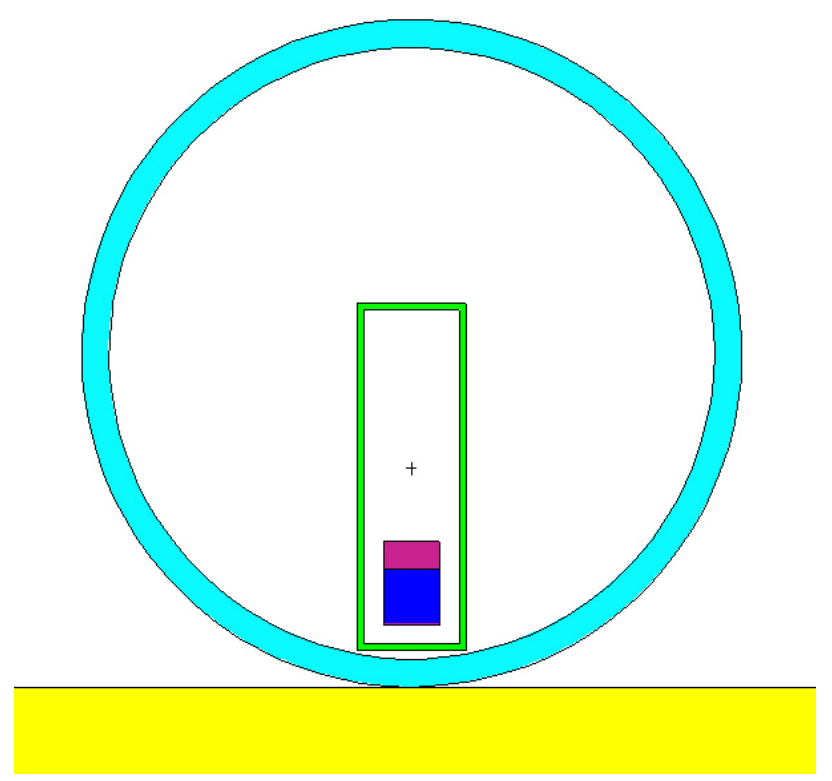

Figure 4. Cross section of model of floating detector. Dark blue is NaI(Tl), yellow is water, light blue is rubber, green is PVC, magenta is aluminum.

Example listings of the MCNP input files are included in Appendix A. 


\subsection{Material Description}

Several basic materials are used in the models. Table 2 gives the chemical composition and density of these materials.

Table 2. Material Composition.

\begin{tabular}{|c|c|c|c|}
\hline Material & Density (g/cc) & $\begin{array}{l}\text { Composition } \\
\text { (MCNP description) }\end{array}$ & Reference \\
\hline \multirow[t]{4}{*}{ Dry Air } & $1.205 \mathrm{E}-3$ & $\begin{array}{l}\text { Carbon (6000 1.24E-4 } \\
\text { weight fraction) }\end{array}$ & ICRU-37, pg. 27 \\
\hline & & $\begin{array}{l}\text { Nitrogen (7014 } \\
0.7555267 \text { weight } \\
\text { fraction) }\end{array}$ & \\
\hline & & $\begin{array}{l}\text { Oxygen (8016 } 0.231781 \\
\text { weight fraction) }\end{array}$ & \\
\hline & & $\begin{array}{l}\text { Argon (18000 } \\
0.0012827 \text { weight } \\
\text { fraction) }\end{array}$ & \\
\hline Aluminum & 2.702 & $\begin{array}{l}\text { Elemental (13027 } 1 \\
\text { atom fraction) }\end{array}$ & $\begin{array}{l}\text { CRC Handbook of } \\
\text { Chemistry and } \\
\text { Physics, 74th ed. }\end{array}$ \\
\hline \multirow[t]{2}{*}{ Sodium Iodide } & 3.667 & $\begin{array}{l}\text { Sodium (11000 } 1 \text { atom } \\
\text { fraction) }\end{array}$ & $\begin{array}{l}\text { CRC Handbook of } \\
\text { Chemistry and } \\
\text { Physics, 74th ed. }\end{array}$ \\
\hline & & $\begin{array}{l}\text { Iodine (53000 } 1 \text { atom } \\
\text { fraction) }\end{array}$ & \\
\hline \multirow[t]{2}{*}{ Water } & 1 & $\begin{array}{l}\text { Hydrogen (1000 } 2 \text { atom } \\
\text { fraction) }\end{array}$ & $\begin{array}{l}\text { CRC Handbook of } \\
\text { Chemistry and } \\
\text { Physics, 74th ed. }\end{array}$ \\
\hline & & $\begin{array}{l}\text { Oxygen (8000 } 1 \text { atom } \\
\text { fraction) }\end{array}$ & \\
\hline \multirow[t]{3}{*}{ Polyvinyl Chloride } & 1.406 & $\begin{array}{l}\text { Hydrogen (1000 } 6 \text { atom } \\
\text { fraction) }\end{array}$ & $\begin{array}{l}\text { The Merck Index, } \\
\text { 11th ed. }\end{array}$ \\
\hline & & $\begin{array}{l}\text { Carbon (6000 } 4 \text { atom } \\
\text { fraction) }\end{array}$ & \\
\hline & & $\begin{array}{l}\text { Chlorine (17000 } 2 \text { atom } \\
\text { fraction) }\end{array}$ & \\
\hline Rubber & 0.95 & Hydrogen (1000 12 & $\begin{array}{l}\text { MatWeb for } \\
\text { density of }\end{array}$ \\
\hline
\end{tabular}




\begin{tabular}{|l|l|l|l|}
\hline Material & Density (g/cc) & $\begin{array}{l}\text { Composition } \\
\text { (MCNP description) }\end{array}$ & Reference \\
\hline & & atom fraction) & $\begin{array}{l}\text { vulcanized natural } \\
\text { rubber; } \\
\text { The Merck Index, } \\
11 \text { th ed. For } \\
\text { chemical } \\
\text { composition }\end{array}$ \\
& & & \\
\hline & & $\begin{array}{l}\text { Carbon (6000 4 atom } \\
\text { fraction) }\end{array}$ & \\
\hline
\end{tabular}

\subsection{Radionuclide Source Descriptions}

There are eleven different radionuclide sources used in this study. Of these radionuclides, ten are direct photon emitters while only ${ }^{90} \mathrm{Sr}+{ }^{90} \mathrm{Y}$ produces $\mathrm{x}$ radiation photons through bremsstrahlung.

Of the ten photon emitters the photon emissions with an intensity greater than $0.5 \%$ were included in the MCNP source term. The photon spectra of these radionuclides used are given in Table 3 . These spectra are from the NUDAT database maintained by National Nuclear Data Center, www.nndc.bnl.gov/nudat2 .

Table 3. Photon emission spectra.

\begin{tabular}{lll}
\hline Radionuclide & $\begin{array}{l}\text { Photon Energy } \\
(\mathrm{MeV})\end{array}$ & $\begin{array}{l}\text { Intensity } \\
\text { (fraction) }\end{array}$ \\
\hline Co-60 & 1.173228 & 0.9985 \\
& 1.332492 & 0.999826 \\
Mo-99 & 0.0405845 & 0.0105 \\
& 0.018251 & 0.0107 \\
& 0.366421 & 0.01191 \\
& 0.018367 & 0.0202 \\
& 0.777921 & 0.0426 \\
& 0.140511 & 0.0452 \\
& 0.181068 & 0.0599 \\
& 0.7395 & 0.1213 \\
& & \\
& 0.020619 & 0.00639
\end{tabular}




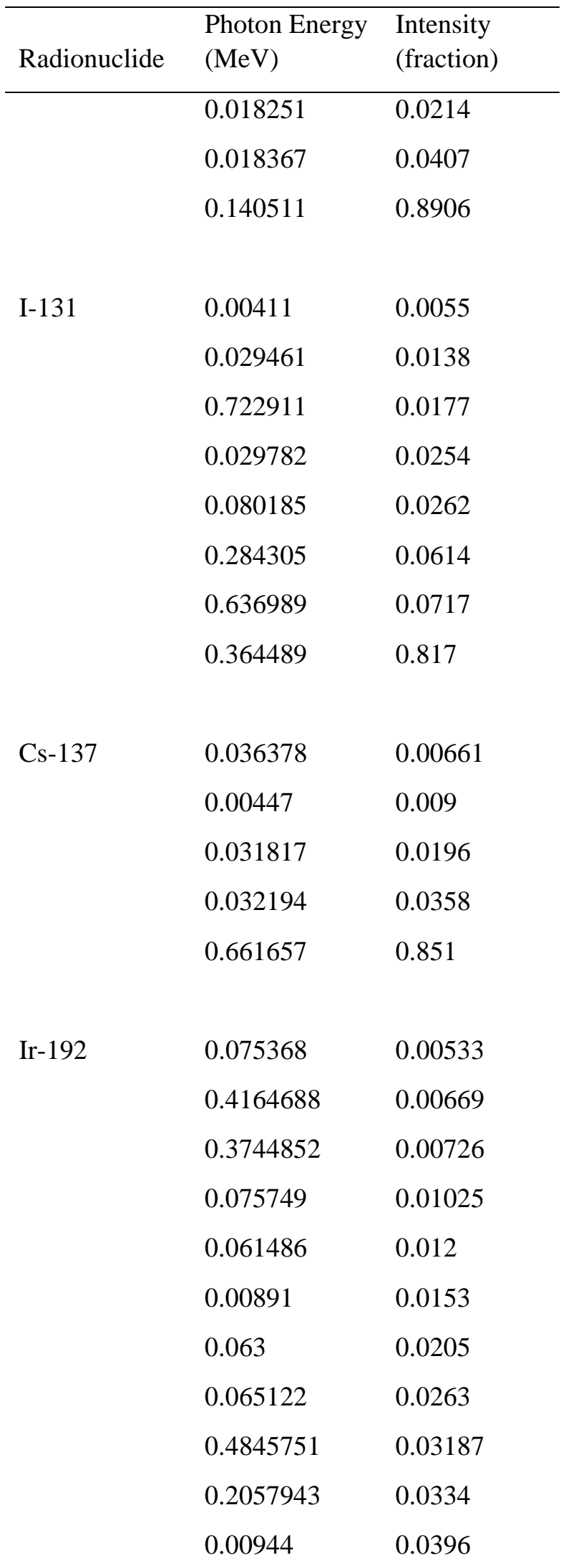




\begin{tabular}{|c|c|c|}
\hline Radionuclide & $\begin{array}{l}\text { Photon Energy } \\
(\mathrm{MeV})\end{array}$ & $\begin{array}{l}\text { Intensity } \\
\text { (fraction) }\end{array}$ \\
\hline & 0.066831 & 0.0446 \\
\hline & 0.588581 & 0.04517 \\
\hline & 0.6124621 & 0.0534 \\
\hline & 0.60441105 & 0.082 \\
\hline & 0.2959565 & 0.2872 \\
\hline & 0.30845507 & 0.2968 \\
\hline & 0.4680688 & 0.4781 \\
\hline & 0.31650618 & 0.8271 \\
\hline \multirow[t]{2}{*}{ Ra-226 } & 0.0117 & 0.008 \\
\hline & 0.186211 & 0.0359 \\
\hline \multirow[t]{13}{*}{$\mathrm{Pb}-214$} & 0.25887 & 0.00524 \\
\hline & 0.83904 & 0.00587 \\
\hline & 0.089784 & 0.00897 \\
\hline & 0.78596 & 0.0107 \\
\hline & 0.0532275 & 0.012 \\
\hline & 0.08683 & 0.0128 \\
\hline & 0.087349 & 0.0244 \\
\hline & 0.074815 & 0.0633 \\
\hline & 0.241997 & 0.0743 \\
\hline & 0.077107 & 0.1055 \\
\hline & 0.0108 & 0.133 \\
\hline & 0.295224 & 0.193 \\
\hline & 0.351932 & 0.376 \\
\hline \multirow[t]{4}{*}{$\mathrm{Bi}-214$} & 0.0111 & 0.00598 \\
\hline & 0.07929 & 0.00661 \\
\hline & 1.58322 & 0.0069 \\
\hline & 1.38531 & 0.00757 \\
\hline
\end{tabular}




\begin{tabular}{|c|c|c|}
\hline Radionuclide & $\begin{array}{l}\text { Photon Energy } \\
(\mathrm{MeV})\end{array}$ & $\begin{array}{l}\text { Intensity } \\
\text { (fraction) }\end{array}$ \\
\hline & 2.11855 & 0.0114 \\
\hline & 1.66128 & 0.0115 \\
\hline & 0.806174 & 0.0122 \\
\hline & 1.4015 & 0.0127 \\
\hline & 1.28096 & 0.0143 \\
\hline & 0.665453 & 0.0146 \\
\hline & 2.44786 & 0.0157 \\
\hline & 1.15519 & 0.0163 \\
\hline & 1.509228 & 0.0211 \\
\hline & 1.84742 & 0.0211 \\
\hline & 1.40798 & 0.0215 \\
\hline & 1.729595 & 0.0292 \\
\hline & 0.934061 & 0.0303 \\
\hline & 1.377669 & 0.04 \\
\hline & 0.768356 & 0.0494 \\
\hline & 2.20421 & 0.0508 \\
\hline & 1.23811 & 0.0579 \\
\hline & 1.120287 & 0.151 \\
\hline & 1.764494 & 0.154 \\
\hline & 0.609312 & 0.461 \\
\hline \multirow[t]{3}{*}{ Am-241 } & 0.0263448 & 0.024 \\
\hline & 0.0595412 & 0.359 \\
\hline & 0.0139 & 0.369 \\
\hline
\end{tabular}

The ${ }^{90} \mathrm{Sr}+{ }^{90} \mathrm{Y}$ beta spectrum was taken from the compilation at www.doseinfo-radar.com . This site has compiled various beta emission spectra for direct use in MCNP. The beta spectrum used is given in Table 4. 
Table 4. ${ }^{90} \mathrm{Sr}+{ }^{90} \mathrm{Y}$ beta spectrum

\begin{tabular}{ll}
\hline Energy $(\mathrm{MeV})$ & $\begin{array}{l}\text { Intensity } \\
\text { (fraction) }\end{array}$ \\
\hline $5.71 \mathrm{E}-02$ & $1.18 \mathrm{E}-01$ \\
$1.71 \mathrm{E}-01$ & $1.23 \mathrm{E}-01$ \\
$2.86 \mathrm{E}-01$ & $1.19 \mathrm{E}-01$ \\
$4.00 \mathrm{E}-01$ & $1.01 \mathrm{E}-01$ \\
$5.14 \mathrm{E}-01$ & $7.67 \mathrm{E}-02$ \\
$6.28 \mathrm{E}-01$ & $7.08 \mathrm{E}-02$ \\
$7.42 \mathrm{E}-01$ & $7.17 \mathrm{E}-02$ \\
$8.57 \mathrm{E}-01$ & $7.15 \mathrm{E}-02$ \\
$9.71 \mathrm{E}-01$ & $7.04 \mathrm{E}-02$ \\
$1.08 \mathrm{E}+00$ & $6.85 \mathrm{E}-02$ \\
$1.20 \mathrm{E}+00$ & $6.57 \mathrm{E}-02$ \\
$1.31 \mathrm{E}+00$ & $6.19 \mathrm{E}-02$ \\
$1.43 \mathrm{E}+00$ & $5.69 \mathrm{E}-02$ \\
$1.54 \mathrm{E}+00$ & $5.07 \mathrm{E}-02$ \\
$1.66 \mathrm{E}+00$ & $4.30 \mathrm{E}-02$ \\
$1.77 \mathrm{E}+00$ & $3.42 \mathrm{E}-02$ \\
$1.88 \mathrm{E}+00$ & $2.46 \mathrm{E}-02$ \\
$2.00 \mathrm{E}+00$ & $1.50 \mathrm{E}-02$ \\
$2.11 \mathrm{E}+00$ & $6.43 \mathrm{E}-03$ \\
$2.23 \mathrm{E}+00$ & $1.13 \mathrm{E}-03$ \\
\hline
\end{tabular}

For the floating detector case only a portion of the water immediately below the detector was used. This source volume was a right circular cylinder $60-\mathrm{cm}$ in diameter and $60-\mathrm{cm}$ thick. This volume was chosen based on the transmission fraction of ${ }^{60}$ Co photons (Vol. 1). By using a smaller source volume a balance is struck between the simulation runtime and the accurate of the result.

\subsection{Tally Description}

Simulation of the detector response is accomplished using the F8 type tally for photons. This tally represents the simulated detector pulses due to incident radiation, in other words the probability of an incident photon interacting with the $\mathrm{NaI}(\mathrm{Tl})$. This tally was modified using the Gaussian Energy Broadening (GEB) special tally treatment. 
Using this treatment results in the photopeaks simulated in the detector broadening to properly represent that of $\mathrm{NaI}(\mathrm{Tl})$. The parameters used to define the GEB specify the full width at half maximum (FWHM) of the observed energy broadening in the physical detector. This treatment follows

$$
F W H M=a+b \sqrt{E+c E^{2}}
$$

where

$a$ is 0 for this simulation

$b$ is 0.05086 for this simulation

$c$ is 0.30486 for this simulation

$E$ is the photon energy in $\mathrm{MeV}$

The values of $a, b$, and $c$ in the FWHM equation were formulated to yield a FWHM value of $7 \%$ at the $661 \mathrm{keV}$ photon energy line of ${ }^{137} \mathrm{Cs}$ (Siciliano et al. 2004). The 7\% FWHM is typical for NaI(Tl).

Fluence information was also collected at several surfaces of the model, the outer PVC, outer aluminum, and the outer $\mathrm{NaI}(\mathrm{Tl})$ surfaces. While this data has been collected it currently is not used in the analysis.

\subsection{Variance Reduction}

As stated earlier, two versions of MCNP have been used for this analysis, MCNP-5 and MCNP-X. The reason for this is that MCNP-X allows the use of a variance reduction method known as importance splitting. This option is not allowed in MCNP-5 for F8 tallies at the present, and is not needed for the photon sources. The use of importance splitting, however, was instrumental in getting acceptable results with the ${ }^{90} \mathrm{Sr}+{ }^{90} \mathrm{Y}$ bremsstrahlung source.

The importance splitting method essentially splits each source particle into $i$ parts at the cell boundaries. As a particle moves from a cell into an adjacent cell if the adjacent cell has a higher importance value the particle is split into the number of particles equal to the ratio of the importance values. This allows for the creation of particle showers to speed up convergence of the tally. A detailed discussion of this variance reduction method can be found in the MCNP manual (Hendricks et al. 2005).

\subsection{Results}

The MCNP results for the pulse height tally are expressed as a probability of an event depositing a particular amount of energy (divided into 1-keV energy bins) in the detector per nuclear transition at randomly chosen locations throughout the source volume.

Such probabilities can be summed over all energy bins (gross counting yield), or summed over energy bins that comprise one or more photopeaks in a spectrum (photopeak counting yield). Figure shows the MCNP results summed over photopeaks for various radionuclides. Two different geometries were used for ${ }^{60} \mathrm{Co}$ (60 cm radius by $60 \mathrm{~cm}$ deep cylinder of water underneath floating detector, and $120 \mathrm{~cm}$ radius by $120 \mathrm{~cm}$ deep cylinder of water underneath floating detector). The 8-fold larger volume increased the gross counting yield in the $3 \times 3$ floating system for ${ }^{60}$ Co by some $27 \%$, but only very slightly increased the counting yield in the photopeaks by $20 \%$. This indicates that using even larger volumes in the calculations would result in very little change in the results. 


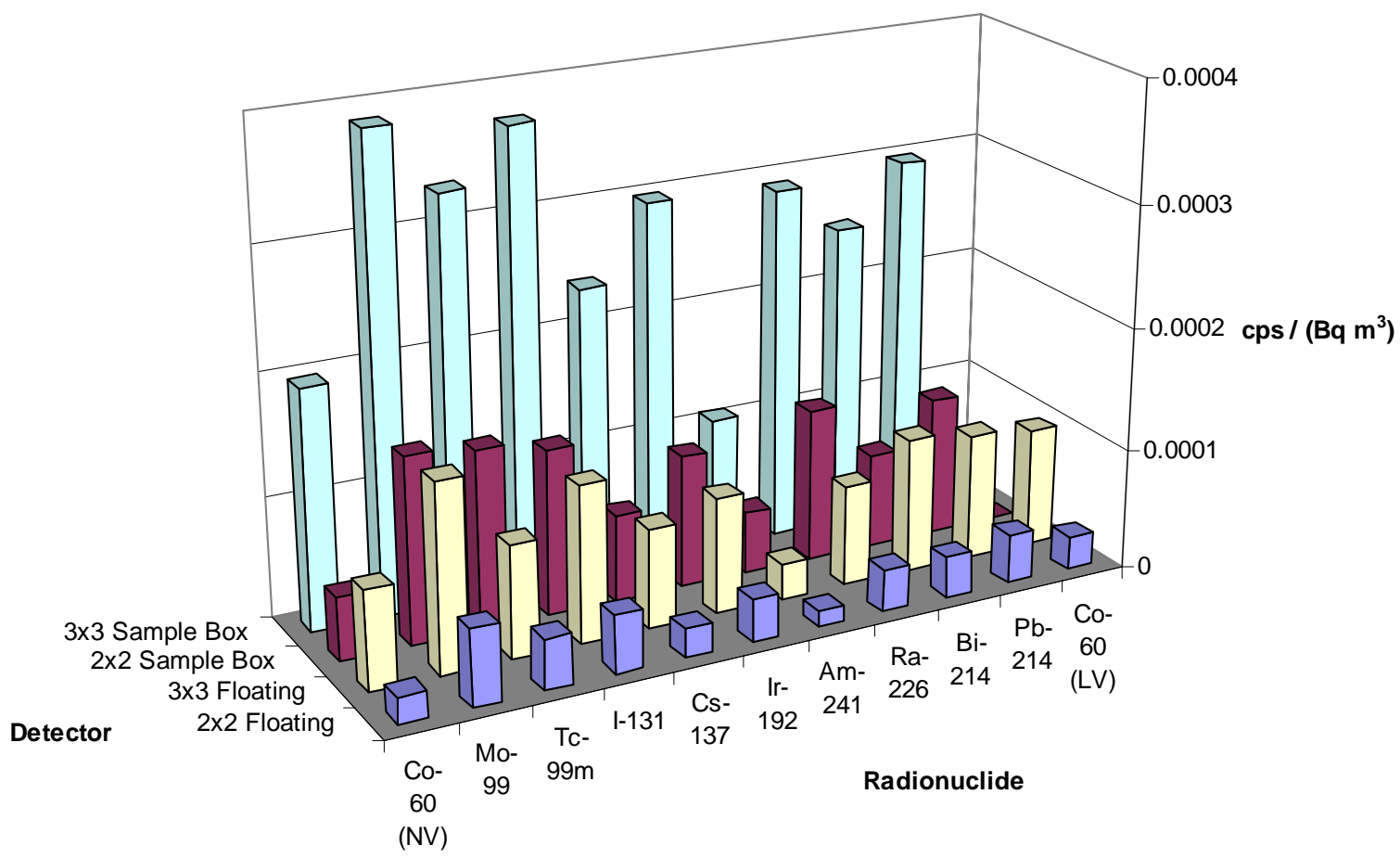

Figure 5. Volume counting yield for full energy events (photopeaks) for the radionuclides in each of the four detector configurations.

The simulated spectra are displayed in Appendix A. As can be seen from these figures the radionuclides of interest have readily identifiable spectra, with exception of ${ }^{90} \mathrm{Sr}+{ }^{90} \mathrm{Y}$, which exhibits no photopeak but rather a broad, and relatively weak, $x$-ray spectrum. The $3 \times 3$ detector is always superior to the $2 \times 2$ detector, and generally placing either detector in the sample box yields better sensitivity than when it is floating (the only exception is ${ }^{90} \mathrm{Sr}+{ }^{90} \mathrm{Y}$ ). The final two figures in this set give show the ${ }^{226} \mathrm{Ra}$ spectra with progeny $\left({ }^{214} \mathrm{Bi}\right.$ and $\left.{ }^{214} \mathrm{~Pb}\right)$ included. These figures differ in that Figure assumes that none of the radon stays in solution in the water, while Figure assumes that $90 \%$ of the radon escapes from the water.

\subsection{Relationship Between MCNP Results and Detection Capabilities}

The relationship between activity, volume, and concentration is

$$
C=\frac{A}{V},
$$

where

$$
\begin{aligned}
& C=\text { radionuclide concentration }\left(\mathrm{Ci} / \mathrm{gal} \text { or } \mathrm{Bq} / \mathrm{m}^{3}\right) \\
& A=\text { the activity }(\mathrm{Ci} \text { or } \mathrm{Bq}) \\
& V=\text { the volume that } A \text { is dissolved or suspended in. }
\end{aligned}
$$

We introduce the concept of volume counting yield, $Y_{\mathrm{V}}$, defined as the observed count rate (counts per second) per unit concentration $\left(\mathrm{Bq} / \mathrm{m}^{3}\right)$, or (counts/second $) /\left(\mathrm{Bq} / \mathrm{m}^{3}\right)$. This unit can be rearranged to give (counts)/(nuclear transition $/ \mathrm{m}^{3}$ ) or (counts $\left.\times \mathrm{m}^{3}\right) /($ nuclear transition). 
One can derive $Y_{\mathrm{V}}$ from the MCNP tally results by multiplying the raw tally results summed over photopeaks or gross spectra by the source volume. The two floating detector volumes used were $0.68 \mathrm{~m}^{3}$ (179 gal.) and $5.43 \mathrm{~m}^{3}$ (1434 gal.). The net volume of water in the sampling box was $0.0815 \mathrm{~m}^{3}$ (21.5 gal.). The $Y_{\mathrm{V}}$ values are plotted in Figure 5 . The amount of activity concentration needed to produce one additional count per second above background in either gross counts or in photopeaks for various isotopes and four detector configurations is shown in Table 5.

Table 5. Activity concentration in $\mathrm{Bq} / \mathrm{m}^{3}$ to produce 1 additional count per second above background in either gross counts or in photopeaks for various isotopes and four detector configurations.

\begin{tabular}{|c|c|c|c|c|c|}
\hline \multirow[b]{2}{*}{ Radionuclide } & \multirow[b]{2}{*}{ Peak (MeV) } & \multicolumn{4}{|c|}{$\left(\mathrm{Bq} / \mathrm{m}^{3}\right)$ to produce 1 additional $\mathrm{c} / \mathrm{s}$} \\
\hline & & $\begin{array}{c}\text { 2x2 } \\
\text { Floating }\end{array}$ & $\begin{array}{c}\text { 2x2 Sample } \\
\text { Box }\end{array}$ & $\begin{array}{c}\text { 3x3 } \\
\text { Floating }\end{array}$ & $\begin{array}{c}\text { 3x3 Sample } \\
\text { Box }\end{array}$ \\
\hline Co-60 (normal volume) & Peak Total & 45,318 & 19,016 & 12,278 & 5,082 \\
\hline Co-60 (normal volume) & Total & 2,178 & 1,478 & 929 & 617 \\
\hline Co-60 (large volume) & Peak Total & 36,306 & & 10,268 & \\
\hline Co-60 (large volume) & Total & 1,708 & & 731 & \\
\hline $\mathrm{Sr} / \mathrm{Y}-90$ & Total Brems & 53,371 & 76,018 & 25,699 & 35,766 \\
\hline Mo-99 & Peak Total & 16,144 & 6,530 & 6,473 & 2,587 \\
\hline Mo-99 & Total & 2,700 & 1,363 & 1,211 & 612 \\
\hline Tc-99m & $1.41 \mathrm{E}-01$ & 24,212 & 6,803 & 10,807 & 3,030 \\
\hline Tc-99m & Total & 3,266 & 1,236 & 1,542 & 590 \\
\hline $\mathrm{I}-131$ & Peak Total & 20,964 & 7,341 & 7,803 & 2,672 \\
\hline $\mathrm{I}-131$ & Total & 2,382 & 1,150 & 1,085 & 520 \\
\hline Cs-137 & $6.62 \mathrm{E}-01$ & 40,824 & 14,032 & 12,239 & 4,224 \\
\hline Cs-137 & Total & 2,327 & 1,324 & 1,025 & 575 \\
\hline Ir-192 & Peak Total & 28,113 & 9,187 & 10,452 & 3,365 \\
\hline Ir-192 & Total & 2,417 & 1,144 & 1,099 & 519 \\
\hline Am-241 & 5.95E-02 & 73,855 & 19,738 & 34,247 & 9,259 \\
\hline Am-241 & Total & 16,443 & 5,203 & 7,898 & 2,519 \\
\hline Ra-226 & $1.86 \mathrm{E}-01$ & 28,108 & 7,965 & 12,179 & 3,449 \\
\hline Ra-226 & Total & 3,245 & 1,308 & 1,520 & 619 \\
\hline $\mathrm{Bi}-214$ & Peak Total & 29,669 & 12,952 & 9,071 & 4,011 \\
\hline $\mathrm{Bi}-214$ & Total & 2,195 & 1,392 & 951 & 593 \\
\hline $\mathrm{Pb}-214$ & Peak Total & 24,593 & 8,785 & 9,673 & 3,363 \\
\hline $\mathrm{Pb}-214$ & Total & 3,101 & 1,371 & 1,429 & 631 \\
\hline
\end{tabular}


Assuming that about one net count per second could be distinguished during a 2 minute count (giving about 120 counts greater than background), one can begin to gauge the concentrations of radionuclides that these detectors can register. The largest of these numbers $\left({ }^{241} \mathrm{Am}\right.$ and floating $2 \times 2$ detector) is about 2 microcuries per cubic meter $\left(\mu \mathrm{Ci} / \mathrm{m}^{3}\right)$, or about $0.007 \mu \mathrm{Ci} /$ gal. For the floating $3 \times 3$ detector, the numbers are about half these values, about $1 \mu \mathrm{Ci} / \mathrm{m}^{3}$ or about $0.004 \mu \mathrm{Ci} /$ gal. In each case, one can see about 6 times lower concentrations of ${ }^{60} \mathrm{Co}$ than of ${ }^{241} \mathrm{Am}$. The use of gross count rate may be more sensitive, but this depends on background levels.

Since it was shown in Vol. 1 that a millicurie per gallon produces no more than one rem per hour, these detection thresholds show that dose rates well below 0.00001 rem per hour, or 0.01 mrem per hour, could be detected with a 2-minute counting time. One can easily detect one curie of any of the listed radionuclides dissolved in 10 million gallons of water, a concentration of $0.1 \mu \mathrm{Ci} / \mathrm{gal}$.

Only for ${ }^{90} \mathrm{Sr}+{ }^{90} \mathrm{Y}$ are the sample box configurations less efficient than the floating detectors.

\subsection{Conclusions from MCNP Calculations}

The use of a submerged or floating $\mathrm{NaI}(\mathrm{Tl})$ based detector $(2 \times 2$ or $3 \times 3)$ allows effective collection of photon spectra from contaminated water. The simulated spectra are readily identifiable with exception of ${ }^{90} \mathrm{Sr}+{ }^{90} \mathrm{Y}$. It is not surprising that ${ }^{90} \mathrm{Sr}+{ }^{90} \mathrm{Y}$ is not identifiable given that the mechanism of photon production, bremsstrahlung, that has a dependence on the atomic number of the media. In these cases the media is water, for which the atomic number of oxygen, 8, is used. While no photopeak characteristic of ${ }^{90} \mathrm{Sr}+{ }^{90} \mathrm{Y}$ exists, it is possible to determine the presence of a radionuclide contaminant purely based on the total detector count rate, dependent on background levels.

These calculations have demonstrated that deploying such detectors would be useful in providing early detection and identification of radionuclides in wastewater. 



\subsection{Recommendations to King County WTD for Radiological Instruments}

Several recommendations are clear from the work to date.

\subsection{Fixed Gamma Spectroscopy Instruments for Early Warning and Quantitative Threat Characterization}

Fixed radiation detection instrumentation should be deployed as part of a defense-in-depth system that provides early warning of significant radioactive material on the way to the WPTP and monitoring at strategic locations within the plant. Such systems should be able to identify the radionuclide(s) and provide estimates of the soluble concentrations.

There is an additional need for detectors capable of functioning in high-dose rate environments that are likely under some scenarios. Such detectors must be capable of functioning from 10 microrems per hour (background) up to 1000 rems per hour, a full eight orders of magnitude (a factor of 100,000,000). In most locations, fixed dose-rate monitors such as area monitors used in nuclear facilities would provide high radiation level capabilities in the case of a large, concentrated source in wastewater, either dissolved or entrained.

\subsubsection{Early Warning from the Interbay Pump Station}

Early warning is quite feasible. Deployment of a 3" $\times 3$ ” $\mathrm{NaI}(\mathrm{Tl})$ scintillation detector in a floating buoy in the wet well of the Interbay Pump Station (Figure ), with a computer workstation in the control room would provide the needed capability. Cabling challenges and temperature stabilization can be overcome. Results would be telemetered via the Secure wideband communications to all authorized locations, including the control room, the South Jackson Street building, and technical support staff off site.

\subsubsection{WPTP Bar Screen Room}

A 3" $\times$ 3" $\mathrm{NaI}(\mathrm{Tl})$ scintillation detector system should be installed on the pipe beyond the hydraulic ram in the rags waste stream in the bar screen room, shown in Figure. This detector should be shielded, and shielding should be wrapped around the pipe itself. A high dose rate monitoring system should be installed in this location as well. Such a combination of detectors provides sensitive, low-level identification and quantification of radioactive materials, and can provide useful information if the lowlevel system becomes overwhelmed.

The high level detector can also serve to detect intact sealed sources that may wind up in the rock box. 


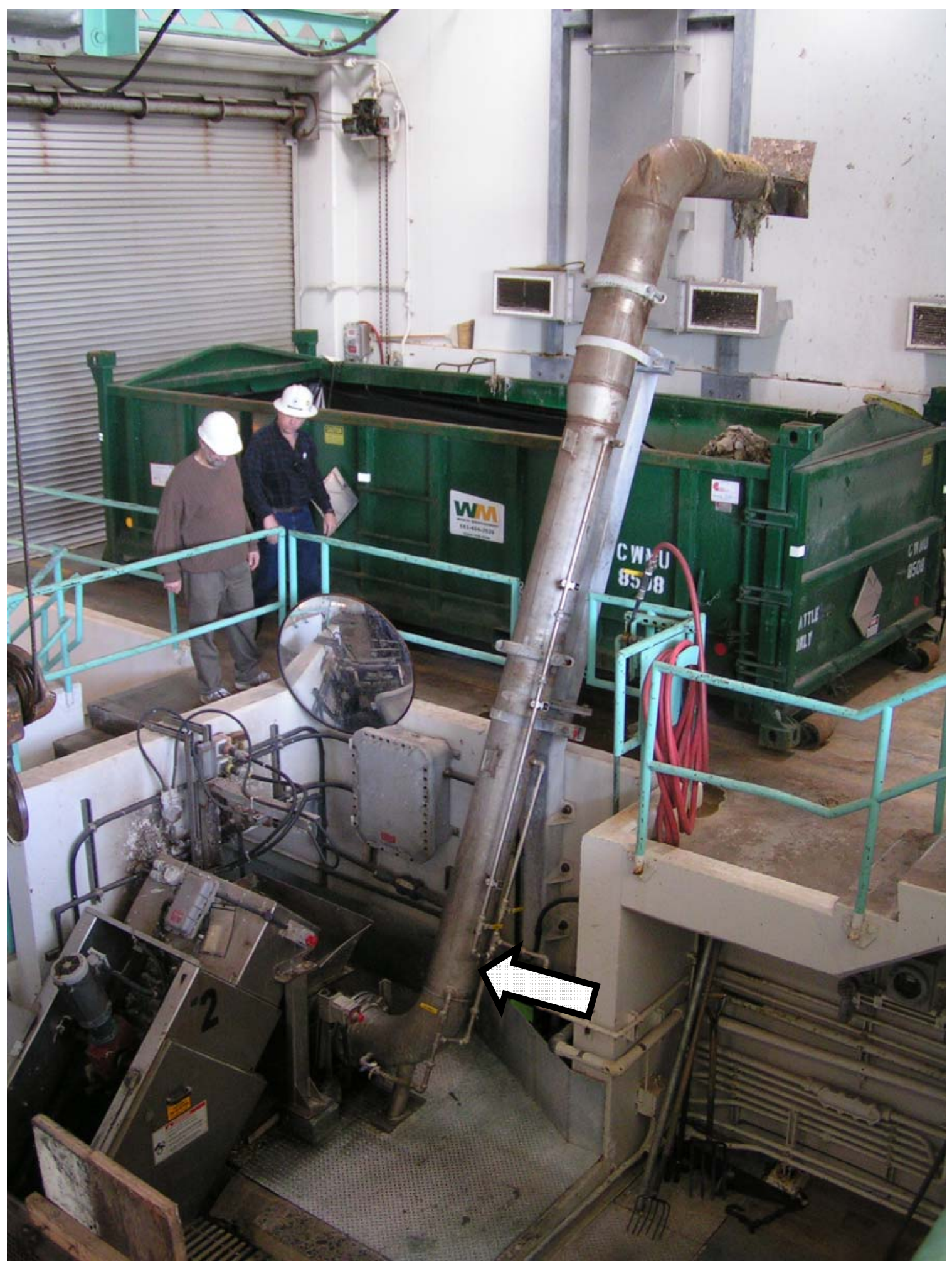

Figure 6. Proposed detector location (arrow) to monitor the rags waste stream in the discharge pipe from the hydraulic ram in the bar screen room at WPTP. 


\subsubsection{Fine Grit Facility}

A dose-rate monitoring system above the collection funnels in the fine grit facility (Figure ) would provide warning and radiation level measurements in the event of an RDE that resulted in insoluble chunks of radioactive material, as discussed in Vol. 1.

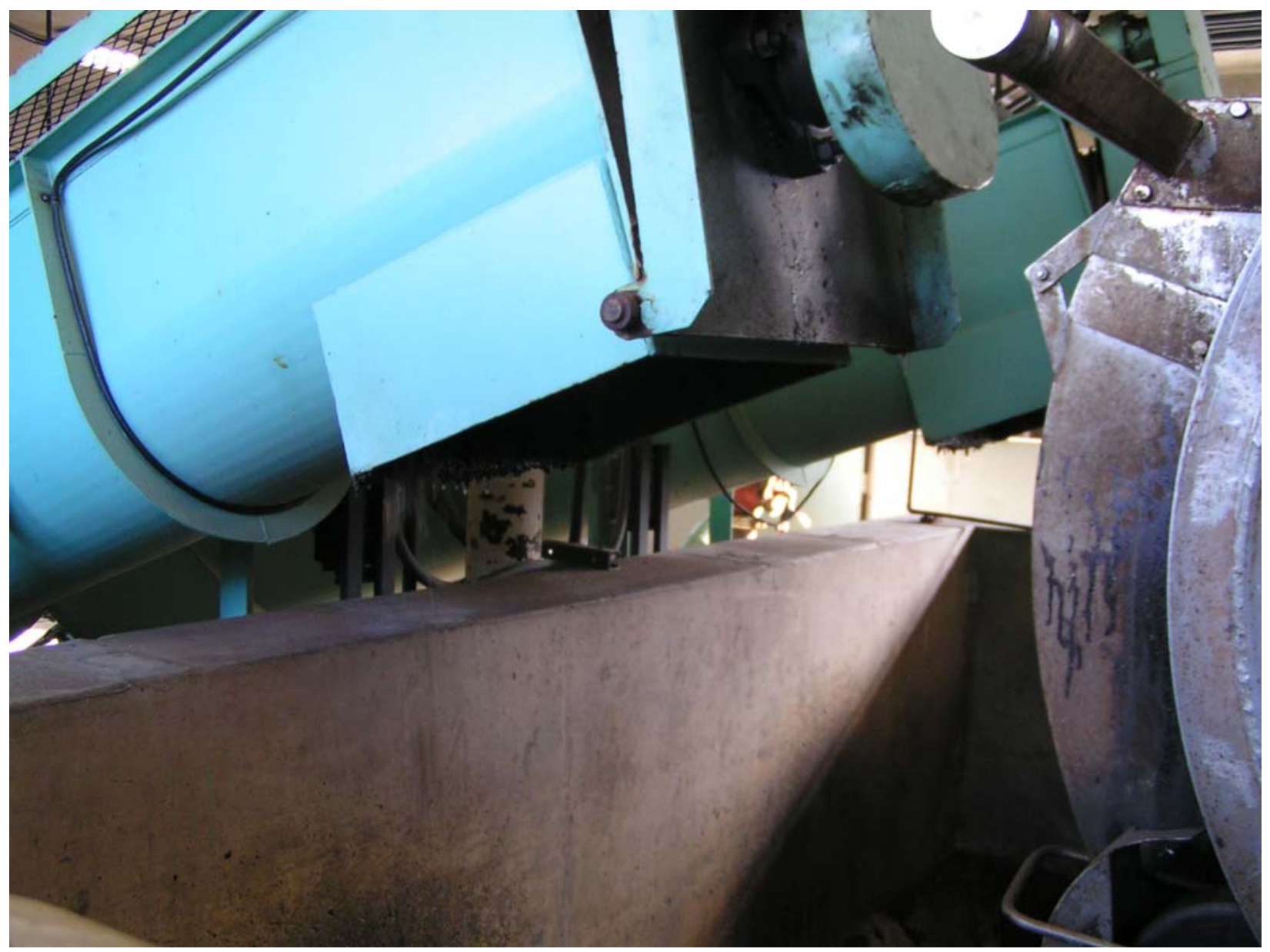

Figure 7. Dose rate monitoring equipment should be located near the grit collection funnels (bottom of photo) in the grit facility 


\subsubsection{Sampling Tank in the Raw Sewage Pump Room}

A 3" $\times$ 3” $\mathrm{NaI}(\mathrm{Tl})$ scintillation detector system should be installed in the sampling tank in the raw sewage pump room (Figure ), along the lines of the design described in Section 4.

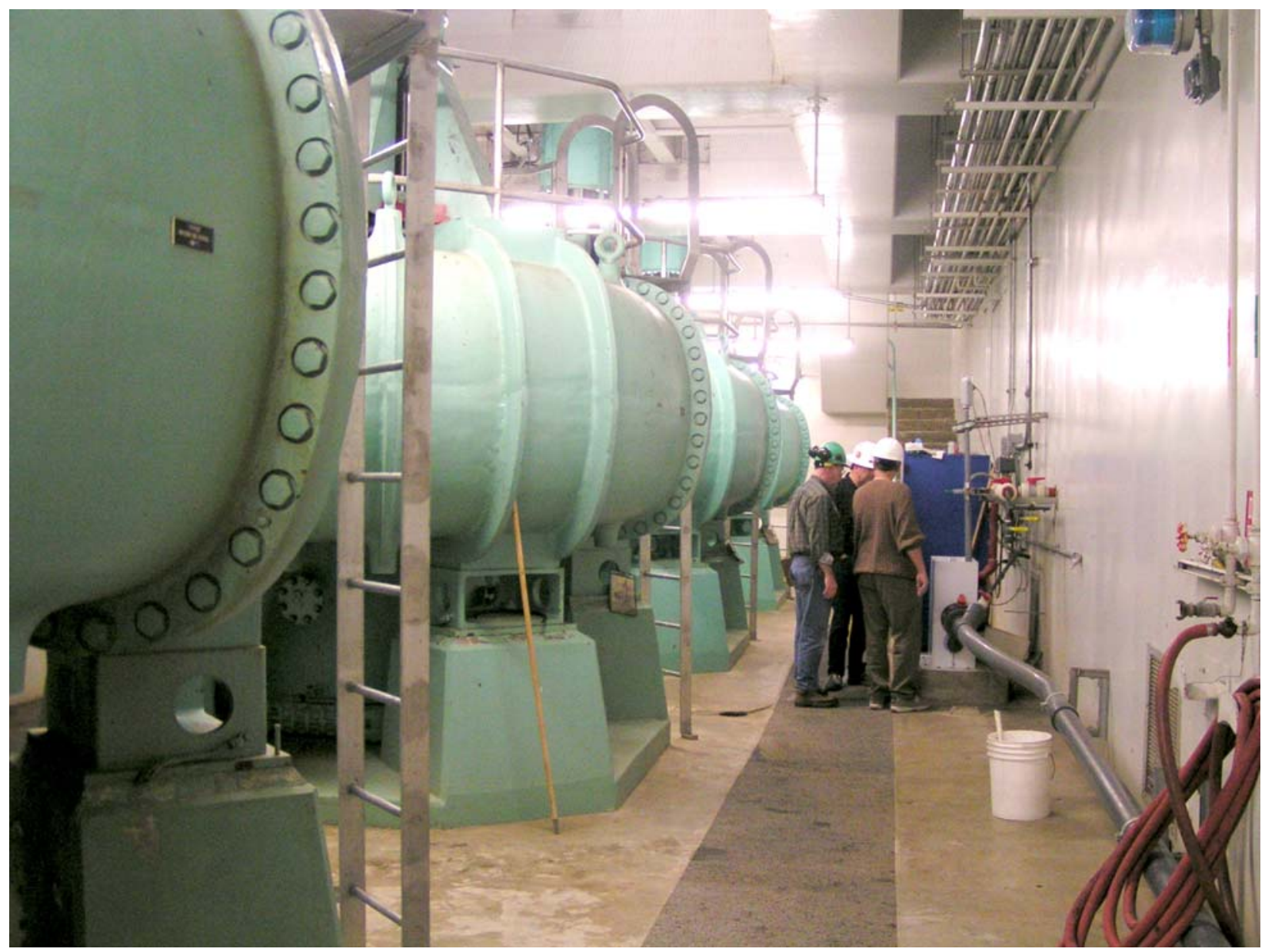

Figure 8. Workers inspect the sampling tank in the raw sewage pump room 


\subsubsection{6\% Thickened, Blended Sludge Pipes}

A 3" × 3" $\mathrm{NaI}(\mathrm{Tl})$ scintillation detector system should be installed downstream of the concentration facilities that produce $6 \%$ thickened blended sludge on the way to the anerobic digesters. One potential location is at a point where the thickened, blended sludge passes through a single pipe (Figure 9).
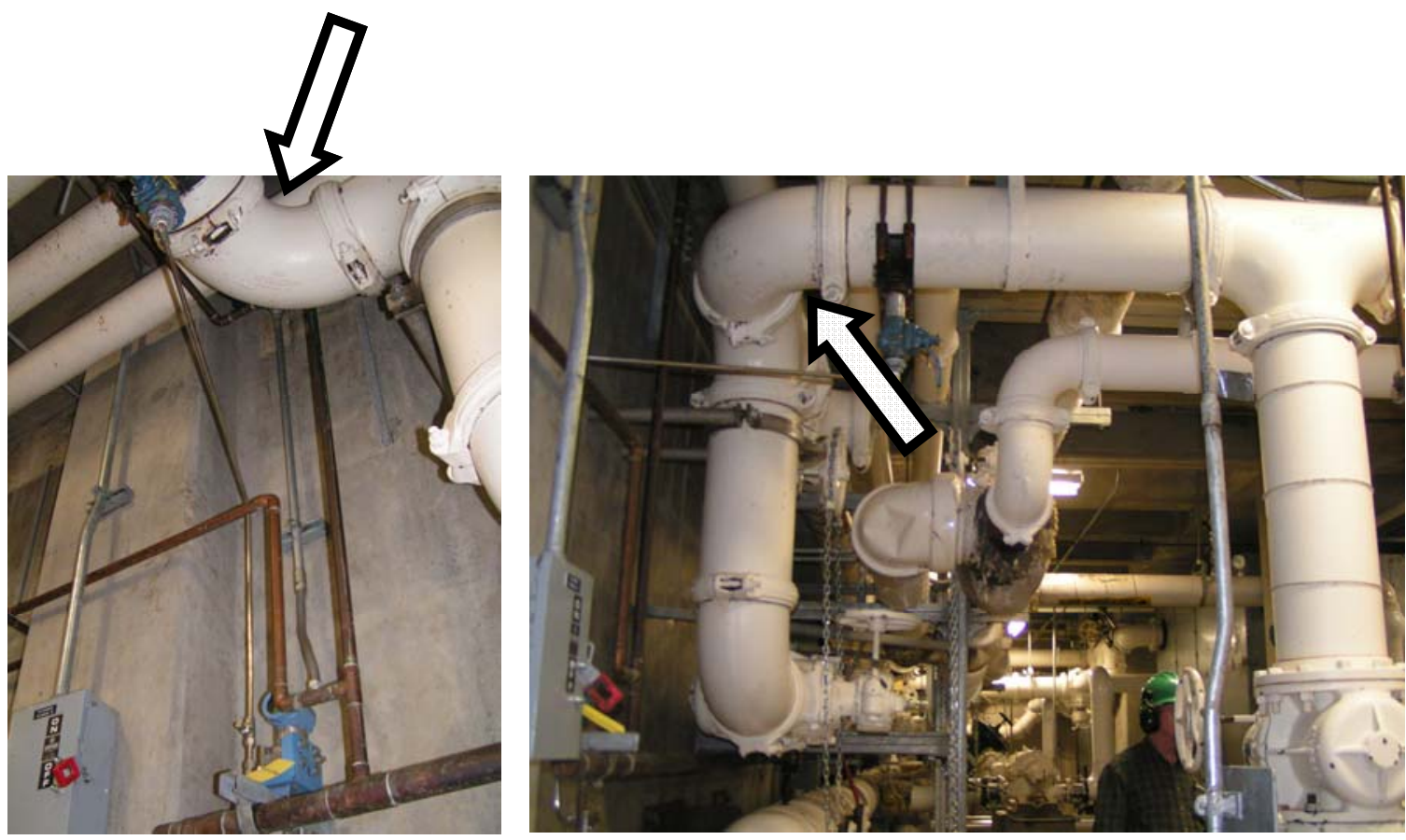

Figure 9. Arrows indicate potential location inside a $90^{\circ}$ elbow for monitoring thickened, blended sludge.

\subsubsection{Engineering Challenges}

Engineering challenges exist for these applications. Explosion-proof, corrosion resistant housings and temperature compensation must be designed for detectors. Cable-length challenges may exist for delivering power to detectors and retrieving required signals out of potentially explosive and corrosive environments. It will be necessary to engineer floating detectors that cannot become dams or become excessively fouled with grease between reasonable service intervals, and that can rise and fall with varying wastewater levels and flow rates.

It is also necessary to deploy both ultra-sensitive detectors to provide early warning and identification and detectors capable of functioning in high-dose rate environments that are likely under some scenarios, capable of functioning from 10 microrems per hour (background) up to 1000 rems per hour, a full eight orders of magnitude (a factor of 100,000,000). While such instrumentation exists for other applications, all of this engineering will require deploying prototypes and perhaps dealing with unforeseen complications.

Software supporting fixed spectroscopic detectors would be developed to provide prompt, reliable, and simple interpretations of spectroscopic outputs that are of use to operators and decision-makers. Software to provide scientists and homeland security personnel with sufficient technical detail for identification, quantification, waste management decisions, and for the inevitable forensic and attribution needs must be developed. Such software is not an off-the-shelf product as of March 2005 but it is expected that, with 
sufficient resources and collaboration between government agencies, scientists, and vendors, it can be specified and developed within two years or less.

\subsection{Portable Instruments}

In addition to fixed instruments, general purpose instruments that can be used to determine the nature and extent of radioactive contamination and measure radiation levels for purposes of protecting personnel and members of the public should be available to WTD personnel.

\subsubsection{Portable Radioisotope Identifiers (RIIDs)}

One or more portable radioisotope identifiers (RIIDs) should be available to WTD personnel for surveying and identifying contaminants in screening waste (rags), grit, and biosolids, as well as anywhere else that radioactivity may concentrate. These are not on the list of approved instruments maintained by the state of Washington.

\subsubsection{Personal Radiation Monitors}

Small, portable battery-powered personal radiation monitors should be widely available to WTD personnel. The personal monitors can be used for personal and group radiation protection decisions, and to alert management to the need to get expert backup.

From the list of state-approved instruments, we recommend that WTD purchase one Item No. 15 (EPD Mk2 Dosimeter Reader), one Item No. 16 (Utility Software Site License for EPD Mk2), and as many EPD Mk2 Siemens EPD MK2 Dosimeters as needed. If the MK2 is no longer available, then we recommend getting the next generation instrument from Siemens.

\subsubsection{Portable, General Purpose Radiological Instruments}

From the state-approved list, we recommend that you purchase one of the Areva/Cogema/ Canberra/Aptec/NRC suitcases "Item No. 12" ERKADV (Emergency Response Kit, Advanced) at \$7,750 each. This kit contains a radiation detection instrument (ADM-300) that can handle alpha, beta, and gamma detection. WTD probably does not need everything in the kit, so we would focus on the built-in detectors and the external GM pancake probe. The XP110 Large Area X-Ray Probe is not needed.

We also recommend the purchase of 10 to 20 RadAlert "Inspectors," a multi-purpose GM-based instrument that can be operated in the count mode, count rate mode, and in the dose rate mode.

\subsection{Laboratory Instruments}

A liquid scintillation counter that can detect any radioactive materials (alpha-, beta-, and gamma-emitters) in water samples should be available for laboratory analysis of samples. Typical liquid scintillation counters analyze a $1 \mathrm{~mL}$ water sample in $10 \mathrm{~mL}$ of "liquid scintillation cocktail," a mixture of a solvent, surfactants, and wavelength-shifting fluors that give off light when ionizing radiation is absorbed by them. Such instruments can give very accurate results and can identify and measure radionuclides that do not emit gamma or $\mathrm{x}$ radiation.

A liquid scintillation counter is a lower priority than other instruments described above. 


\subsection{Training}

All uses of radiological instrumentation will require training and periodic retraining of personnel, as well as periodic calibration and maintenance of instruments. Routine innocent alarms will occur due to medical radionuclides that are legally discharged into sanitary sewers on a daily basis. Innocent alarms may also be triggered by WTD workers who have recently been treated with medical radioisotopes.

Instrumentation must provide signals that distinguish between routine medical discharges and off-normal occurrences that are due to malicious acts or undetected accidents. Operators and others who deal with instrument signals must be prepared to deal with innocent but real alarms, while being vigilant for alarms indicating malicious or other serious discharges.

\subsection{Funding}

The King County Wastewater Treatment Division should seek Homeland Security or EPA resources to become the model POTW in the U.S. to design, deploy, and test such radiological instrumentation, and integrate the use of such instrumentation into its radiological emergency response plan. 



\subsection{Conclusions and Next Steps}

This report is the second of three volumes. The first volume, a radiological risk assessment, contains basic information on radiation and radioactive materials, and develops scenarios that could lead to the introduction of radioactive material into a combined storm and sanitary sewer system. Vol. 1 analyzes the consequences resulting from various scenarios.

\subsection{Conclusions}

Based on the analysis in Volume 1 and a second visit to the King County WTD, this document, Volume 2 of PNNL-15163, provides an assessment of the radiological instrumentation needs for detection of radiological or nuclear terrorism, in support of decisions to treat contaminated wastewater or to bypass the West Point Treatment Plant (WPTP), and in support of radiation protection of the workforce, the public, and the infrastructure of this POTW.

Two broad categories of scenarios were considered in Volume 1. The first category includes events that may be suspected from the outset, such as an explosion of a "dirty bomb" in downtown Seattle. The explosion would most likely be heard, but the type of explosion (e.g., sewer methane gas or RDD) may not be immediately known. Emergency first responders must be able to quickly detect the radioisotopes listed in Vol. 1, assess the situation, and deploy a response to contain and mitigate (if possible) detrimental effects resulting from the incident. In such scenarios, advance notice of about an hour or two might be available before any contaminated wastewater reaches a treatment plant.

The second category includes RDEs that could go initially undetected by emergency personnel. Examples of such a scenario would be the inadvertent or surreptitious introduction of radioactive material into the sewer system. Intact rogue radioactive sources from industrial radiography devices, well-logging apparatus, or moisture density gauges may get into wastewater and be carried to the treatment plant. Other scenarios include a terrorist deliberately putting a dispersible radioactive material into wastewater. Alternatively, a botched terrorism preparation of an RDD may result in radioactive material entering wastewater without anyone's knowledge. Drinking water supplies may also be contaminated, with the result that some or most of the radioactivity ends up in wastewater. In these cases, the wastewater management and treatment infrastructure may be the first opportunity that government has to detect such events.

Fixed radiation detection instrumentation should be deployed in a defense-in-depth system that provides 1) early warning of significant radioactive material on the way to the WPTP, including identification of the radionuclide(s) and estimates of the soluble concentrations, with a floating detector located in the wet well at the Interbay Pump Station and telemetered via the secure wideband communications to all authorized locations, 2) monitoring at strategic locations within the plant, including

a) the pipe beyond the hydraulic ram in the bar screen room

b) above the collection funnels in the fine grit facility

c) in the sampling tank in the raw sewage pump room

d) downstream of the concentration facilities that produce $6 \%$ blended and concentrated biosolids.

Engineering challenges exist for these applications. Explosion-proof, corrosion resistant housings and temperature compensation must be designed for detectors. Cable-length challenges may exist for delivering power to detectors and retrieving required signals out of potentially explosive and corrosive 
environments. It will be necessary to engineer floating detectors that cannot become dams or become excessively fouled with grease between reasonable service intervals, and that can rise and fall with varying wastewater levels and flow rates. It is also necessary to deploy both ultra-sensitive detectors to provide early warning and identification and detectors capable of functioning in high-dose rate environments that are likely under some scenarios, capable of functioning from 10 microrems per hour (background) up to 1000 rems per hour, a full eight orders of magnitude (a factor of 100,000,000). While such instrumentation exists for other applications, all of this engineering will require deploying prototypes and perhaps dealing with unforeseen complications.

Software supporting fixed spectroscopic detectors would be developed to provide prompt, reliable, and simple interpretations of spectroscopic outputs that are of use to operators and decision-makers. Software to provide scientists and homeland security personnel with sufficient technical detail for identification, quantification, waste management decisions, and for the inevitable forensic and attribution needs must be developed. Such software is not an off-the-shelf product as of March, 2005, but it is expected that, with sufficient resources and collaboration between government agencies, scientists, and vendors, it can be specified and developed within two years or less.

Computational modeling using the Monte Carlo N-Particle (MCNP) software has demonstrated that useful detection capabilities can be deployed. In particular, any of the isotopes examined can be detected at levels between 0.01 and $0.1 \mu \mathrm{Ci}$ per gallon. Thus, a $1 \mathrm{Ci}$ source dissolved in 10 million gallons of water could be detected within minutes.

In addition to fixed instruments, general purpose instruments that can be used to determine the nature and extent of radioactive contamination and measure radiation levels for purposes of protecting personnel and members of the public should be available to WTD personnel. One or more portable RIIDs should be available to WTD personnel. Small, portable battery-powered personal radiation monitors should be widely available to WTD personnel. The personal monitors can be used for personal and group radiation protection decisions, and to alert management to the need to get expert backup.

All uses of radiological instrumentation will require training and periodic retraining of personnel, as well as periodic calibration and maintenance of instruments. Routine "innocent" alarms will occur due to medical radionuclides that are legally discharged into sanitary sewers on a daily basis. Innocent alarms may also be triggered by WTD workers who have recently been treated with medical radioisotopes. Instrumentation must provide signals that distinguish between routine medical discharges and off-normal occurrences that are due to malicious acts or undetected accidents. Operators and others who deal with instrument signals must be prepared to deal with innocent but real alarms, while being vigilant for alarms indicating malicious or other serious discharges.

\subsection{Next Steps}

The King County Wastewater Treatment Division should seek Homeland Security resources to become the model POTW in the U.S. to design, deploy, and test such radiological instrumentation. 


\subsection{References}

American National Standards Institute (ANSI). 2004a. American National Standard for Evaluation and Performance of Radiation Detection Portal Monitors for Use in Homeland Security. ANSI N42.35-2004, The Institute of Electrical and Electronics Engineers, Inc., New York.

American National Standards Institute (ANSI). 2004b. American National Standard for Portable Radiation Detection Instrumentation for Homeland Security. ANSI N42.33-2003, The Institute of Electrical and Electronics Engineers, Inc., New York.

American National Standards Institute (ANSI). 2004c. American National Standard Performance Criteria for Alarming Personal Radiation Detectors for Homeland Security. ANSI N42.32-2003, The Institute of Electrical and Electronics Engineers, Inc., New York.

American National Standards Institute (ANSI). 2004d. American National Standard Performance Criteria for Hand-held Instruments for the Detection and Identification of Radionuclides. ANSI N42.34-2003, The Institute of Electrical and Electronics Engineers, Inc., New York.

Hendricks JS, GW McKinney, LS Waters, JW Durkee, MR James, DB Pelowitz, HR Trellue, TL Roberts, HW Edgorf, JP Finch, DS Mashnik, FX Gallmeier, and J-C David. 2005. MCNPX, VERSION 2.5.f. LA-UR-05-0891.

Interagency Steering Committee on Radiation Standards. 2003. ISCORS Assessment of Radioactivity in Sewage Sludge: Recommendations on Management of Radioactive Materials in Sewage Sludge and Ash at Publicly Owned Treatment Works. Draft Final Report. DOE/EH-0668 EPA 832-R-03002B ISCORS Technical Report 2003-04 http://www.iscors.org/POTWrec.pdf.

International Atomic Energy Agency (IAEA). 2003. Categorization of radioactive sources. Revision of IAEA-TECDOC-1191, Categorization of radiation sources. IAEA-TECDOC-1344; http://hps.org/documents/IAEATecDoc1344.pdf, Interantional Atomic Energy Agency, Vienna.

LANL - Lawrence Livermore National Laboratory. 2003. (Para 4.6)

National Council on Radiation Protection and Measurements (NCRP). 2001. Management of Terrorist Events Involving Radioactive Material. PNNL-13945. NCRP Report No. 138, NCRP Publications, Bethesda, Maryland.

Siciliano EA, JE Schweppe, DC Stromswold, JH Ely, BD Geelhood, RT Kouzes, and BD Milbrath. 2004. Comparison of PVT and NaI(Tl) Scintillators for Vehicle Portal Monitor Applications. PNNL14487, Pacific Northwest National Laboratory, Richland, Washington.

Strom DJ. 2005. Radiological Risk Assessment for King County Wastewater Treatment Division. PNNL15163 Vol. 1 Rev. 1, Pacific Northwest National Laboratory, Richland, Washington.

X-5 Monte Carlo Team. 2004. MCNP Overview and Theory. LA-UR-03-1987 Vol. 1, Los Alamos National Laboratory, Los Alamos, New Mexico. 



\section{Appendix A. MCNP Results}

Appendix A contains graphs of spectra for ten radionuclides, ${ }^{60} \mathrm{Co},{ }^{90} \mathrm{Sr}+{ }^{90} \mathrm{Y},{ }^{99} \mathrm{Mo},{ }^{99 \mathrm{~m}} \mathrm{Tc},{ }^{131} \mathrm{I},{ }^{137} \mathrm{Cs}$, ${ }^{192} \mathrm{Ir},{ }^{214} \mathrm{Bi},{ }^{214} \mathrm{~Pb},{ }^{226} \mathrm{Ra}$, and ${ }^{241} \mathrm{Am}$ that would be observed in each of the four detector configurations described in Section 4. Additional drawings of the detector layouts are also shown.

Table 6 shows the numerical results in $\mathrm{cps} /\left(\mathrm{Bq} / \mathrm{m}^{3}\right)$ from the MCNP calculations.

Table 6. Numerical results in $\mathrm{cps} /\left(\mathrm{Bq} / \mathrm{m}^{3}\right)$ from the MCNP calculations for each photopeak, for all photopeaks, and for gross counts for various radionuclides.

\begin{tabular}{|c|c|c|c|c|c|}
\hline $\begin{array}{l}\text { Radio- } \\
\text { nuclide }\end{array}$ & Peak (MeV) & $2 \times 2$ Floating & $\begin{array}{c}2 \times 2 \text { Sample } \\
\text { Box }\end{array}$ & $3 \times 3$ Floating & $\begin{array}{c}3 \times 3 \text { Sample } \\
\text { Box }\end{array}$ \\
\hline \multirow[t]{4}{*}{ Co-60 } & $1.17 \mathrm{E}+00$ & 1.31E-05 & 3.00E-05 & 4.61E-05 & $1.09 \mathrm{E}-04$ \\
\hline & $1.33 \mathrm{E}+00$ & 8.92E-06 & 2.26E-05 & 3.54E-05 & 8.76E-05 \\
\hline & Peak Total & 2.21E-05 & 5.26E-05 & 8.14E-05 & 1.97E-04 \\
\hline & Total & 4.59E-04 & 6.77E-04 & $1.08 \mathrm{E}-03$ & $1.62 \mathrm{E}-03$ \\
\hline \multirow[t]{6}{*}{ Mo-99 } & 3.66E-01 & 2.43E-05 & 5.58E-05 & 5.19E-05 & $1.22 \mathrm{E}-04$ \\
\hline & $1.41 \mathrm{E}-01$ & 1.85E-05 & 5.01E-05 & 4.34E-05 & 1.13E-04 \\
\hline & $1.81 \mathrm{E}-01$ & 7.64E-06 & 1.52E-05 & 1.92E-05 & $4.04 \mathrm{E}-05$ \\
\hline & $7.40 \mathrm{E}-01$ & $1.15 \mathrm{E}-05$ & 3.20E-05 & 4.00E-05 & $1.11 \mathrm{E}-04$ \\
\hline & Peak Total & 6.19E-05 & $1.53 \mathrm{E}-04$ & $1.54 \mathrm{E}-04$ & 3.87E-04 \\
\hline & Total & 3.70E-04 & 7.33E-04 & 8.26E-04 & $1.64 \mathrm{E}-03$ \\
\hline \multirow[t]{2}{*}{ Tc-99m } & $1.41 \mathrm{E}-01$ & 4.13E-05 & $1.47 \mathrm{E}-04$ & 9.25E-05 & 3.30E-04 \\
\hline & Total & 3.06E-04 & 8.09E-04 & 6.49E-04 & $1.69 \mathrm{E}-03$ \\
\hline \multirow[t]{6}{*}{$\mathrm{I}-131$} & 7.23E-01 & $1.40 \mathrm{E}-05$ & 3.16E-05 & 3.70E-05 & $8.20 \mathrm{E}-05$ \\
\hline & 2.84E-01 & 3.12E-05 & 9.78E-05 & 8.31E-05 & 2.69E-04 \\
\hline & 6.37E-01 & 2.02E-06 & 5.64E-06 & 6.43E-06 & $1.88 \mathrm{E}-05$ \\
\hline & 3.64E-01 & 5.09E-07 & $1.22 \mathrm{E}-06$ & 1.67E-06 & 4.35E-06 \\
\hline & Peak Total & 4.77E-05 & 1.36E-04 & 1.28E-04 & 3.74E-04 \\
\hline & Total & 4.20E-04 & 8.70E-04 & $9.21 \mathrm{E}-04$ & 1.92E-03 \\
\hline \multirow[t]{2}{*}{ Cs-137 } & 6.62E-01 & 2.45E-05 & 7.13E-05 & 8.17E-05 & 2.37E-04 \\
\hline & Total & 4.30E-04 & 7.55E-04 & 9.76E-04 & $1.74 \mathrm{E}-03$ \\
\hline \multirow[t]{4}{*}{ Ir-192 } & $6.04 \mathrm{E}-01$ & $2.52 \mathrm{E}-05$ & 7.96E-05 & $6.50 \mathrm{E}-05$ & $2.08 \mathrm{E}-04$ \\
\hline & 4.68E-01 & 8.45E-06 & 2.31E-05 & 2.39E-05 & 6.93E-05 \\
\hline & 3.17E-01 & $1.89 \mathrm{E}-06$ & $6.15 \mathrm{E}-06$ & $6.75 \mathrm{E}-06$ & 1.99E-05 \\
\hline & Peak Total & 3.56E-05 & $1.09 \mathrm{E}-04$ & 9.57E-05 & 2.97E-04 \\
\hline
\end{tabular}




\begin{tabular}{|c|c|c|c|c|c|}
\hline $\begin{array}{l}\text { Radio- } \\
\text { nuclide }\end{array}$ & Peak (MeV) & $2 \times 2$ Floating & $\begin{array}{c}2 \times 2 \text { Sample } \\
\text { Box }\end{array}$ & $3 \times 3$ Floating & $\begin{array}{c}3 \times 3 \text { Sample } \\
\text { Box }\end{array}$ \\
\hline & Total & $4.14 \mathrm{E}-04$ & 8.74E-04 & $9.10 \mathrm{E}-04$ & $1.93 \mathrm{E}-03$ \\
\hline \multirow[t]{2}{*}{ Am-241 } & 5.95E-02 & 1.35E-05 & 5.07E-05 & 2.92E-05 & $1.08 \mathrm{E}-04$ \\
\hline & Total & 6.08E-05 & 1.92E-04 & 1.27E-04 & 3.97E-04 \\
\hline \multirow[t]{2}{*}{ Ra-226 } & $1.86 \mathrm{E}-01$ & 3.56E-05 & $1.26 \mathrm{E}-04$ & 8.21E-05 & 2.90E-04 \\
\hline & Total & 3.08E-04 & 7.64E-04 & 6.58E-04 & 1.62E-03 \\
\hline \multirow[t]{7}{*}{$\mathrm{Bi}-214$} & $1.38 \mathrm{E}+00$ & 1.49E-05 & 3.87E-05 & 4.81E-05 & $1.23 \mathrm{E}-04$ \\
\hline & 7.68E-01 & 5.35E-06 & 1.06E-05 & 1.67E-05 & 3.11E-05 \\
\hline & $1.12 \mathrm{E}+00$ & 6.41E-06 & 1.25E-05 & 1.99E-05 & 4.13E-05 \\
\hline & $1.76 \mathrm{E}+00$ & 3.51E-06 & 7.77E-06 & 1.28E-05 & 2.52E-05 \\
\hline & 6.09E-01 & 3.51E-06 & 7.60E-06 & 1.28E-05 & 2.89E-05 \\
\hline & Peak Total & 3.37E-05 & 7.72E-05 & 1.10E-04 & 2.49E-04 \\
\hline & Total & 4.56E-04 & 7.19E-04 & $1.05 \mathrm{E}-03$ & $1.69 \mathrm{E}-03$ \\
\hline \multirow[t]{5}{*}{ Pb-214 } & 2.42E-01 & $1.27 \mathrm{E}-05$ & 3.02E-05 & 2.97E-05 & 7.41E-05 \\
\hline & 2.95E-01 & 1.37E-05 & 3.73E-05 & 3.50E-05 & 9.69E-05 \\
\hline & 3.52E-01 & 1.43E-05 & 4.63E-05 & 3.87E-05 & $1.26 \mathrm{E}-04$ \\
\hline & Peak Total & 4.07E-05 & $1.14 \mathrm{E}-04$ & 1.03E-04 & 2.97E-04 \\
\hline & Total & 3.23E-04 & 7.30E-04 & $7.00 \mathrm{E}-04$ & $1.58 \mathrm{E}-03$ \\
\hline \multirow{4}{*}{$\begin{array}{r}\text { Co-60 } \\
\text { (large } \\
\text { volume) }\end{array}$} & $1.17 \mathrm{E}+00$ & 1.58E-05 & & 5.45E-05 & \\
\hline & $1.33 \mathrm{E}+00$ & $1.18 \mathrm{E}-05$ & & 4.29E-05 & \\
\hline & Peak Total & 2.75E-05 & & 9.74E-05 & \\
\hline & Total & 5.85E-04 & & 1.37E-03 & \\
\hline
\end{tabular}




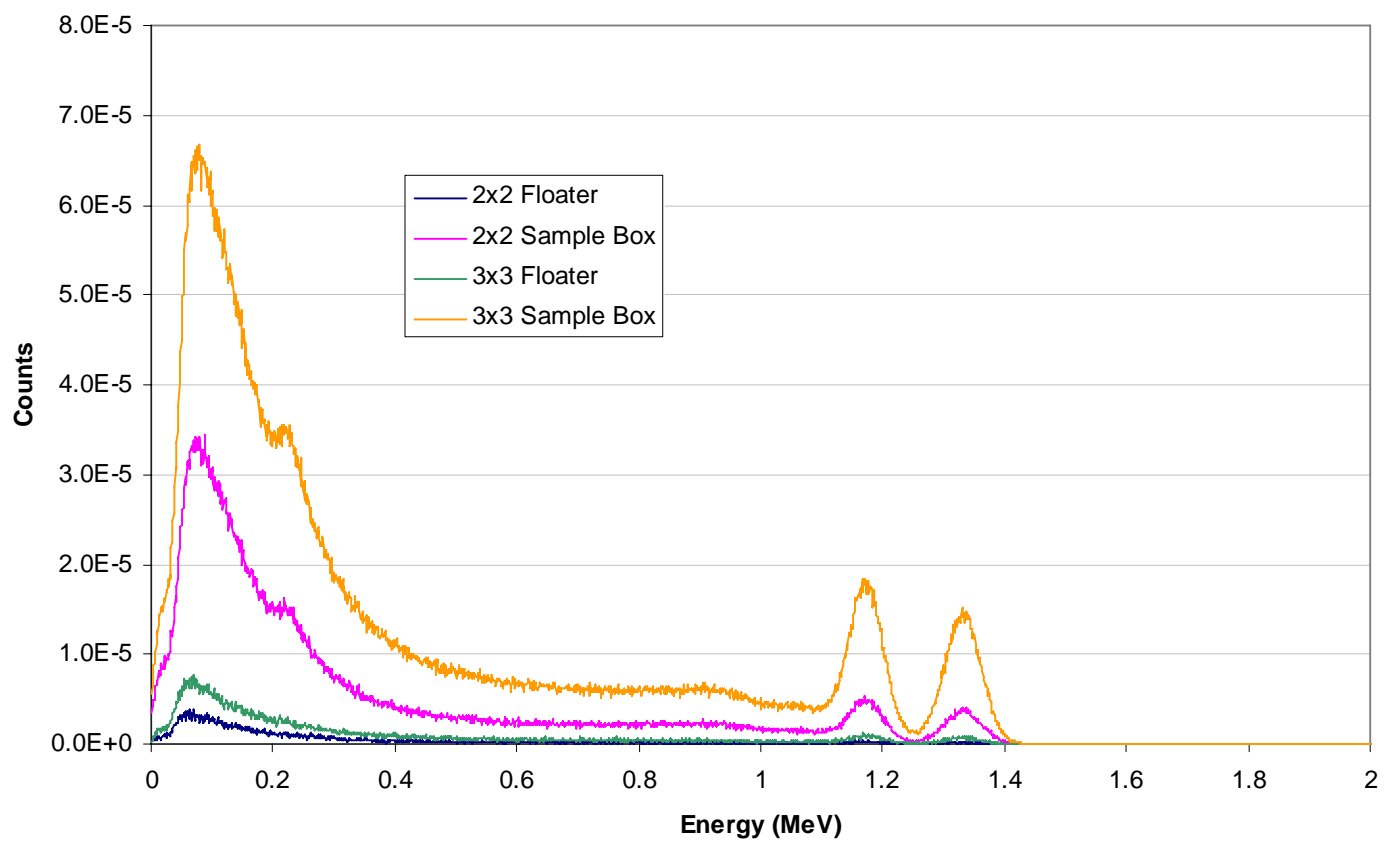

Figure 10. ${ }^{60}$ Co Detector Comparison. (Linear Scale)

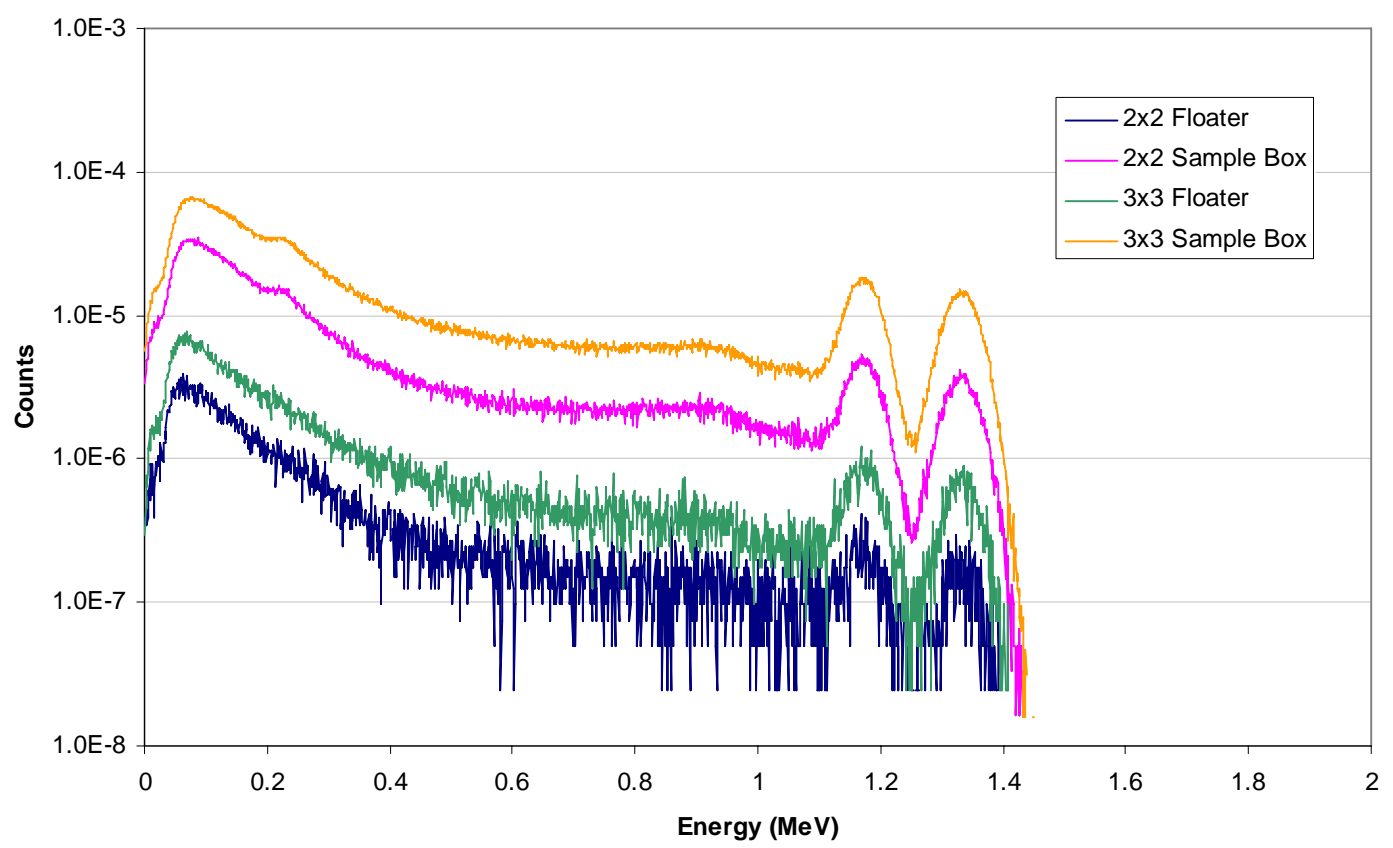

Figure 11. ${ }^{60}$ Co Detector Comparison. (Log Scale) 


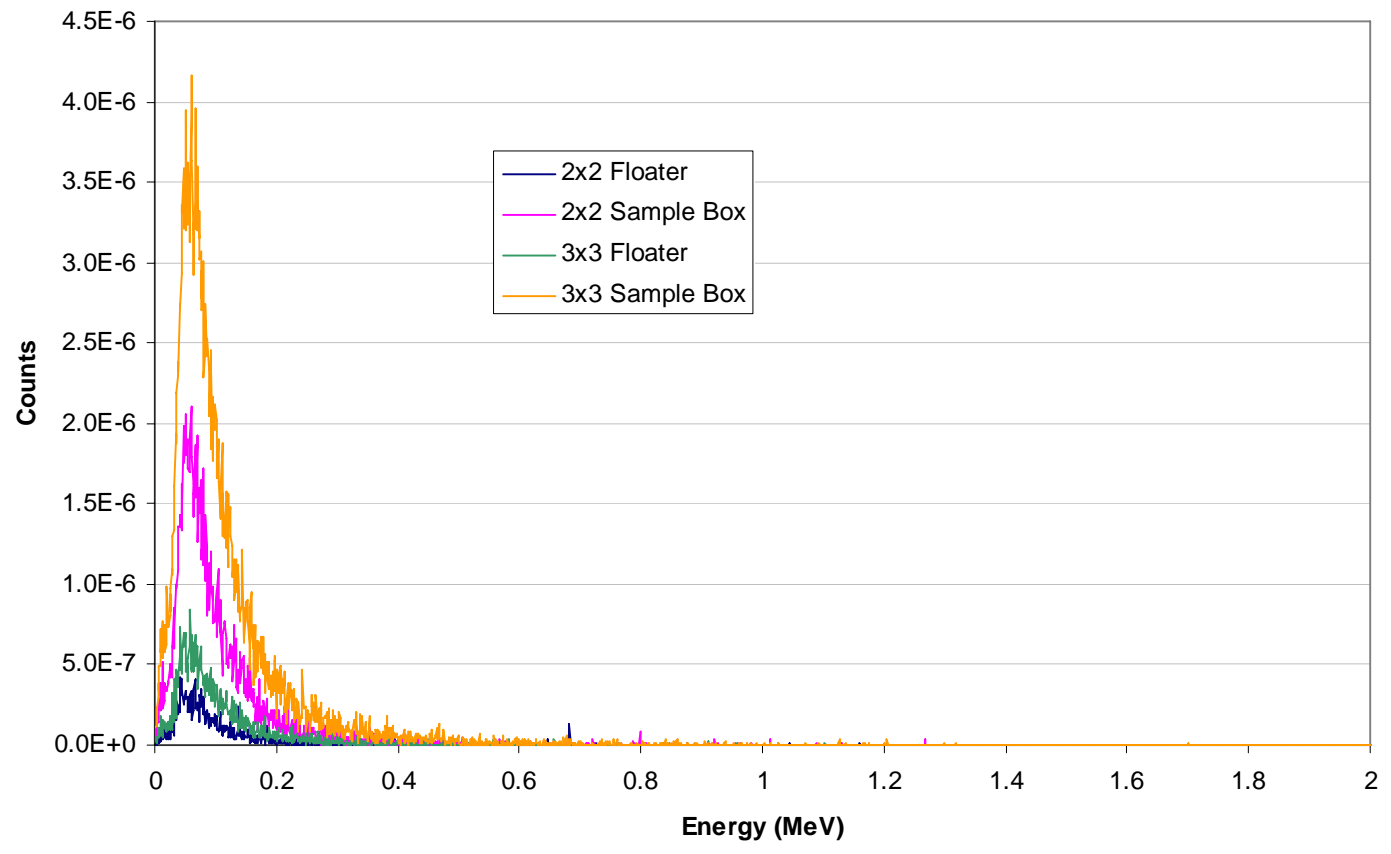

Figure 12. ${ }^{90} \mathrm{Sr} / \mathrm{Y}$ Detector Comparison. (Linear Scale)

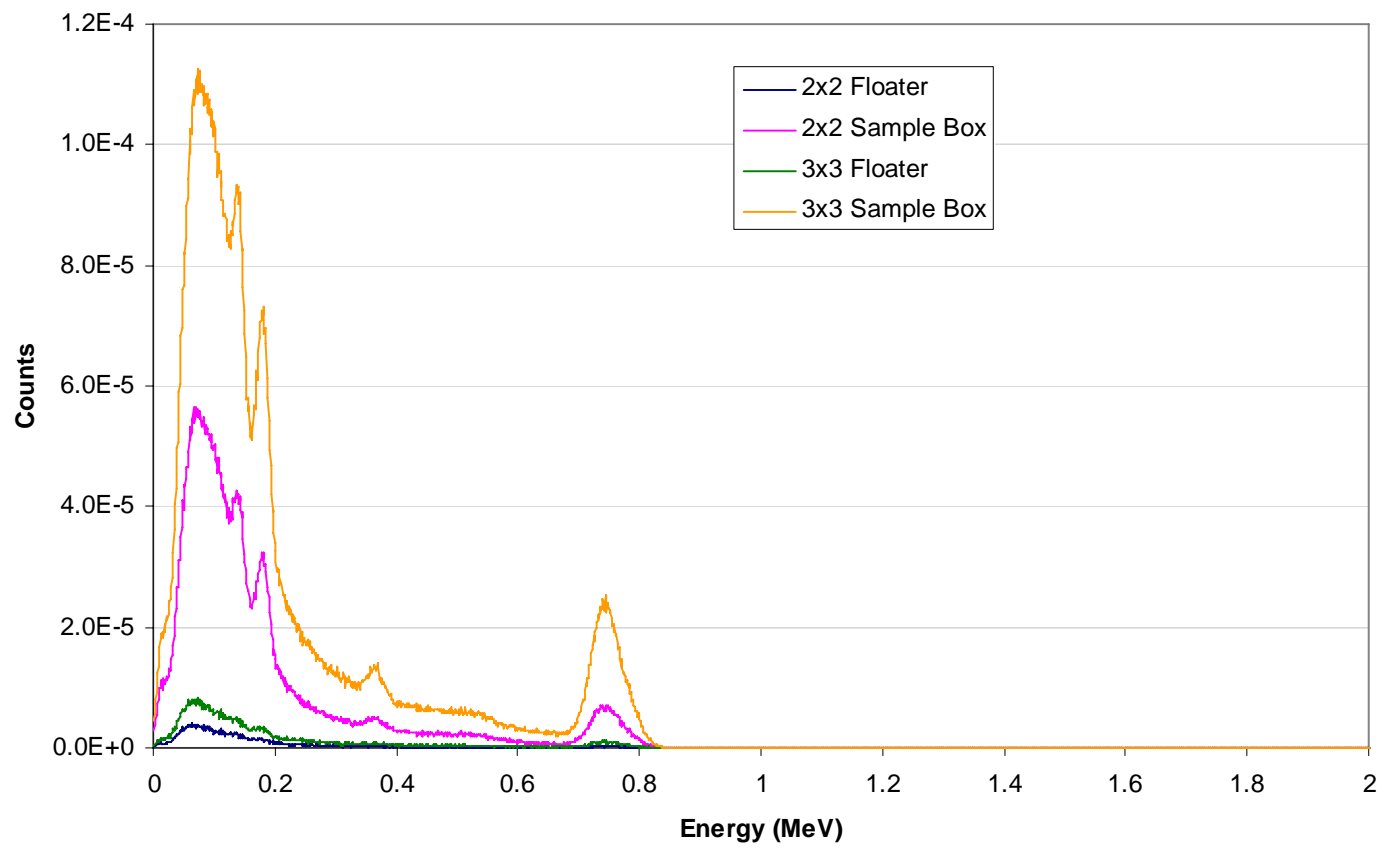

Figure 13. ${ }^{99}$ Mo Detector Comparison. (Linear Scale) 


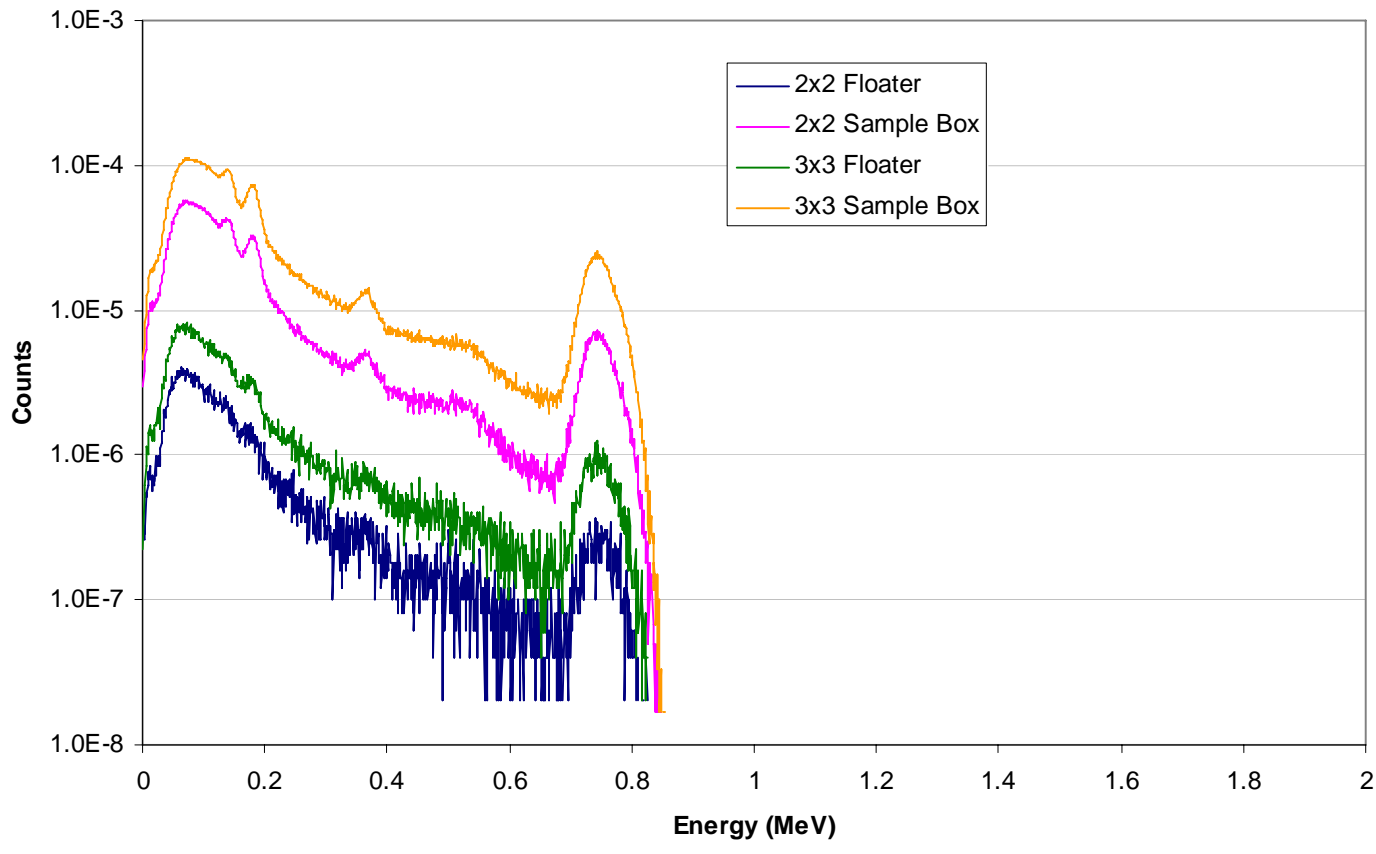

Figure 14. ${ }^{99}$ Mo Detector Comparison. (Log Scale)

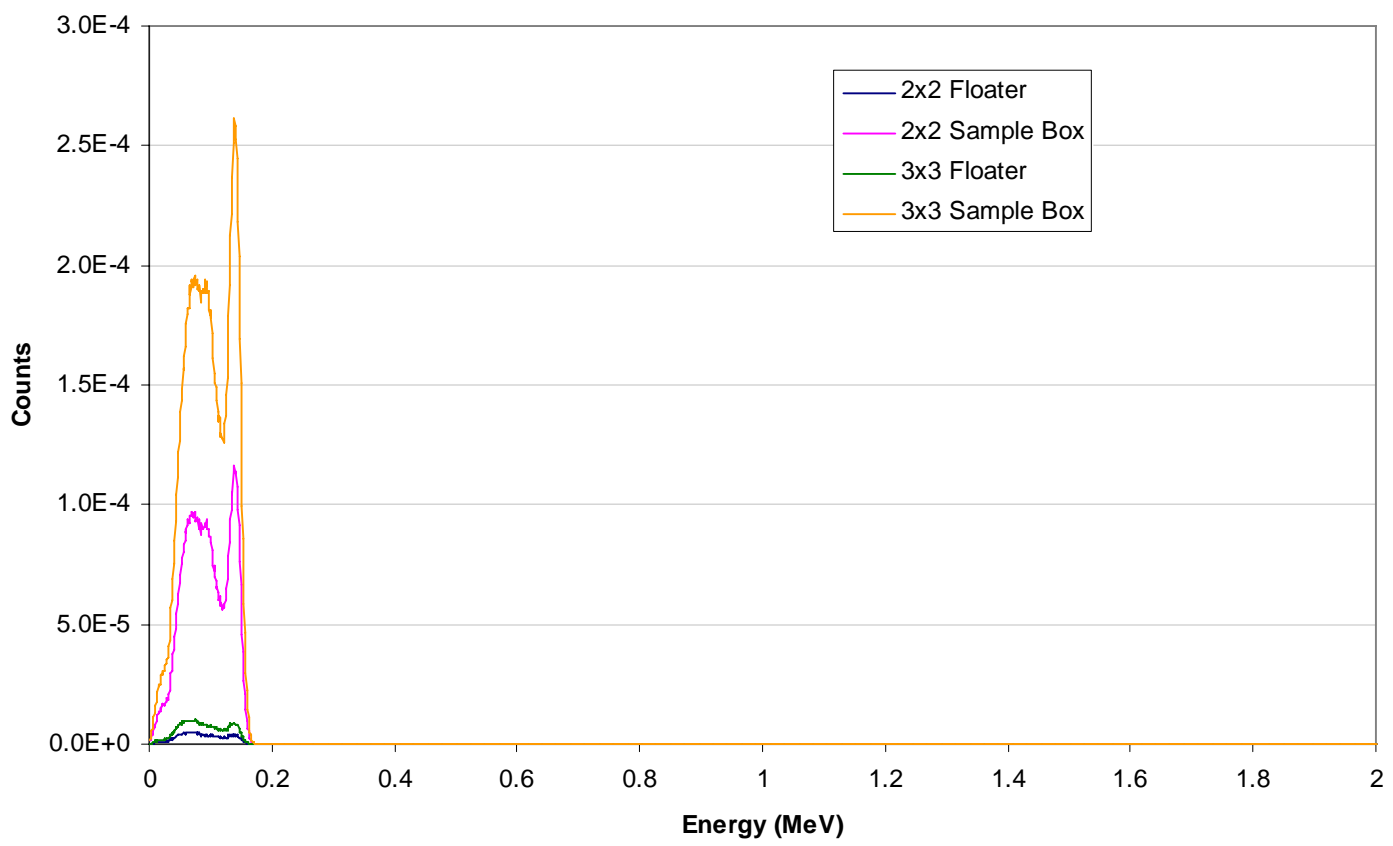

Figure 15. ${ }^{99 \mathrm{~m}}$ Tc Detector Comparison. (Linear Scale) 


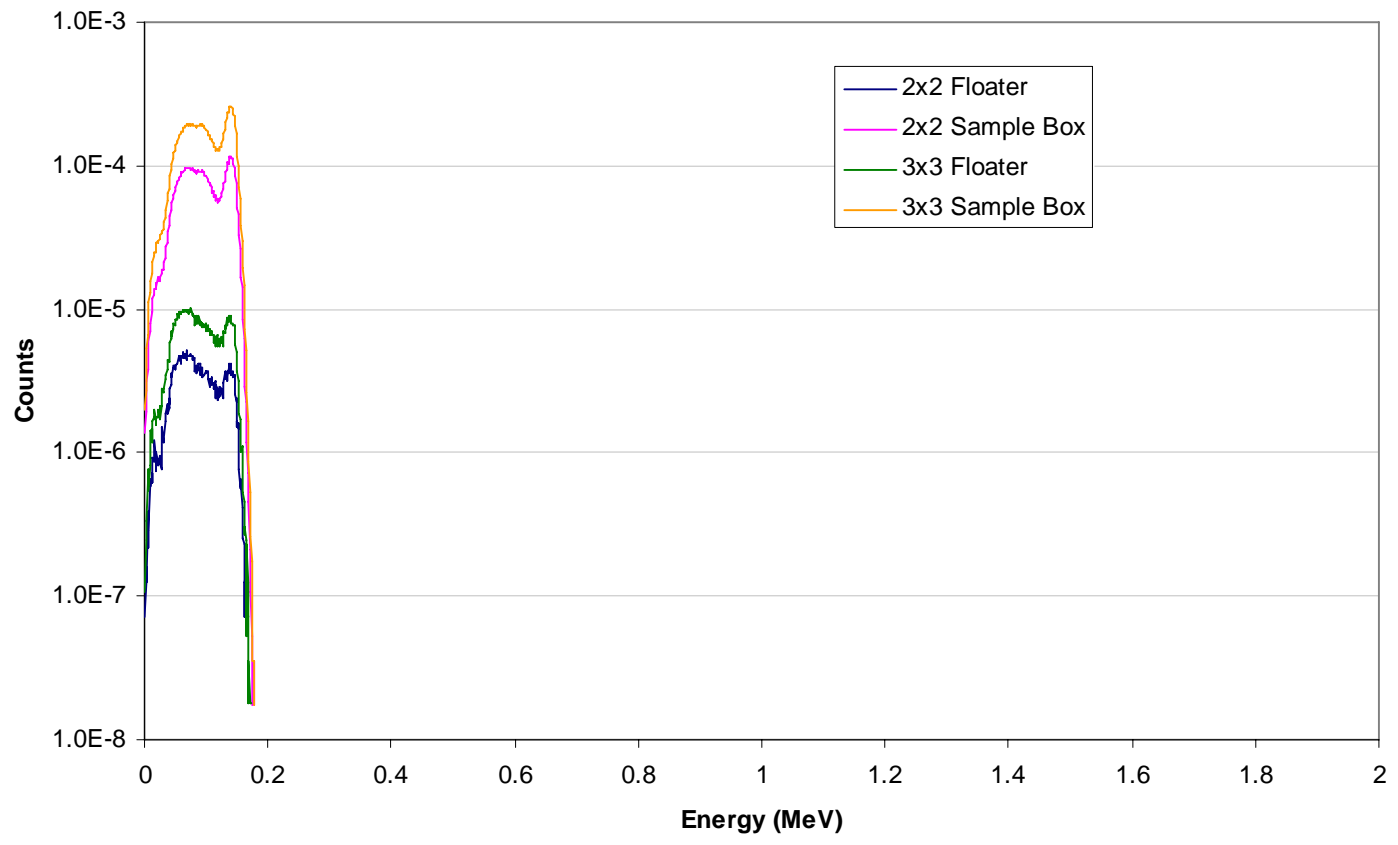

Figure 16. ${ }^{99 \mathrm{~m}}$ Tc Detector Comparison. (Log Scale)

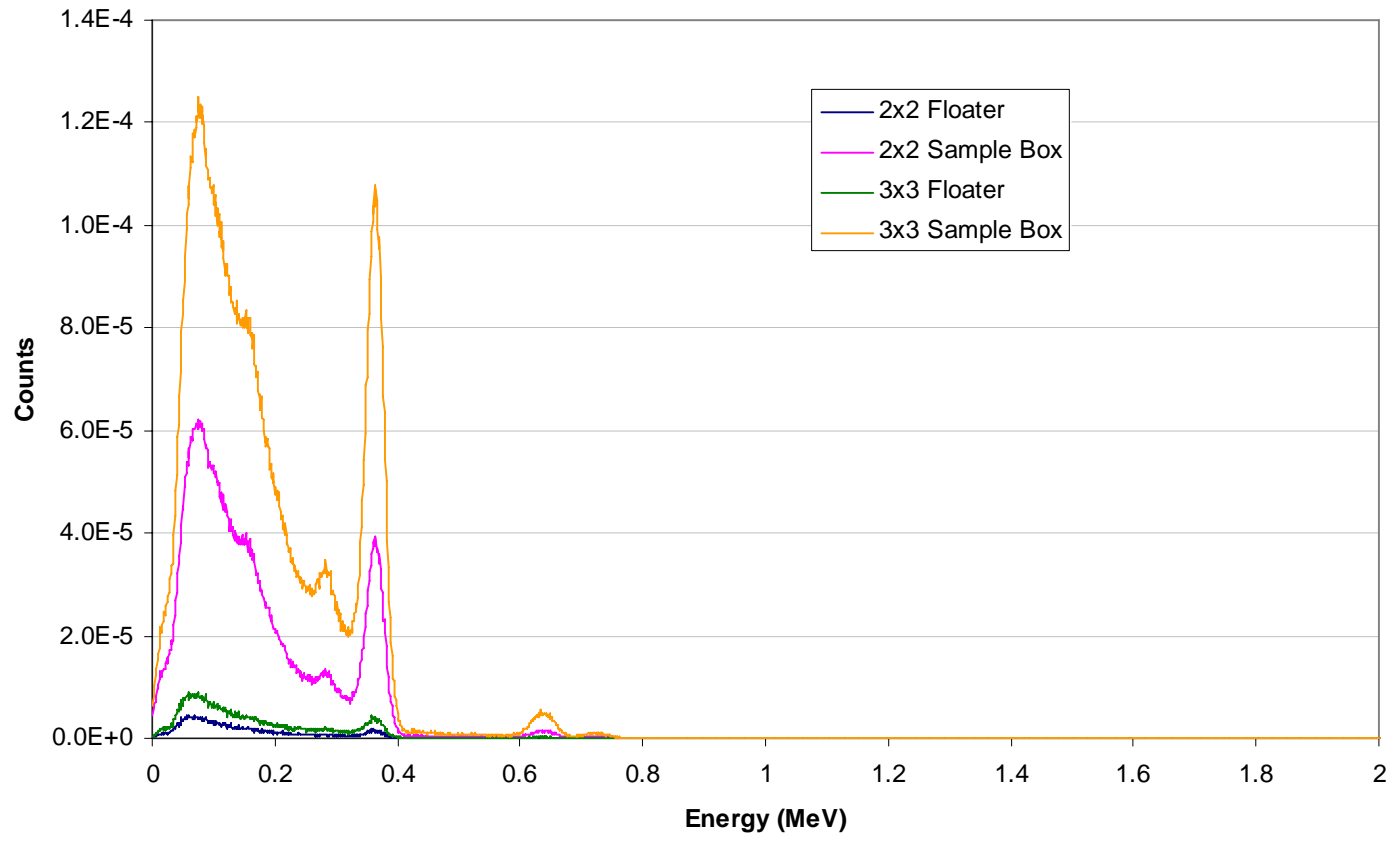

Figure 3. ${ }^{131}$ I Detector Comparison. (Linear Scale) 


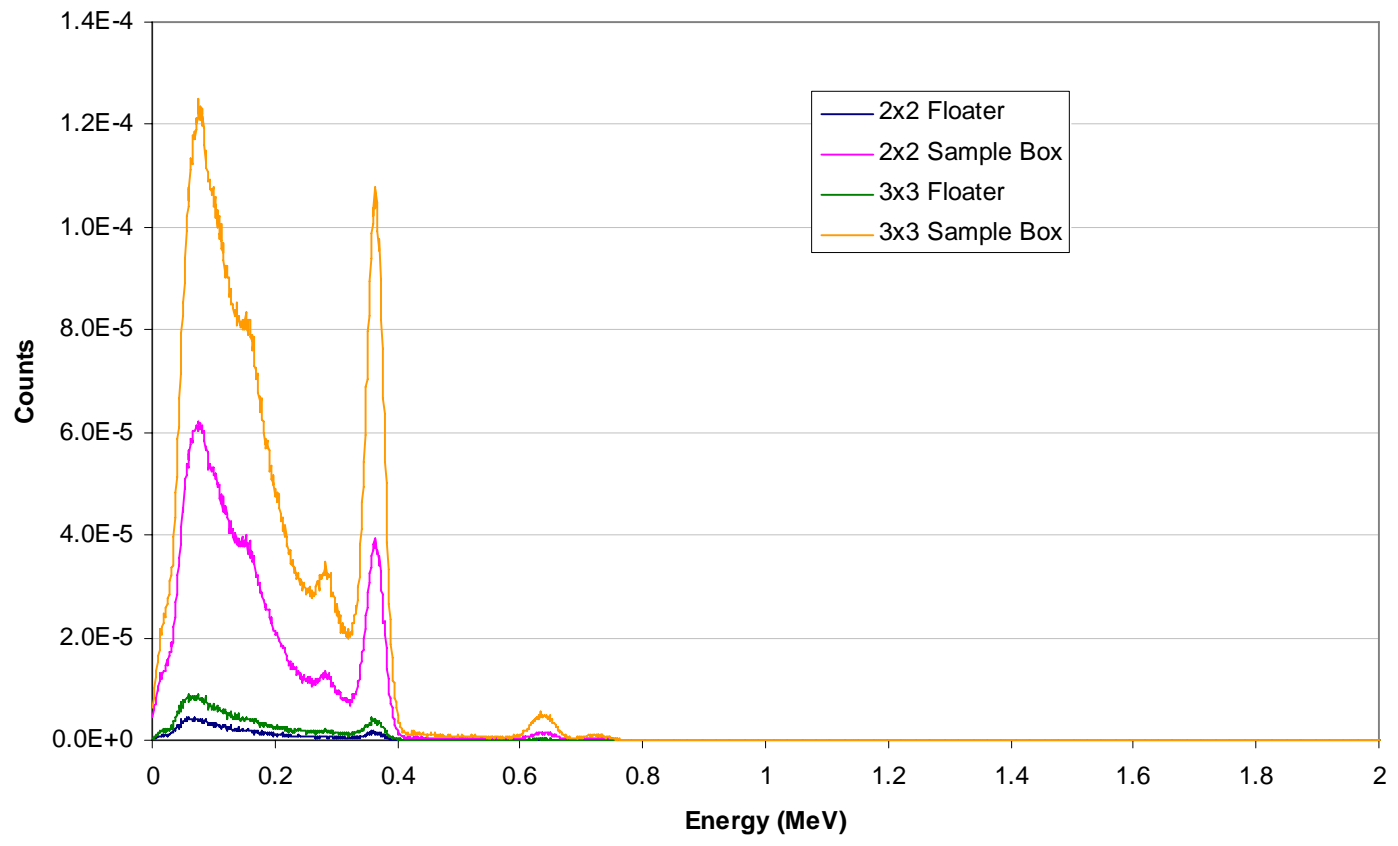

Figure 4. ${ }^{131}$ I Detector Comparison. (Log Scale)

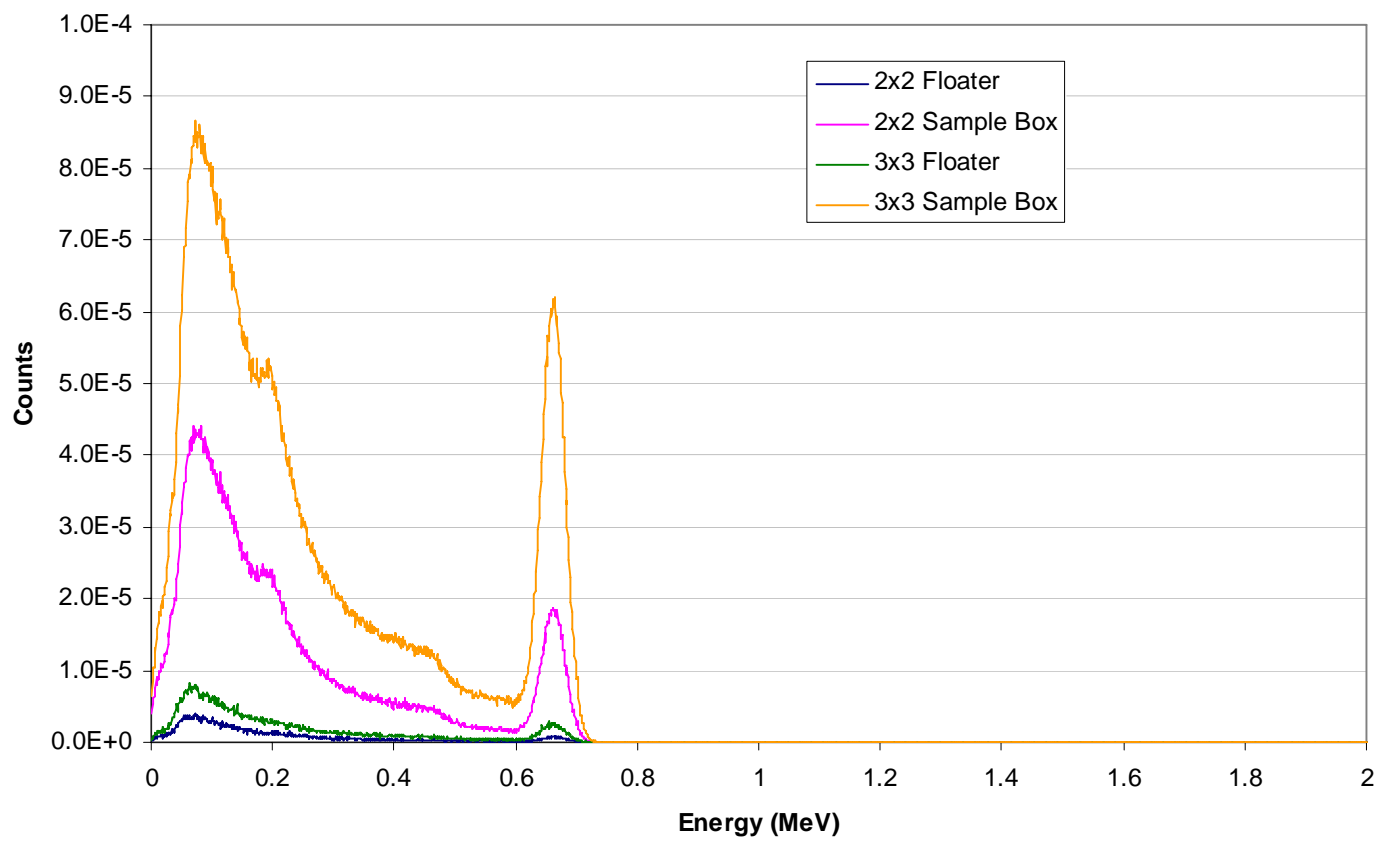

Figure 19. ${ }^{137}$ Cs Detector Comparison. (Linear Scale) 


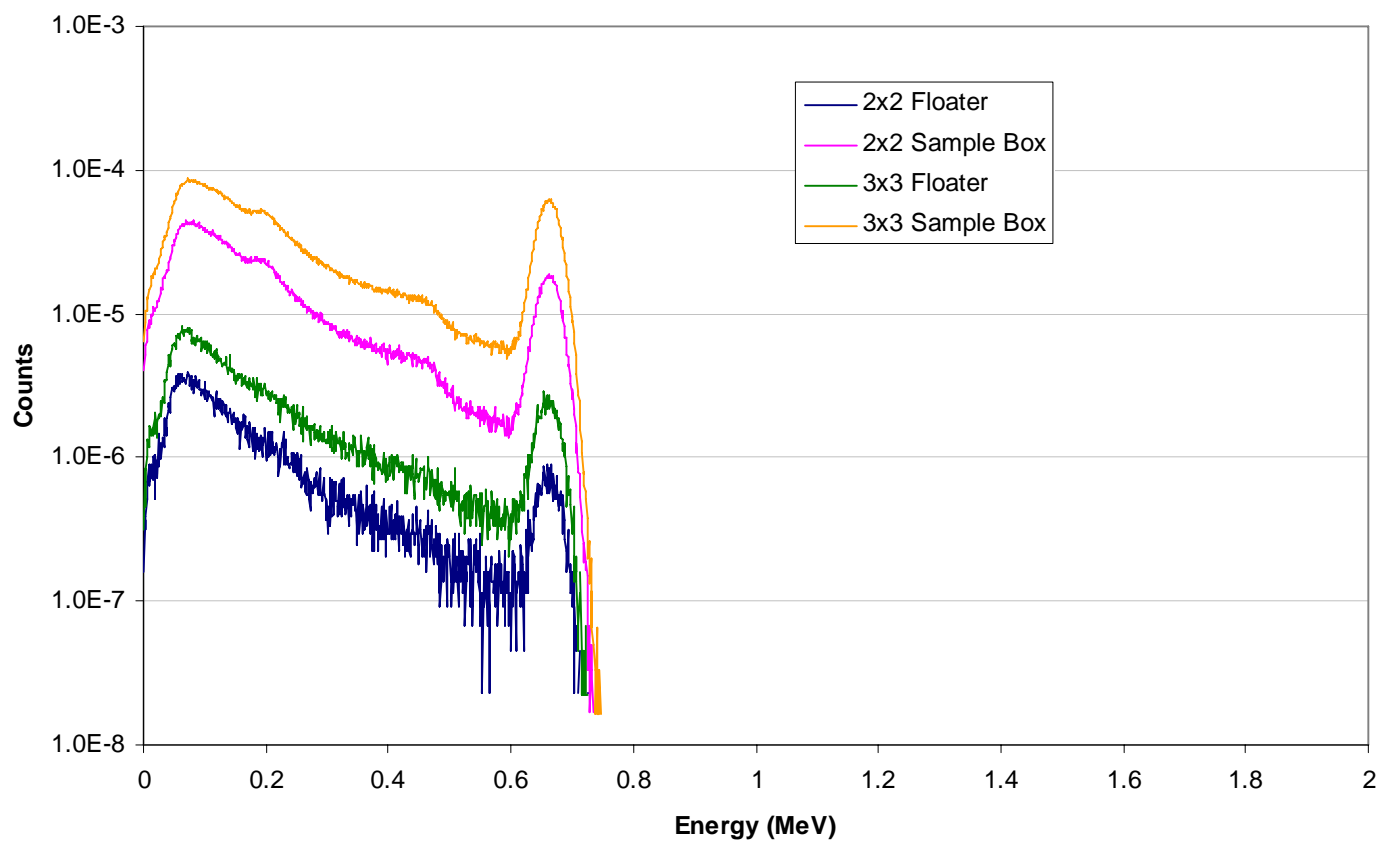

Figure 20. ${ }^{137}$ Cs Detector Comparison. (Log Scale)

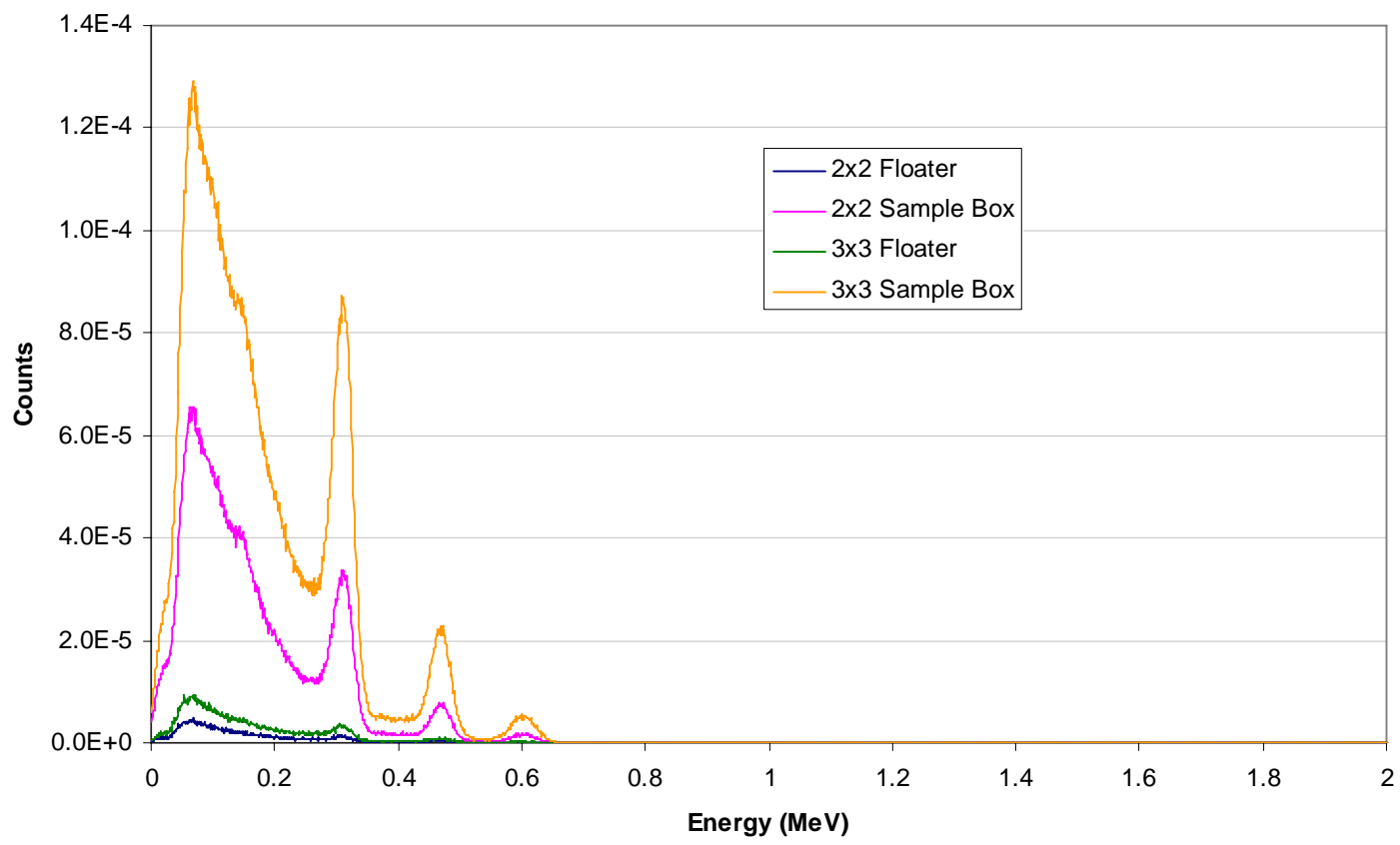

Figure 21. ${ }^{192}$ Ir Detector Comparison. (Linear Scale) 


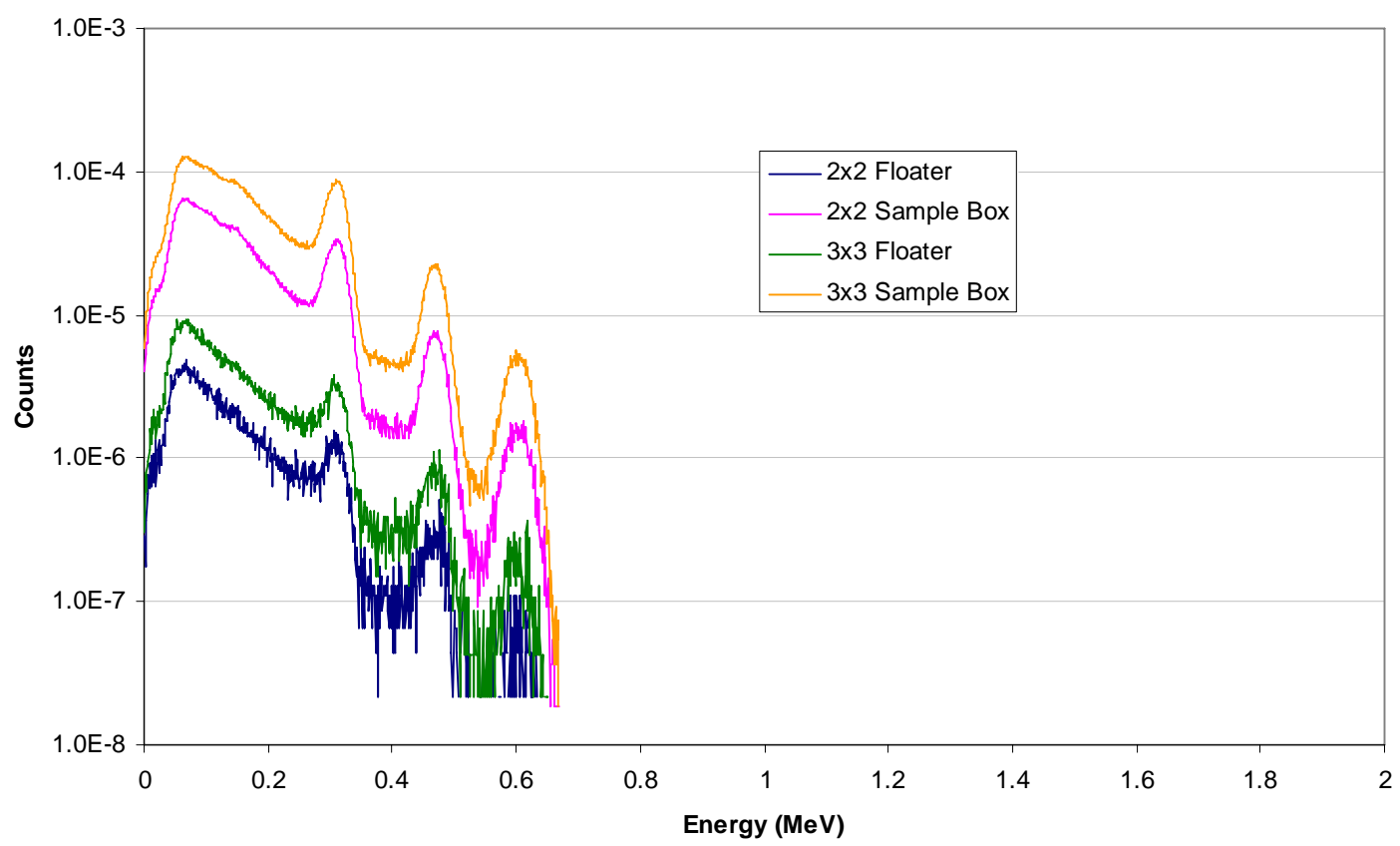

Figure 22. ${ }^{192}$ Ir Detector Comparison. (Log Scale)

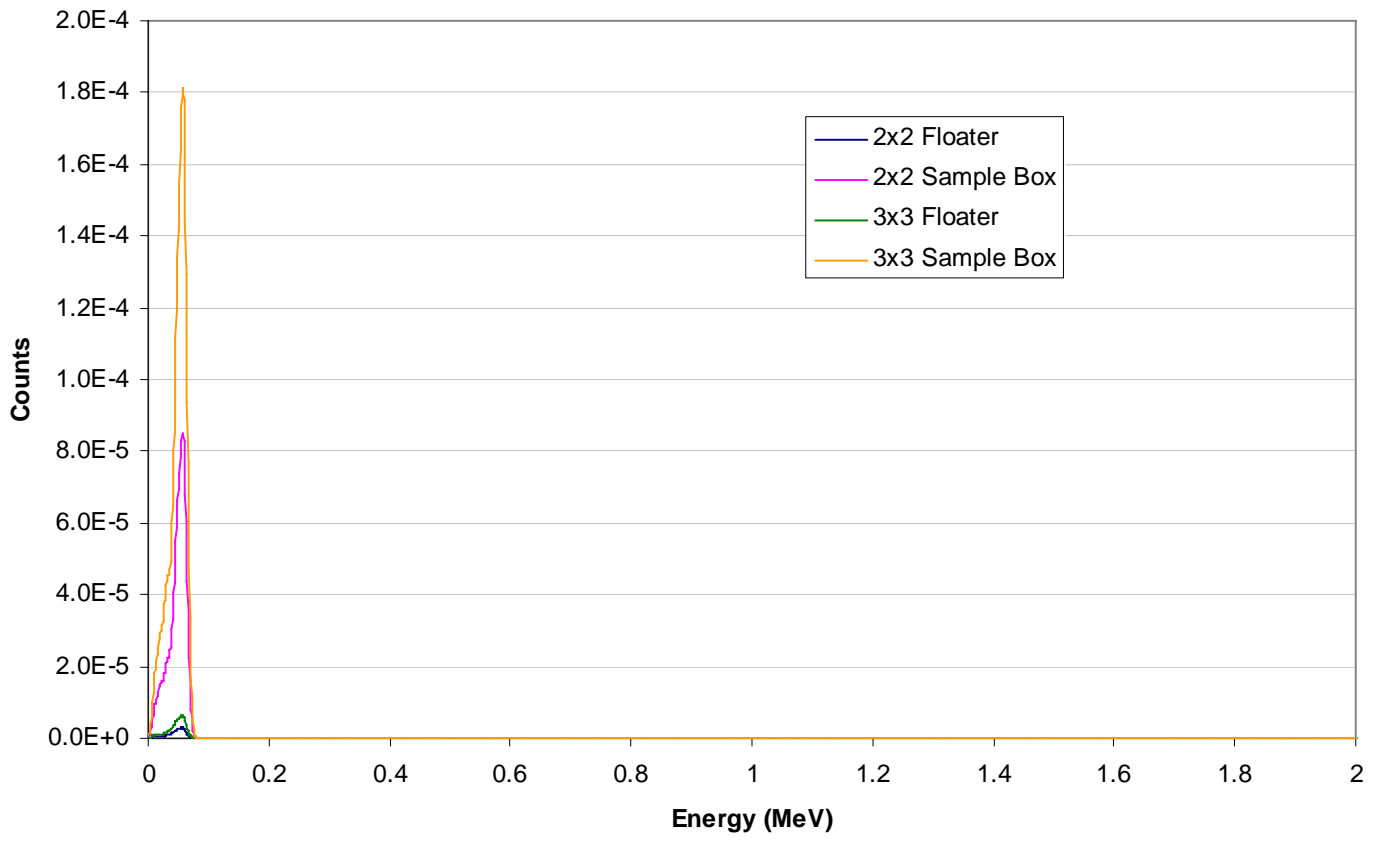

Figure 23. ${ }^{241} \mathrm{Am}$ Detector Comparison. (Linear Scale) 


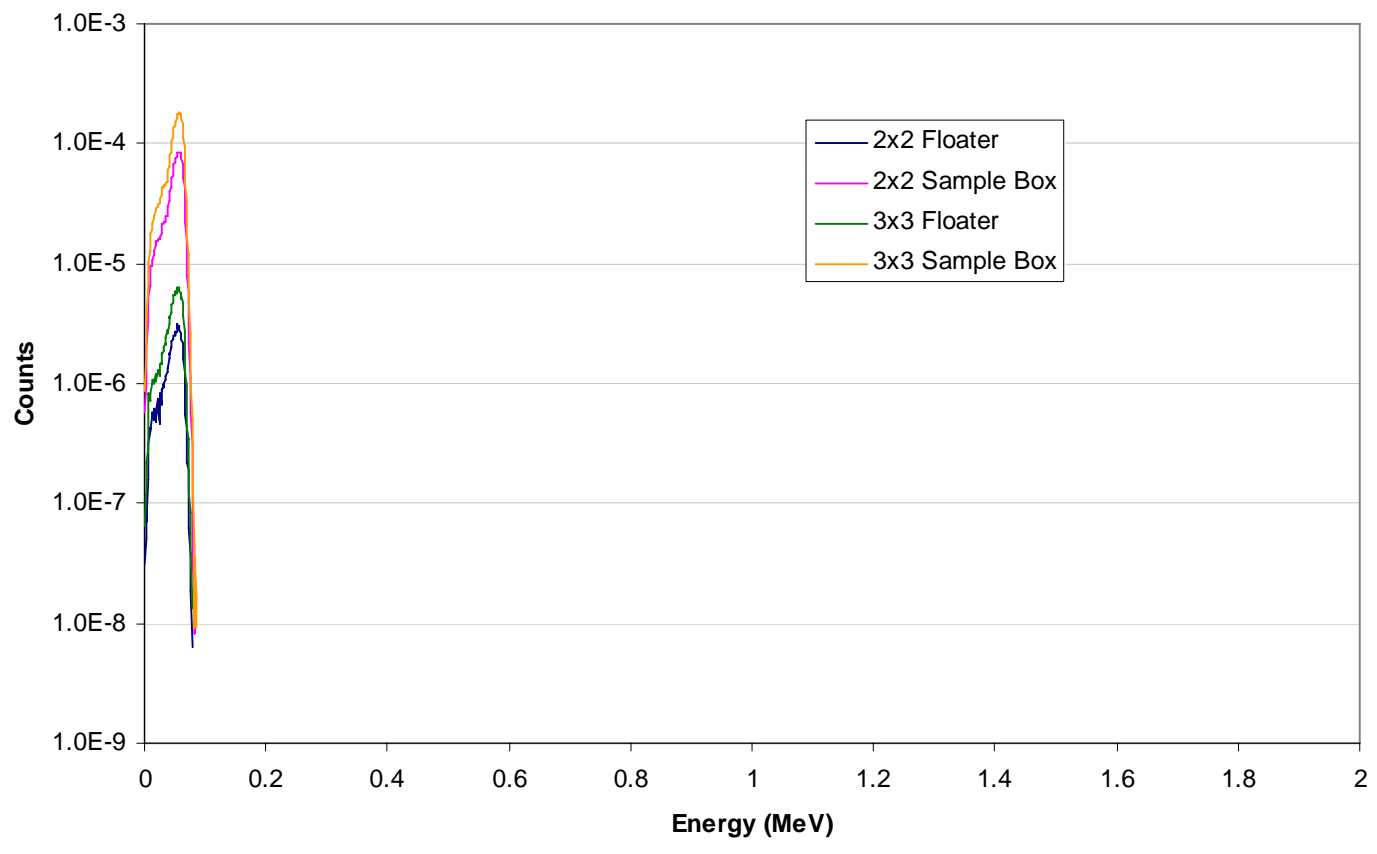

Figure 24. ${ }^{241} \mathrm{Am}$ Detector Comparison. (Log Scale)

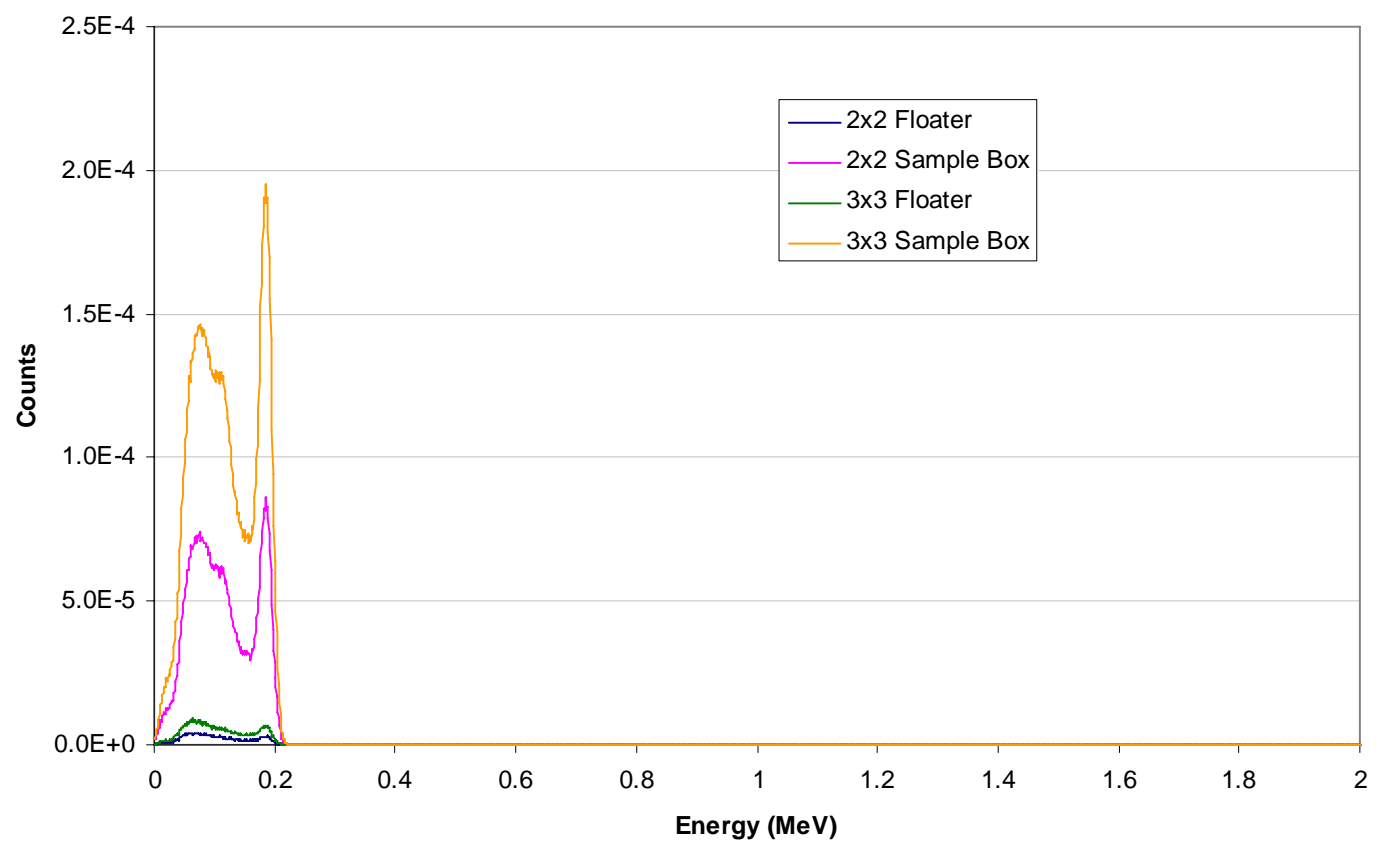

Figure 25. ${ }^{226} \mathrm{Ra}$ Detector Comparison. (Linear Scale) 


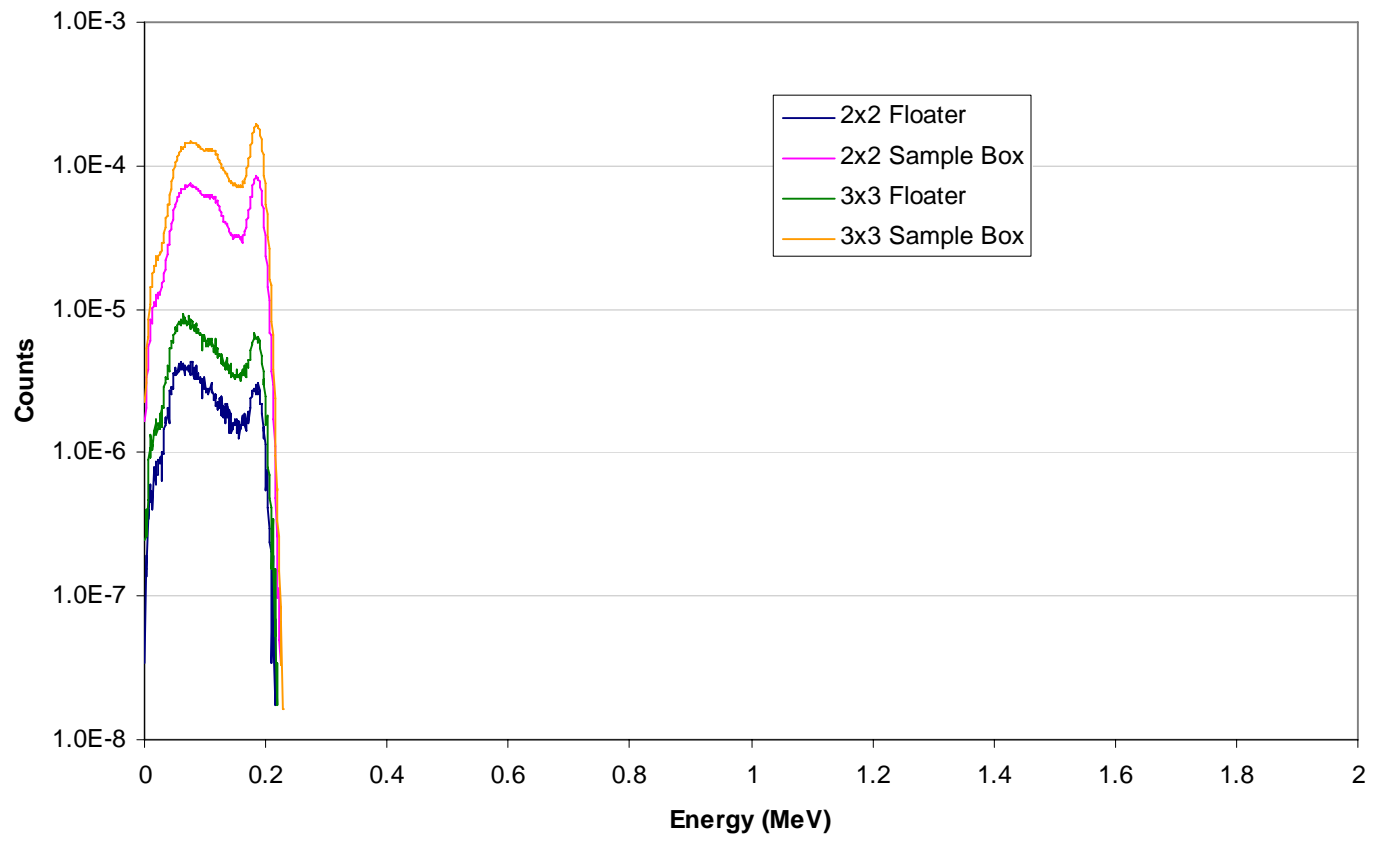

Figure 26. ${ }^{226}$ Ra Detector Comparison. (Log Scale)

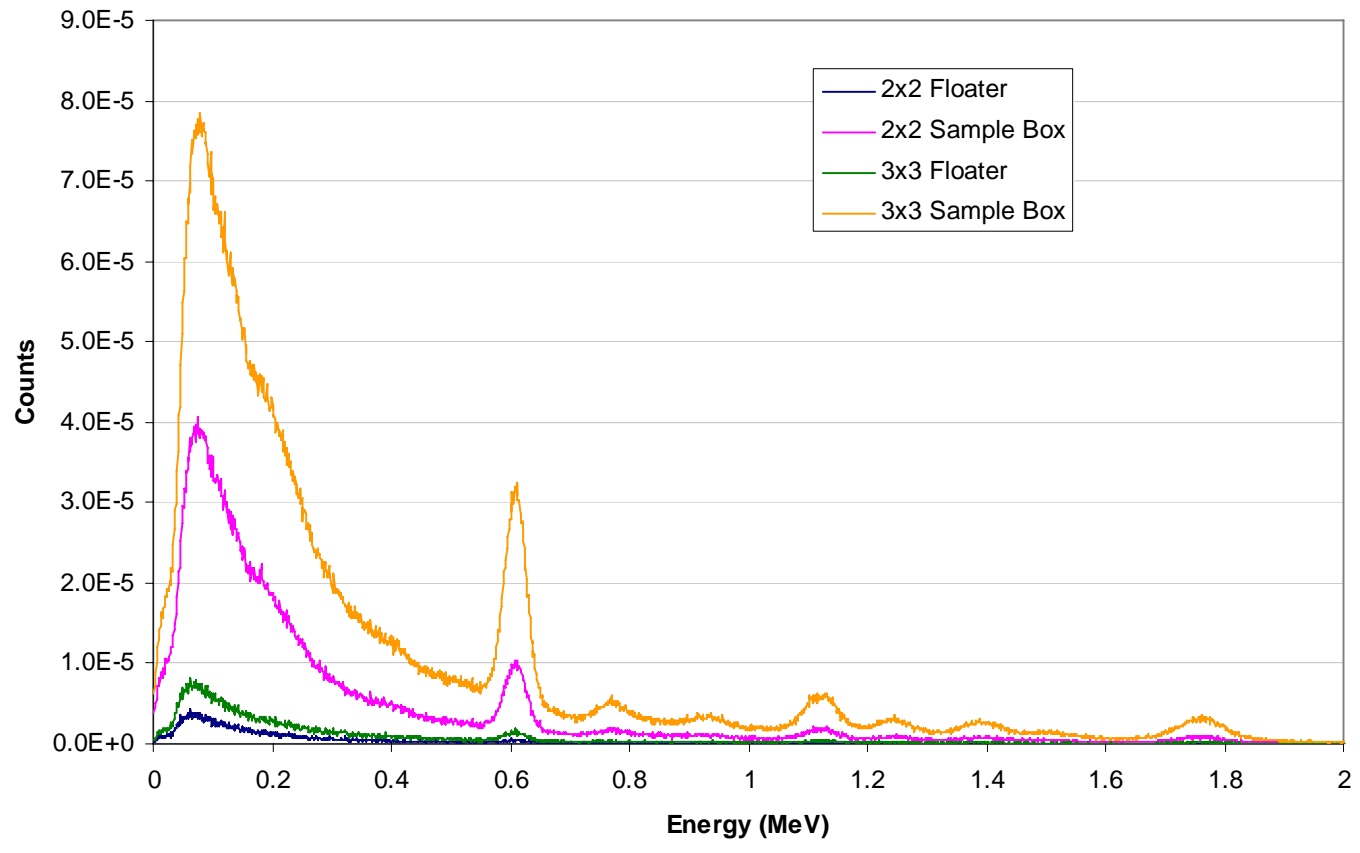

Figure 27. ${ }^{214} \mathrm{Bi}$ Detector Comparison. (Linear Scale) 


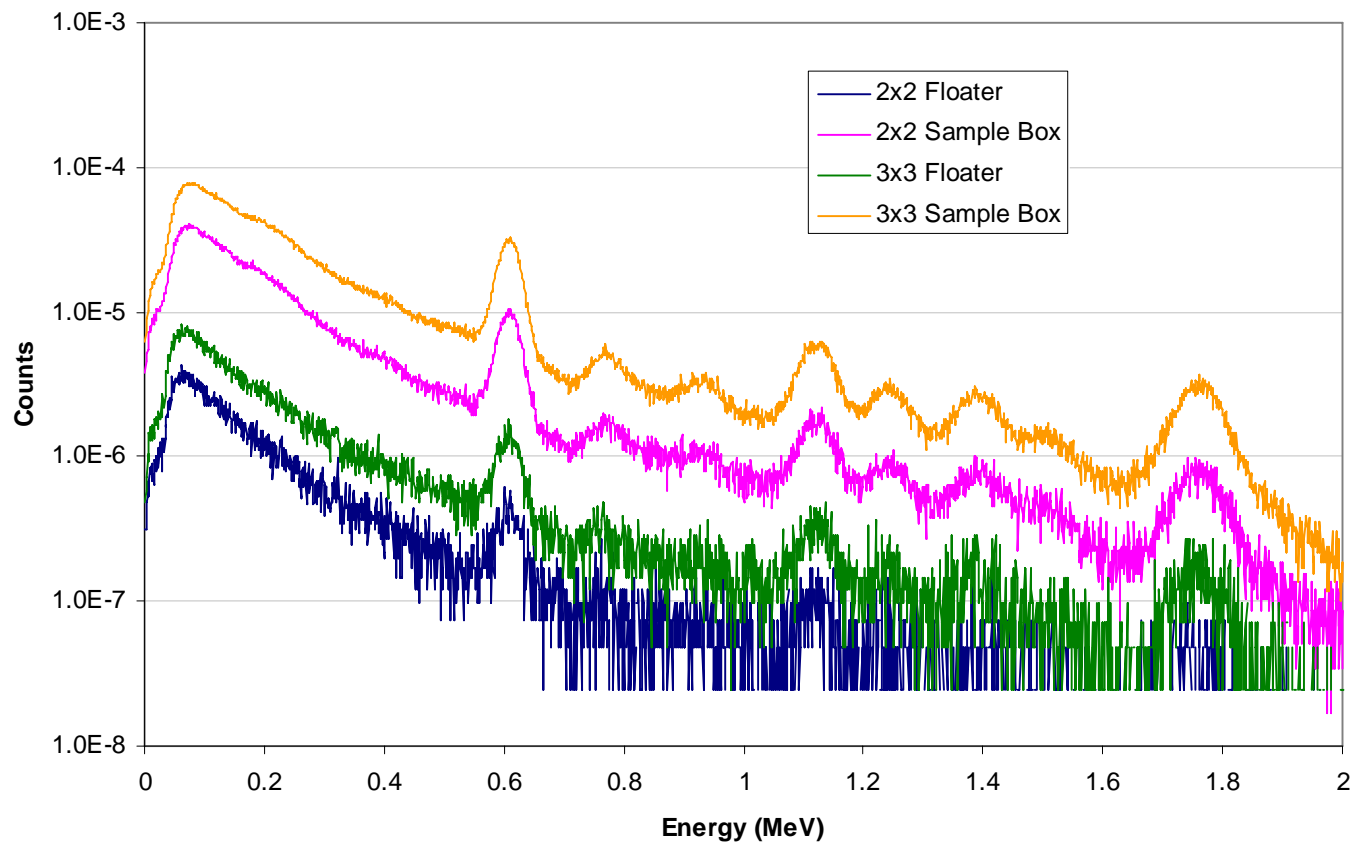

Figure 5. ${ }^{214} \mathrm{Bi}$ Detector Comparison. (Log Scale)

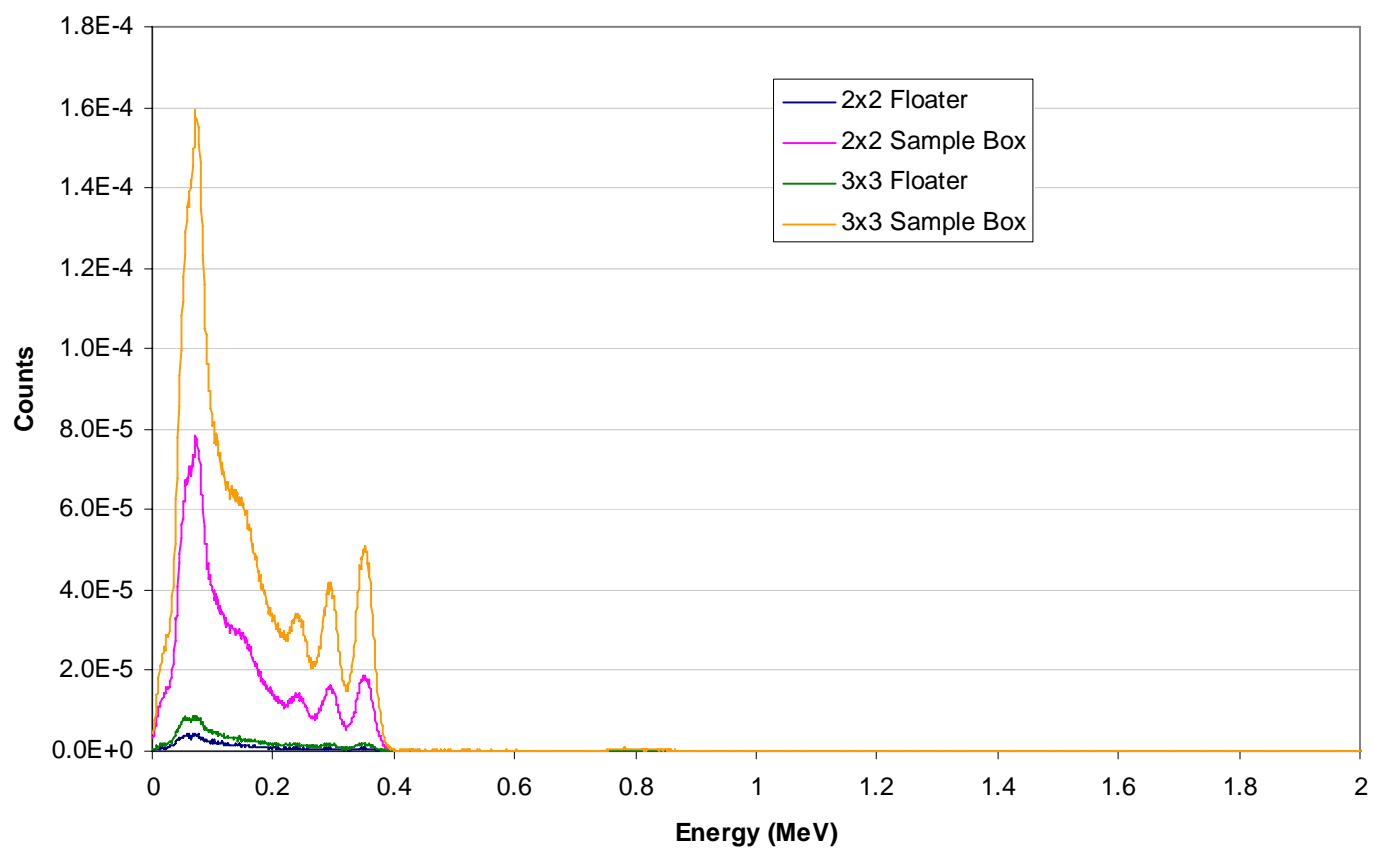

Figure 6. ${ }^{214} \mathrm{~Pb}$ Detector Comparison. (Linear Scale) 


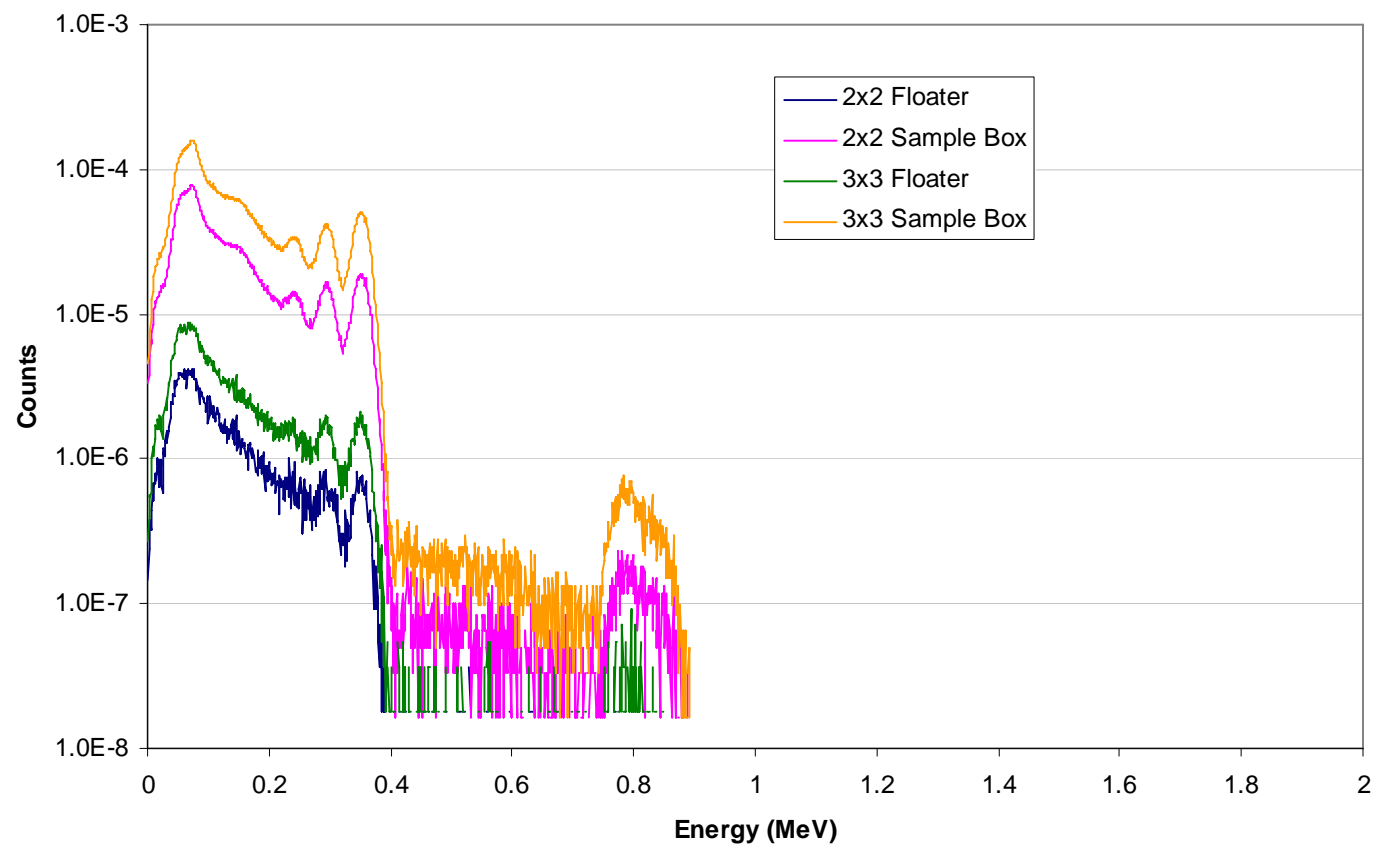

Figure 30. ${ }^{214} \mathrm{~Pb}$ Detector Comparison. (Log Scale)

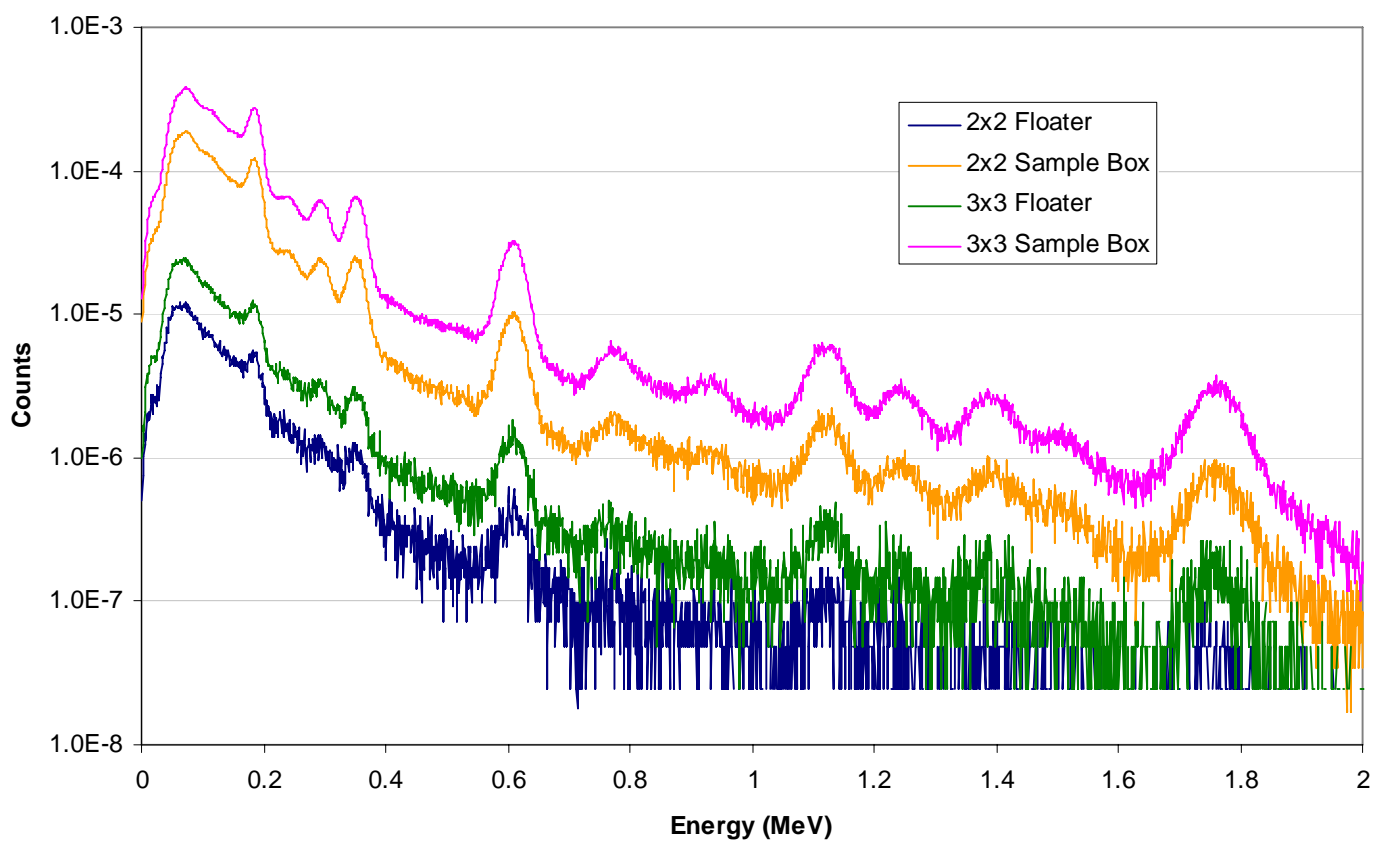

Figure 31. ${ }^{226}$ Ra plus Progeny Detector Comparison, Radon Escape Fraction=0. (Log Scale) 


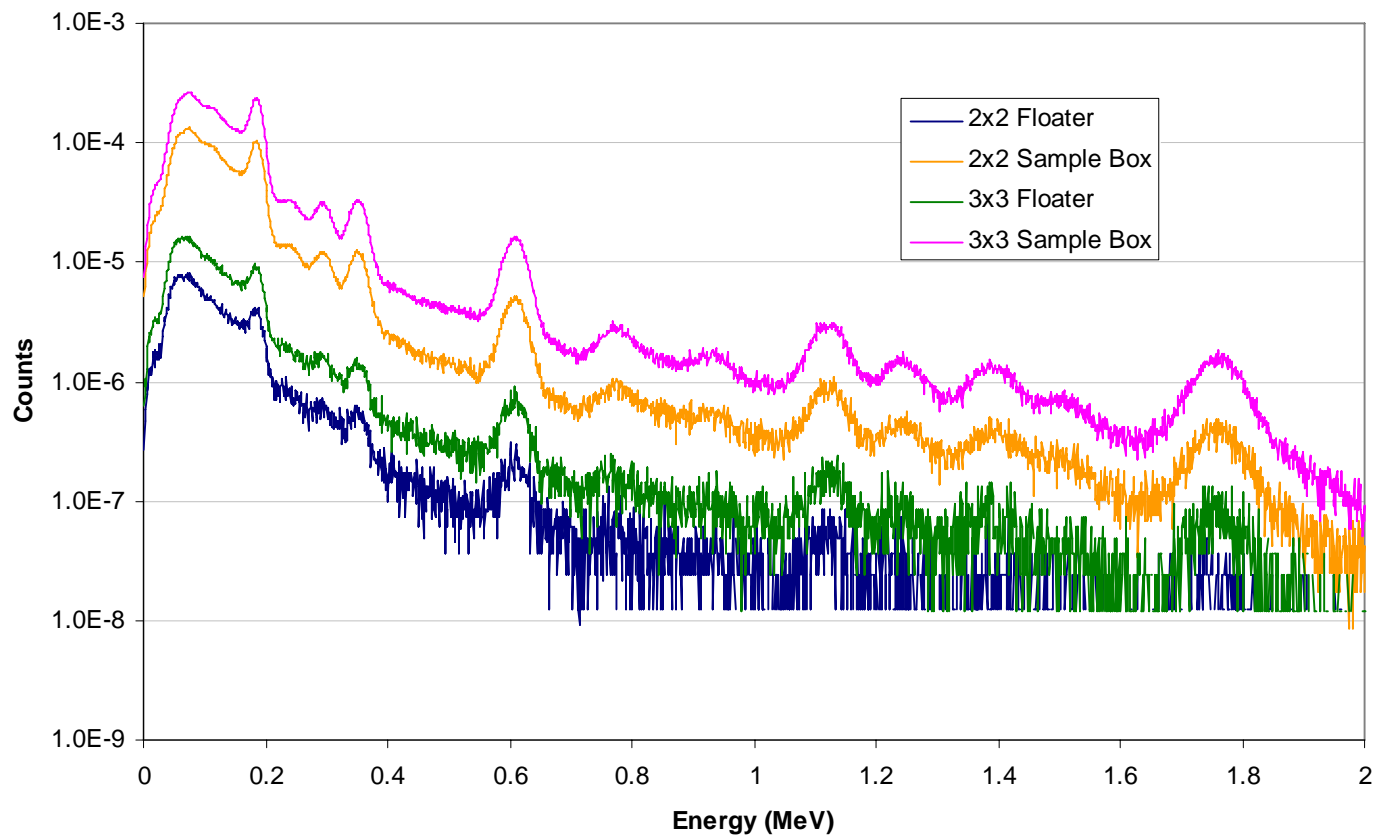

Figure 32. ${ }^{226}$ Ra plus Progeny Detector Comparison, Radon Escape Fraction=0.5. (Log Scale)

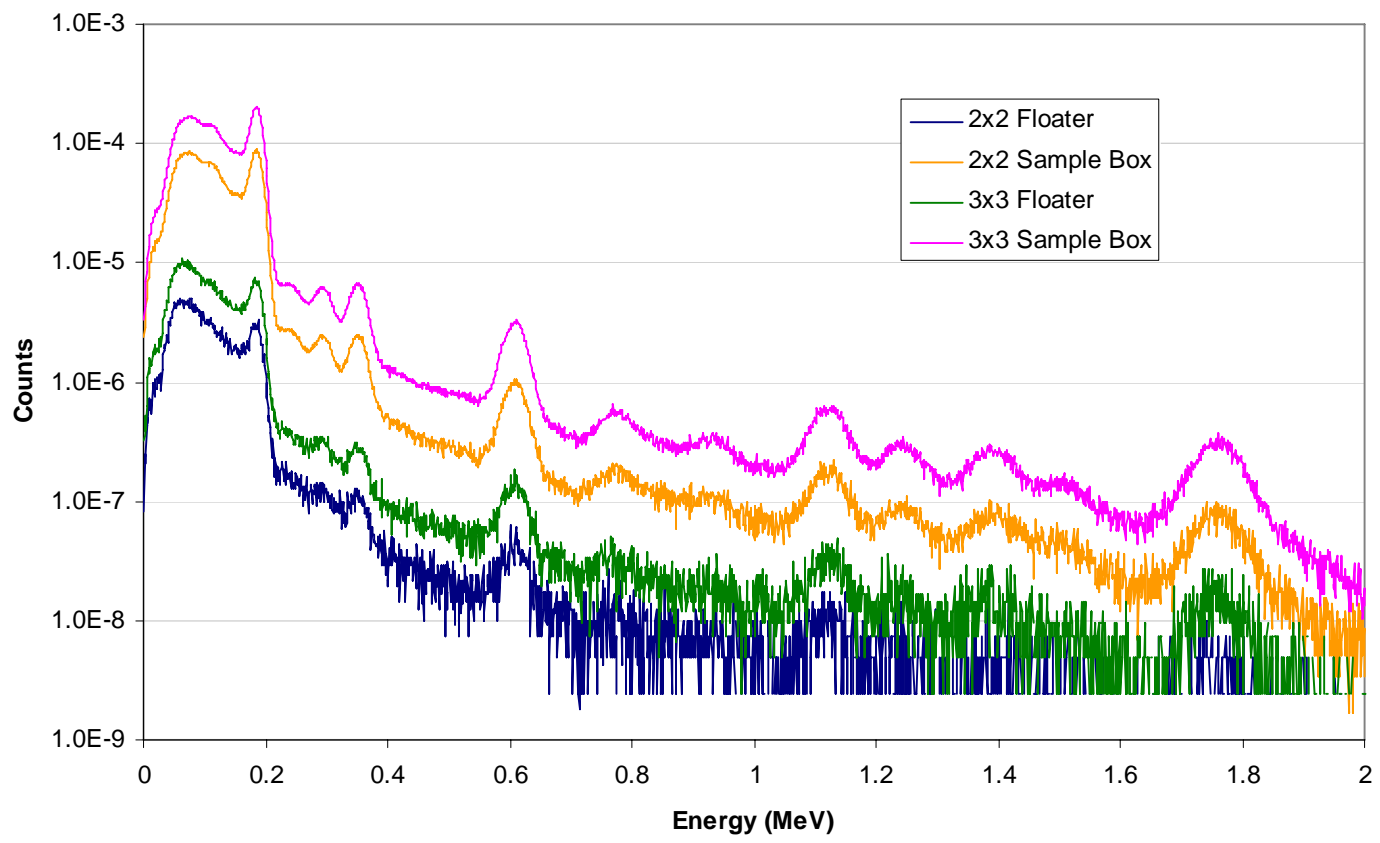

Figure 33. ${ }^{226}$ Ra plus Progeny Detector Comparison, Radon Escape Fraction=0.9. (Log Scale) 


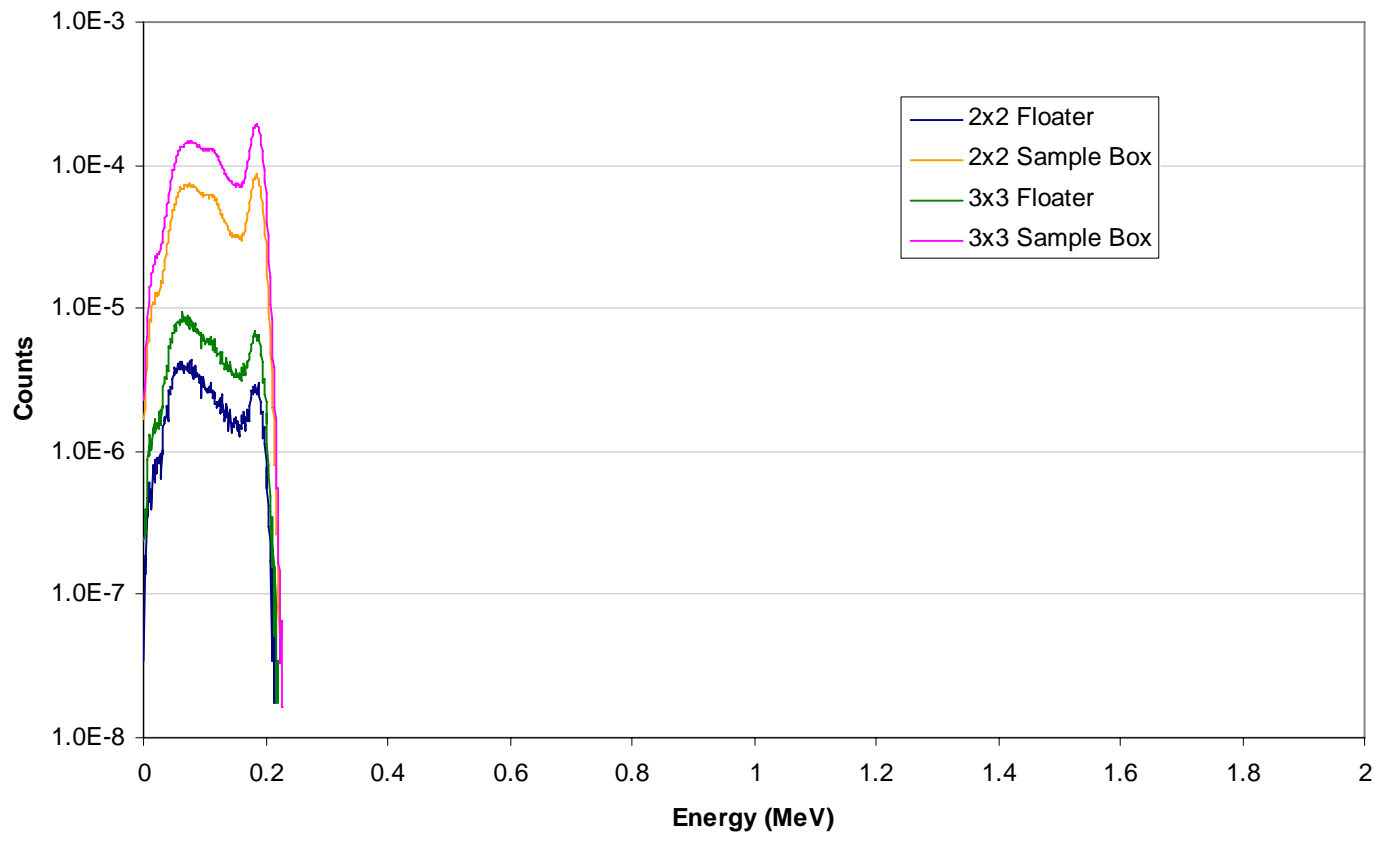

Figure 34. ${ }^{226}$ Ra plus Progeny Detector Comparison, Radon Escape Fraction=1. (Log Scale)

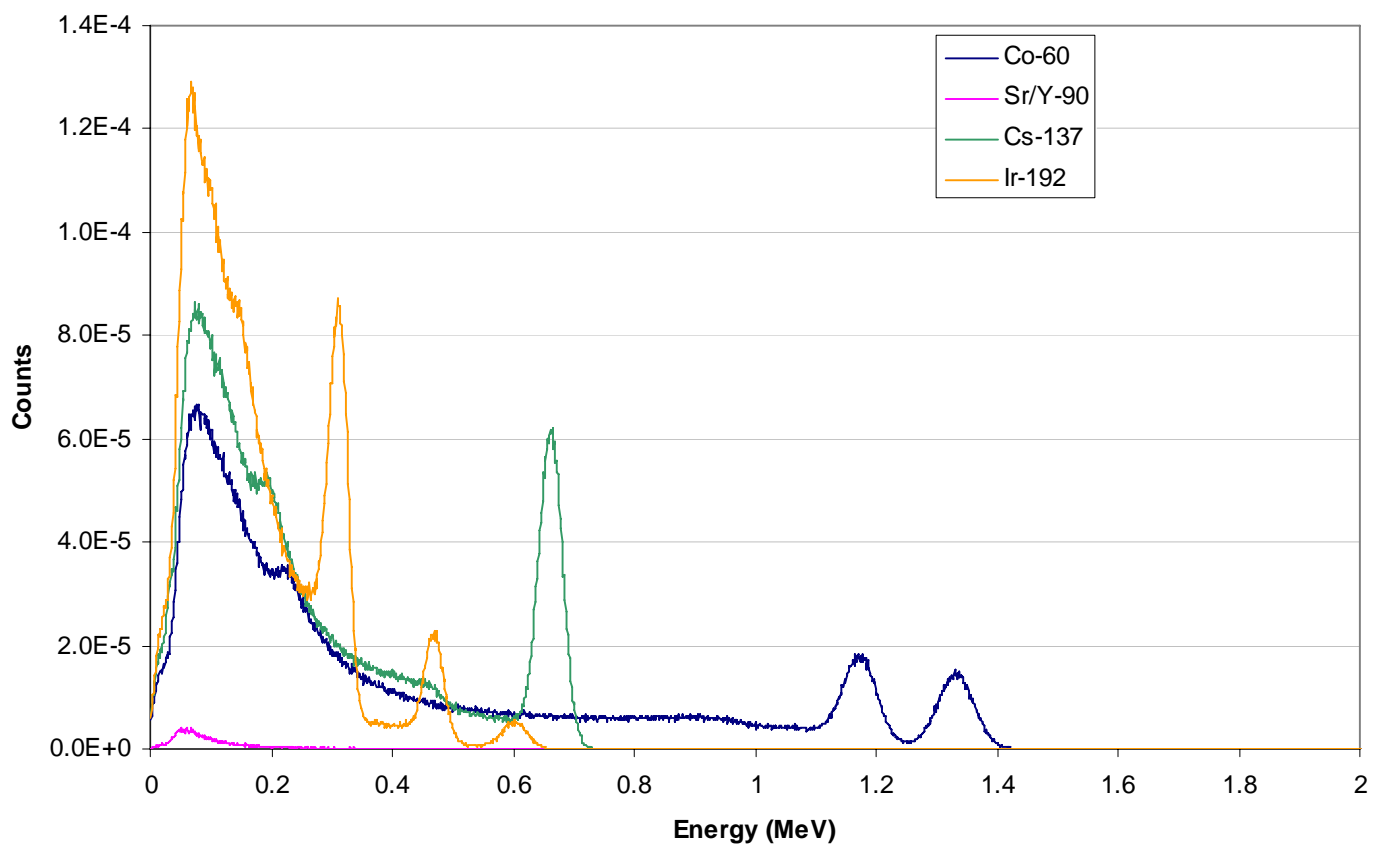

Figure 35. Multi Nuclide Detector Comparison. $3 \times 3$ Sample Box Detector 


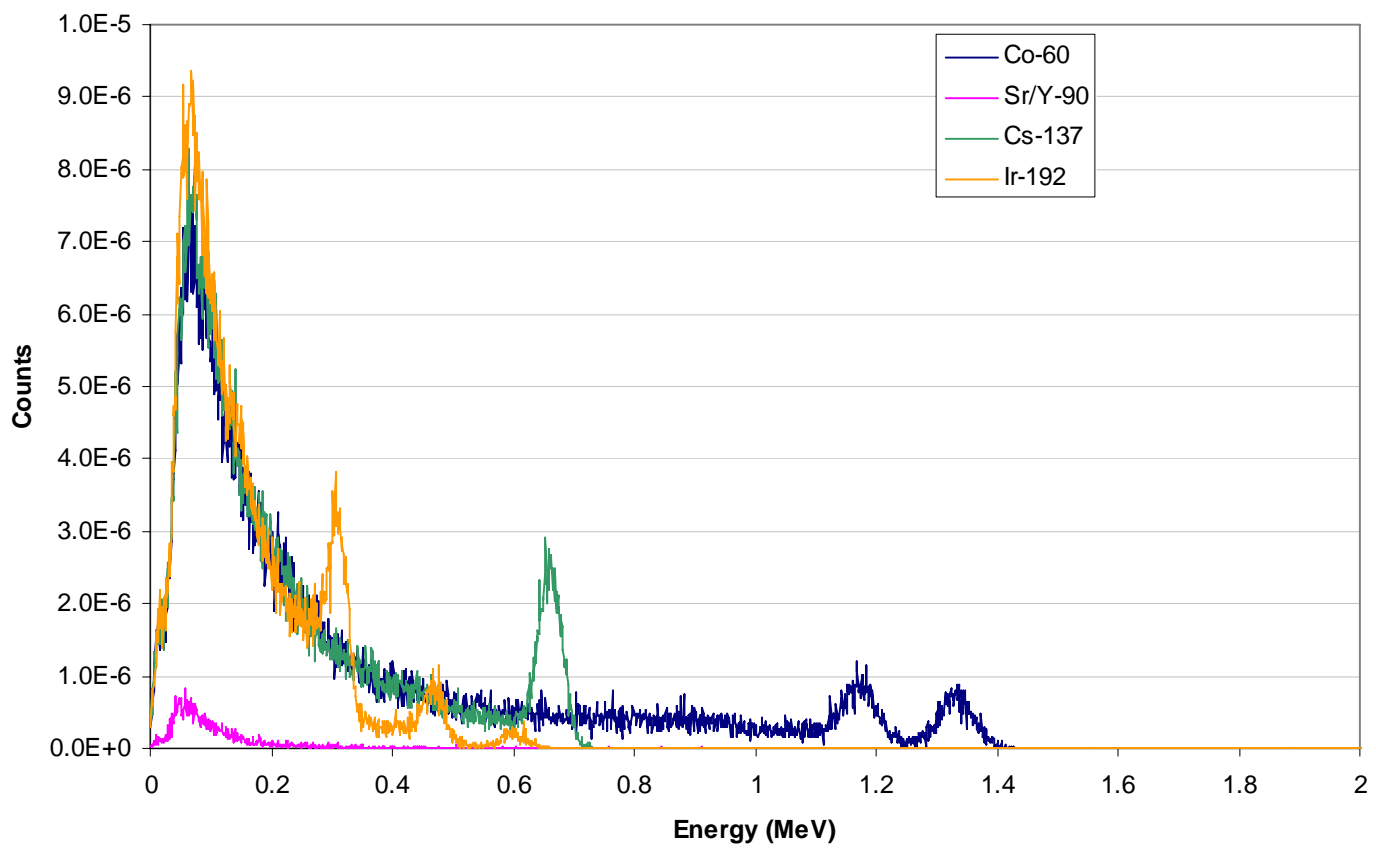

Figure 36. Multi Nuclide Detector Comparison. $3 \times 3$ Floating Detector

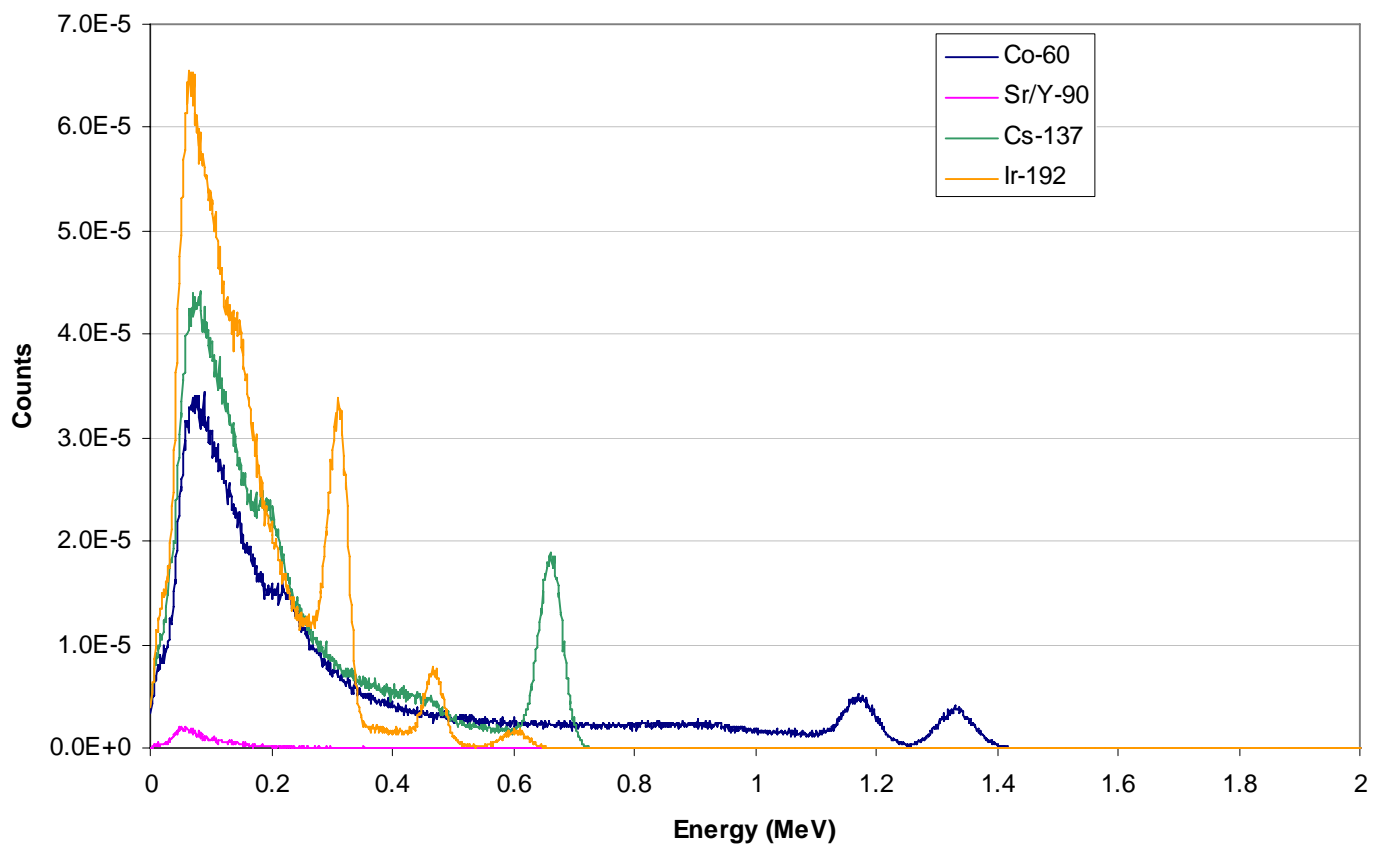

Figure 37. Multi Nuclide Detector Comparison. $2 \times 2$ Sample Box Detector 


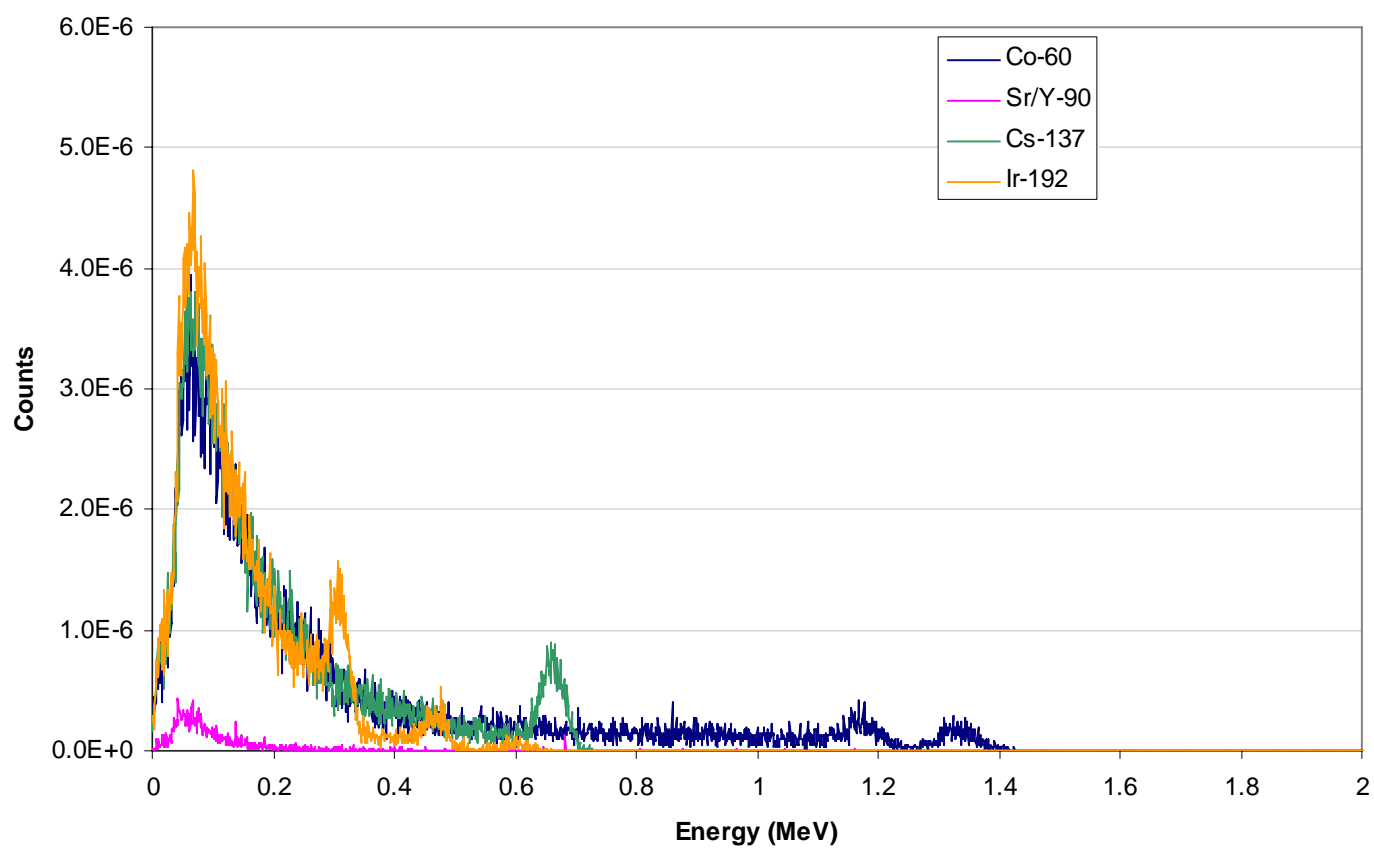

Figure 38. Multi Nuclide Detector Comparison. $2 \times 2$ Floating Detector 


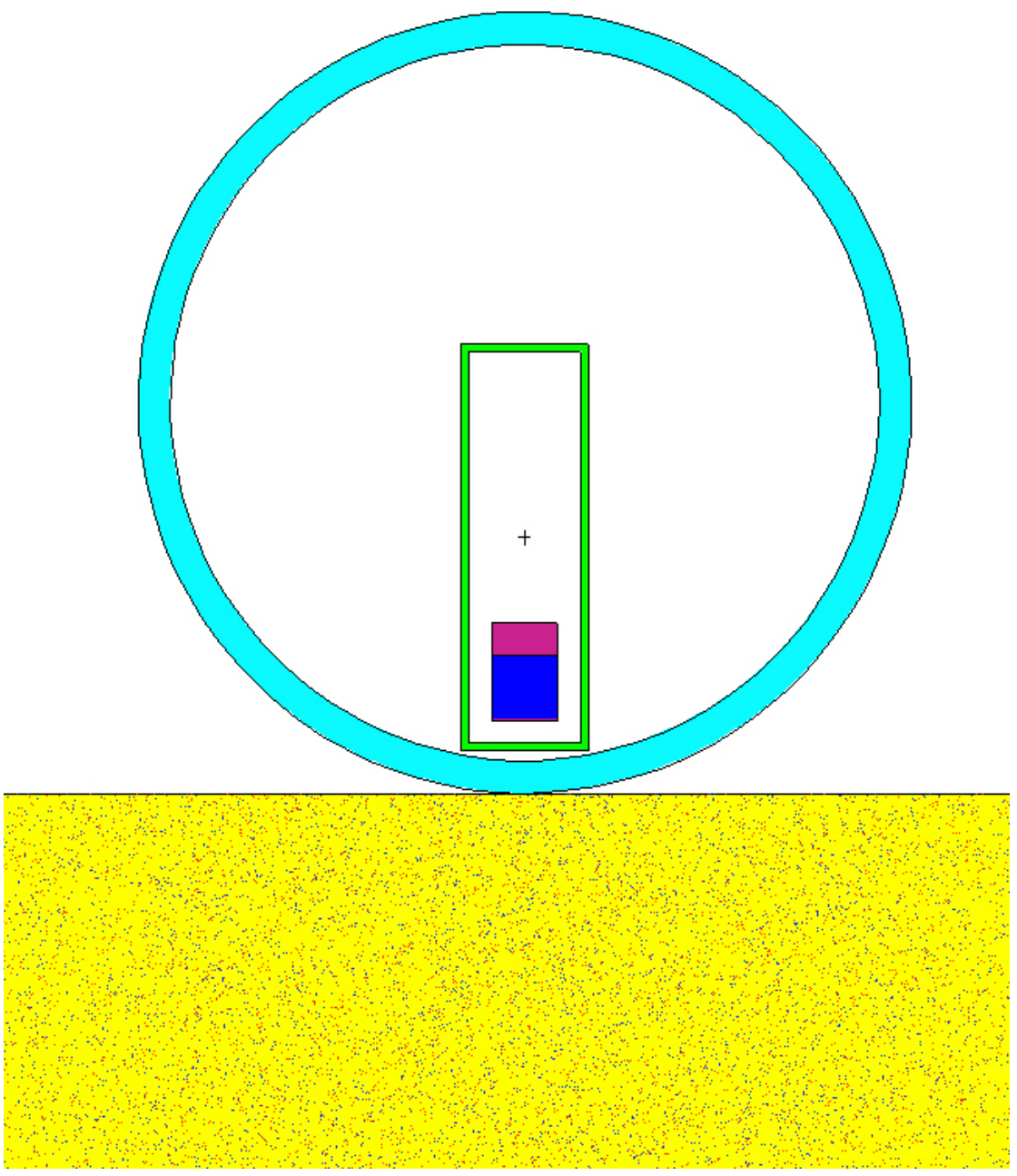

Figure 7. Floating detector cross section. Dark blue is $\mathrm{NaI}(\mathrm{Tl})$, yellow is water, light blue is rubber, green is PVC, magenta is aluminum. Dots in water represent locations of individual nuclear transitions. 


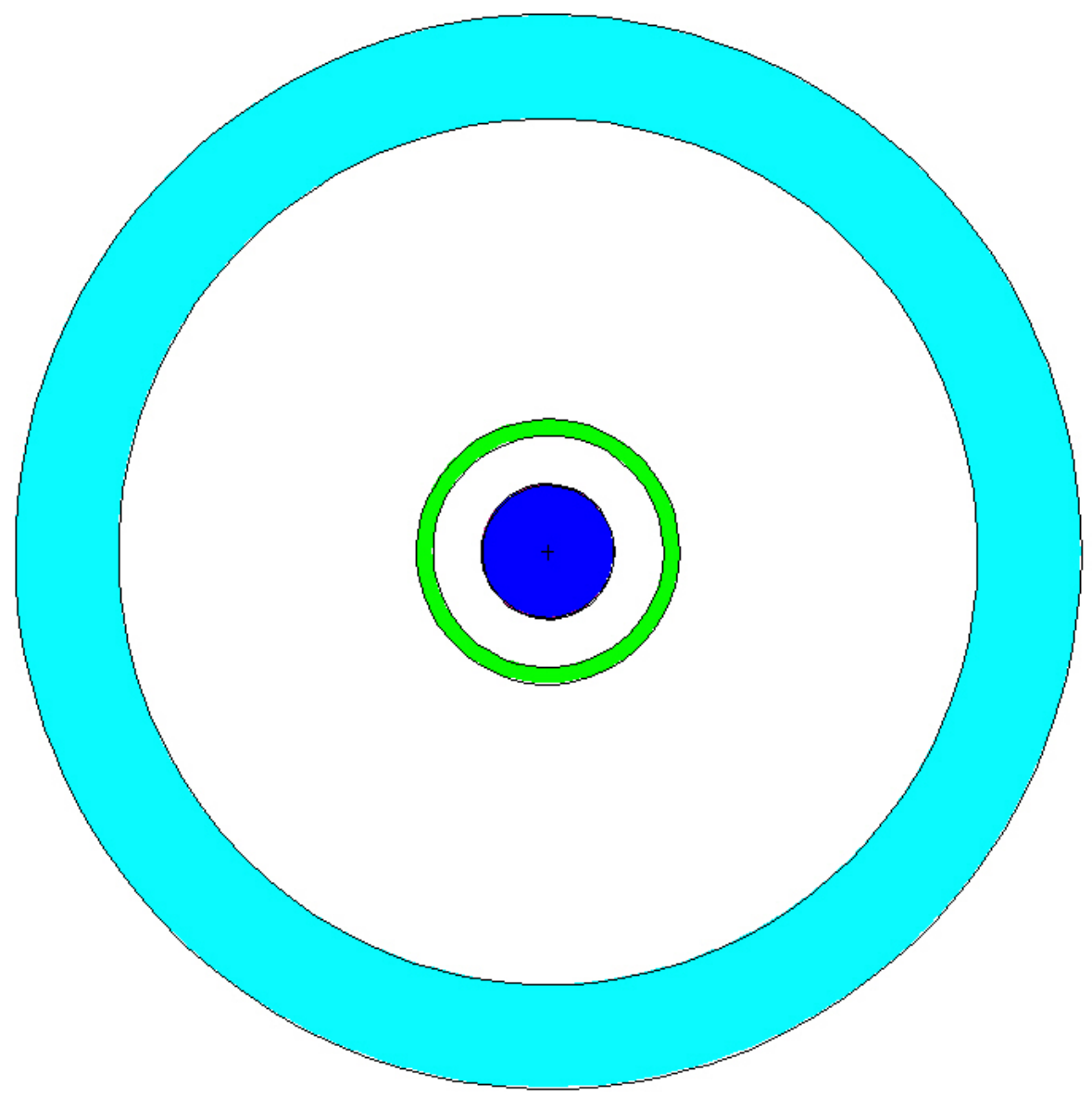

Figure 40. Floating detector horizontal cross section through sodium iodide crystal. Dark blue is NaI(Tl), light blue is rubber, green is PVC. 


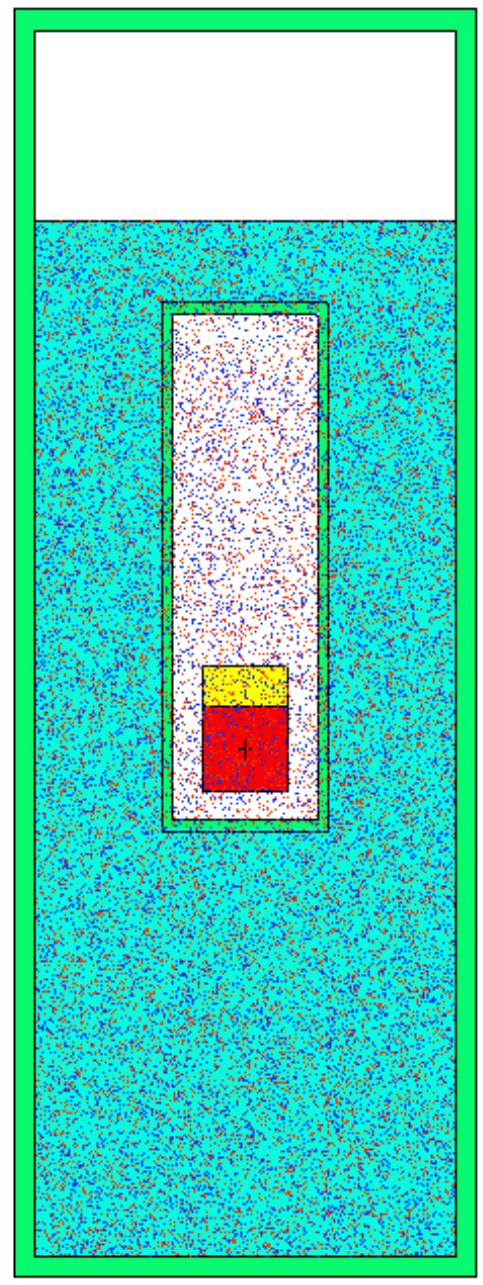

Figure 8. Sample box detector cross section seen from end. Red is $\mathrm{NaI}(\mathrm{Tl})$, green is PVC, light blue is water, white is dry air, yellow is aluminum. Dots in water represent locations of individual nuclear transitions in all planes, i.e., in front of and behind the detector suspended in the water. 


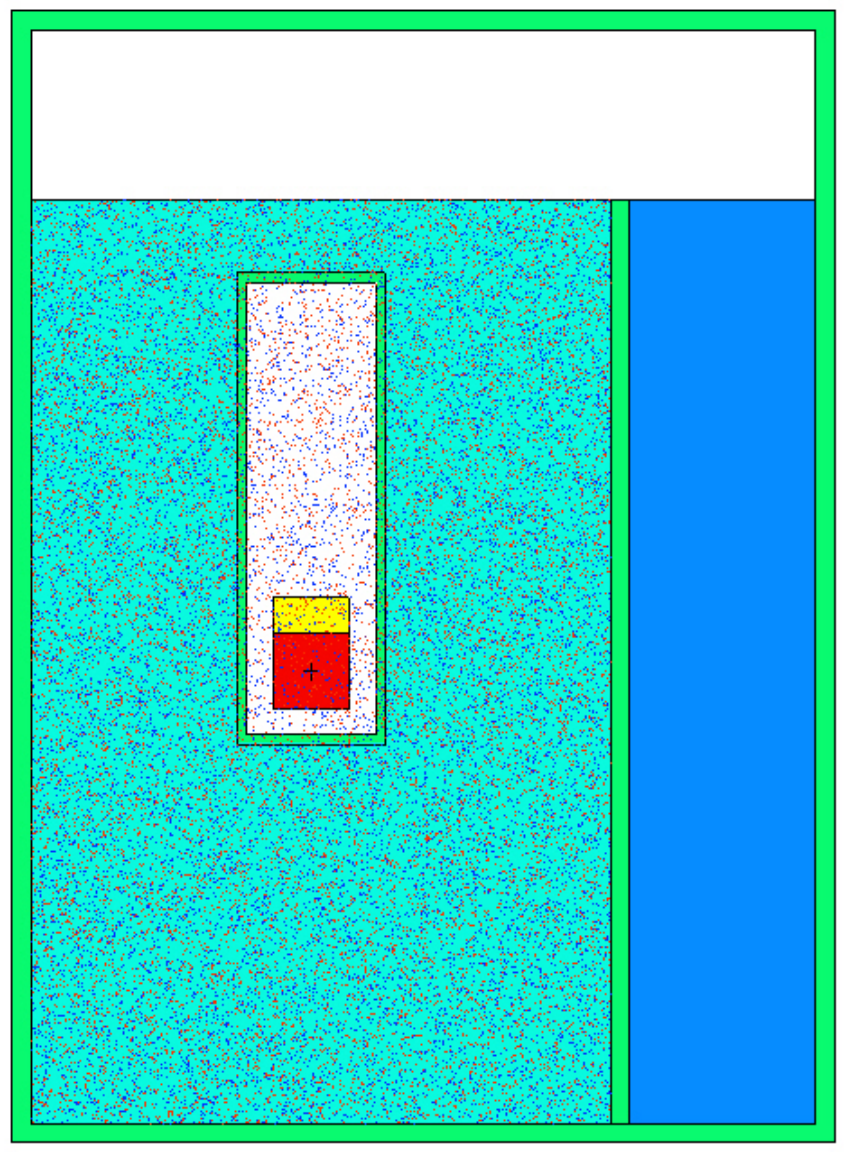

Figure 9. Sample box detector cross section seen from side. Red is NaI(Tl), green is PVC, light blue is water, dark blue is water at $50 \%$ density (that is, frothy, foamy water spilling over the top of the overflow), white is dry air, yellow is aluminum. Dots in water represent locations of individual nuclear transitions in all planes, i.e., in front of and behind the detector suspended in the water. 


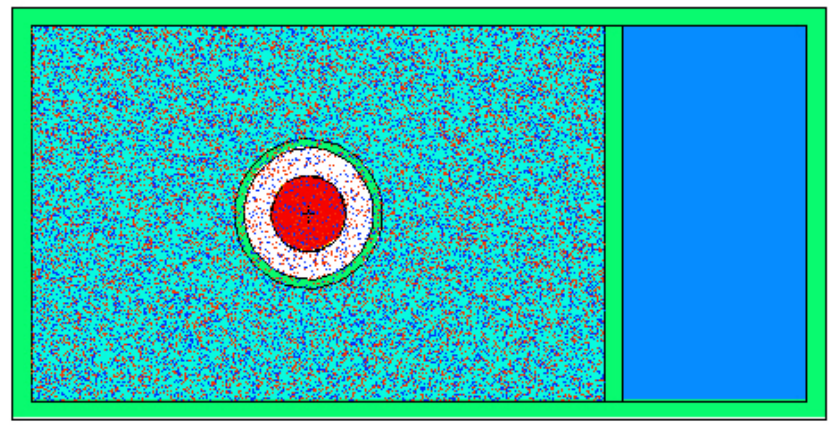

Figure 10. Sample box detector cross section (through detector) seen from top. Red is $\mathrm{NaI}(\mathrm{Tl})$, green is PVC, light blue is water, dark blue is water at $50 \%$ density (that is, frothy, foamy water spilling over the top of the overflow), white is dry air, yellow is aluminum. Dots in water represent locations of individual nuclear transitions in all planes, i.e., in front of and behind the detector suspended in the water. 